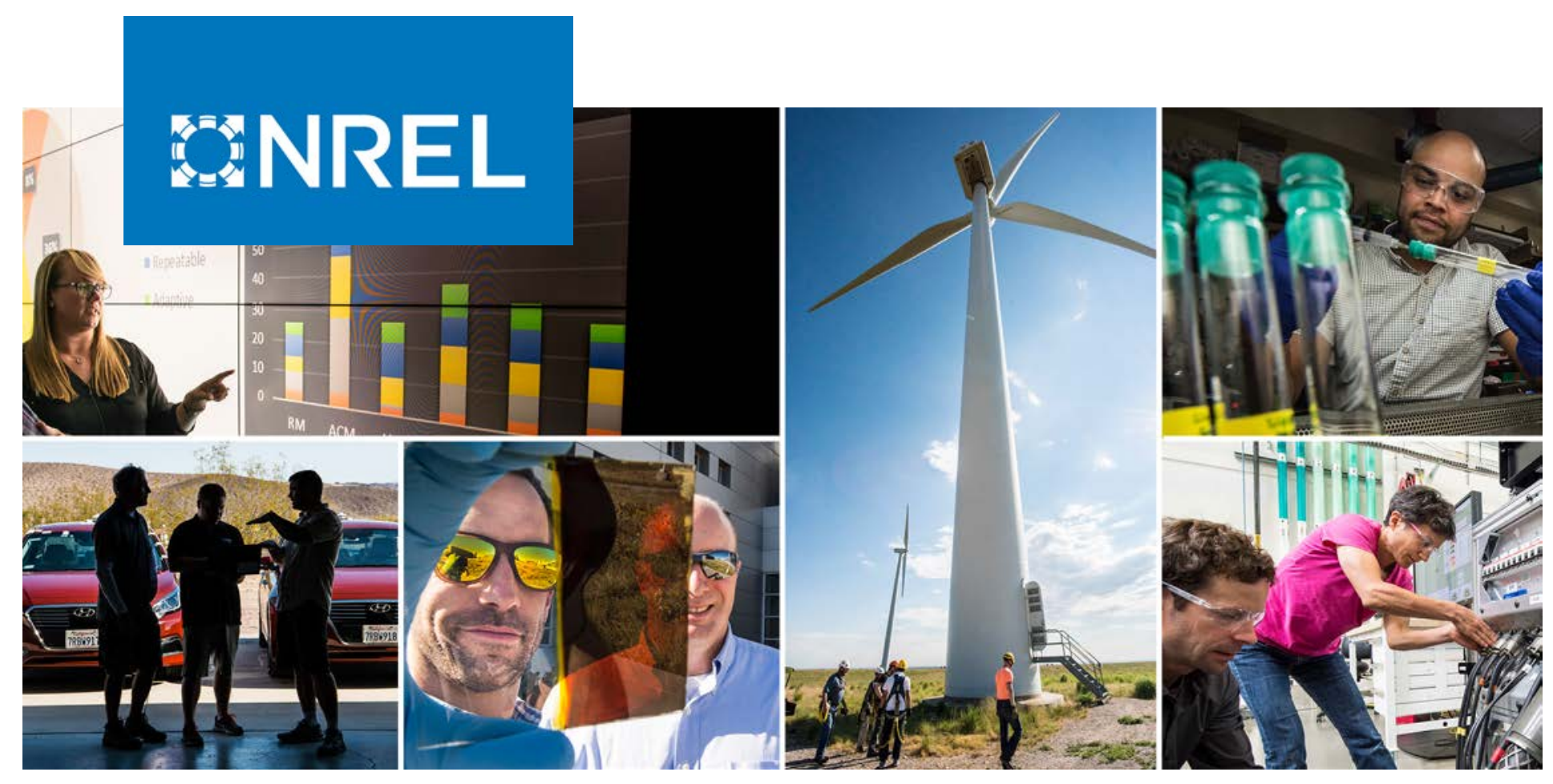

\title{
On-Road Heavy-Duty Low-NOx Technology Cost Study
}

Lauren A. Lynch, Chad A. Hunter, Bradley T. Zigler, Matthew J. Thornton, and Evan P. Reznicek

National Renewable Energy Laboratory

NREL is a national laboratory of the U.S. Department of Energy Office of Energy Efficiency \& Renewable Energy Operated by the Alliance for Sustainable Energy, LLC

This report is available at no cost from the National Renewable Energy Laboratory (NREL) at www.nrel.gov/publications.

Contract No. DE-AC36-08GO28308
Technical Report

NREL/TP-5400-76571

May 2020 


\section{BHREL}

\section{On-Road Heavy-Duty Low-NOx Technology Cost Study}

Lauren A. Lynch, Chad A. Hunter, Bradley T. Zigler, Matthew J. Thornton, and Evan P. Reznicek

National Renewable Energy Laboratory

\section{Suggested Citation}

Lynch, Lauren, A. Chad A. Hunter, Bradley T. Zigler, Matthew J. Thornton, and Evan P. Reznicek. 2020. On-Road Heavy-Duty Low-NOx Technology Cost Study. Golden, CO: National Renewable Energy Laboratory. NREL/TP-5400-76571.

https://www.nrel.gov/docs/fy20osti/76571.pdf.

NREL is a national laboratory of the U.S. Department of Energy Office of Energy Efficiency \& Renewable Energy Operated by the Alliance for Sustainable Energy, LLC

This report is available at no cost from the National Renewable Energy Laboratory (NREL) at www.nrel.gov/publications.

Contract No. DE-AC36-08G028308
Technical Report

NREL/TP-5400-76571

May 2020

National Renewable Energy Laboratory 15013 Denver West Parkway Golden, CO 80401

303-275-3000 • www.nrel.gov 


\section{NOTICE}

This work was authored by the National Renewable Energy Laboratory, operated by Alliance for Sustainable Energy, LLC, for the U.S. Department of Energy (DOE) under Contract No. DE-AC3608GO28308. Funding provided by the California Air Resources Board under Funds-In Agreement number 16MSC005/FIA-17-1855. The views expressed herein do not necessarily represent the views of the DOE, the U.S. Government, or the California Air Resources Board.

This report is available at no cost from the National

Renewable Energy Laboratory (NREL) at

www.nrel.gov/publications.

U.S. Department of Energy (DOE) reports produced

after 1991 and a growing number of pre-1991

documents are available

free via www.OSTI.gov.

Cover Photos by Dennis Schroeder: (clockwise, left to right) NREL 51934, NREL 45897, NREL 42160, NREL 45891, NREL 48097, NREL 46526.

NREL prints on paper that contains recycled content. 


\section{Disclaimer}

The statements and conclusions in this report are those of the contractor and not necessarily those of the California Air Resources Board. The mention of commercial products, their source, or their use in connection with material reported herein is not to be construed as actual or implied endorsement of such products. 


\section{Acknowledgments}

The authors would like to thank Rasto Brezny from the Manufacturers of Emission Controls Association (MECA), Chris Sharp from Southwest Research Institute (SwRI), George Mitchell and James Sanchez of the U.S. Environmental Protection Agency (EPA), and all of the participating Tier 1 suppliers and engine original equipment manufacturers for their collaboration and information provided in support of this study. This study would not have been possible without the strong support and engagement of those industry partners who participated in supplying incremental cost information. The authors would also like to thank Brian Bush for his development and support of the Scenario Evaluation and Regionalization Analysis model, Margaret Mann for her contributions and input, and Whitney Yeldell for her diligence and attention to detail while editing this report.

This report was written in fulfillment of the California Air Resources Board/U.S. Department of Energy National Renewable Energy Laboratory agreement 16MSC005/FIA-17-1855 under the sponsorship of the California Air Resources Board. Work was completed as of March 2020. 


\section{List of Acronyms}

\begin{tabular}{ll} 
ASC & ammonia slip catalyst \\
CARB & California Air Resources Board \\
DEF & diesel exhaust fluid \\
DOC & diesel oxidation catalyst \\
DPF & diesel particulate filter \\
EGR & exhaust gas recirculation \\
EMFAC & EMission FACtor model \\
EPA & U.S. Environmental Protection Agency \\
FTP & Federal Test Procedure \\
FUL & full useful life \\
g/bhp-hr & grams per brake horsepower-hour \\
GHG & greenhouse gas \\
GVWR & gross vehicle weight rating \\
HD & heavy-duty \\
HDO & heavy-duty Otto-cycle \\
HHDD & heavy heavy-duty diesel \\
hp & horsepower \\
LHDD & light heavy-duty diesel \\
LLC & low-load certification \\
LO-SCR & light-off selective catalytic reduction \\
MECA & Manufacturers of Emission Controls Association \\
MHDD & medium heavy-duty diesel \\
MY & model year \\
\hline
\end{tabular}




$\begin{array}{ll}\mathrm{NH}_{3} & \text { ammonia } \\ \mathrm{NO}_{x} & \text { oxides of nitrogen } \\ \text { NREL } & \text { National Renewable Energy Laboratory } \\ \text { OBD } & \text { on-board diagnostics } \\ \text { OEM } & \text { original equipment manufacturer } \\ \text { OOS } & \text { out of state } \\ \text { PM } & \text { particulate matter } \\ \text { PNA } & \text { passive NOx absorber } \\ \text { R\&D } & \text { research and development } \\ \text { SCAB } & \text { South Coast Air Basin } \\ \text { SCR } & \text { selective catalytic reduction } \\ \text { SCRF } & \text { selective catalytic reduction on filter } \\ \text { SERA } & \text { Scenario Evaluation and Regionalization Analysis } \\ \text { SET-RMC } & \text { Supplemental Emission Test with Ramped Mode Cycles } \\ \text { SI } & \text { spark ignition } \\ \text { SwRI } & \text { Southwest Research Institute } \\ \text { TWC } & \text { three-way catalyst }\end{array}$




\section{Executive Summary}

The National Renewable Energy Laboratory (NREL) conducted a cost analysis for emission control technologies under contract to the California Air Resources Board (CARB). CARB sought incremental cost analysis for emission control technologies for on-road heavy-duty (HD) engines used in vehicles greater than 14,000 pounds (lb) gross vehicle weight rating (GVWR) to achieve oxides of nitrogen $\left(\mathrm{NO}_{\mathrm{x}}\right)$ emissions rates significantly lower than those required by current emissions standards (CARB 2017). This low- $\mathrm{NO}_{\mathrm{x}}$ emission technology cost analysis comprised two main tasks:

- Task 1: An incremental cost analysis for engine and exhaust aftertreatment systems

- Task 2: An engine and exhaust aftertreatment life-cycle cost analysis incorporating incremental upfront costs and operating costs.

The incremental cost analysis included a review of current and under-development engine and exhaust aftertreatment technologies that could achieve 0.02 grams per brake horsepower-hour (g/bhp-hr) $\mathrm{NO}_{\mathrm{x}}$ on certification test cycles, including a proposed updated certification test cycle that includes additional low-load operating conditions. Diesel, natural gas, and gasoline HD engine applications were studied. Three diesel technology package combinations of engine and exhaust aftertreatment options were selected based on research in progress at Southwest Research Institute (SwRI), also funded by CARB. The three diesel technology packages were intended to bracket potential cost ranges across two engine displacement levels: $\sim 6-7$ liters (L) and $\sim 12-13 \mathrm{~L}$. Representative technology packages for HD natural gas $(12 \mathrm{~L})$ and gasoline $(6 \mathrm{~L})$ engines were also defined, each with a single displacement level providing a tie point to similar diesel options.

Diesel engines were the primary consideration, as they comprise the majority of HD engines. In addition to studying three diesel technology packages across two engine displacement levels, incremental cost bracketing also included model year (MY) 2023 versus 2027 introduction, U.S. versus California-only implementation, and current full useful life (FUL) versus extended FUL and warranty. Direct and indirect incremental costs were broken down to as discrete a level as possible while maintaining data confidentiality. The calculation of incremental costs was limited by a small number of respondents.

The surveyed original equipment manufacturers (OEMs), Tier 1 suppliers, and trade organizations such as the Manufacturers of Emission Controls Association (MECA) responded with incremental cost, not validation that $0.02 \mathrm{~g} / \mathrm{bhp}-\mathrm{hr}$ emissions levels or specific technology packages are feasible. Engine OEM participation was crucial, as only they could provide estimates for indirect costs that represented a significant portion of the total cost. Incremental costs are largely driven by indirect costs associated with engineering research and development costs and warranty costs. The indirect costs are highly dependent on production volumes over which to amortize research and development costs. Indirect costs due to warranty are high, reflecting high uncertainty with new technology and the introduction timeframes. The incremental costs were not adjusted to reflect a retail markup due to the complexity with which pricing decisions are made.

The average incremental cost for the 6-7-L diesel engines for MY 2023 with current FUL ranged from $\$ 3,685$ to $\$ 5,344$, but the absolute low and high bounds were between $\sim \$ 2,000$ and over 
$\$ 9,000$. Extending FUL and warranty moved the average incremental costs to a range of $\$ 15,370$ to $\$ 16,245$, with tighter low and high bounds (constrained in part by the limited number of responses). The average incremental cost for the 12-13-L diesel engines for MY 2023 with current FUL ranged from $\$ 5,340$ to $\$ 6,063$, but the absolute low and high bounds were between $\sim \$ 3,000$ and over $\$ 10,000$. Extending FUL and warranty moved the average incremental costs to a range of $\$ 28,868$ to $\$ 47,042$, with much wider low and high bounds (driven in part by the limited number of responses). The natural gas 12-L engine application was unable to be studied in detail, but OEM feedback indicated the anticipated incremental cost for natural gas engines and aftertreatment technology is within $10 \%$ of the low-cost diesel technology package incremental cost for equivalent displacement, possibly due to requiring a moving average window method to assess emission compliance. The gasoline engine 6-L application was also unable to be studied in detail due to lack of OEM feedback, but comparatively low incremental costs were estimated.

A life-cycle cost analysis was completed to understand the full costs to the owner of the vehicles with a $0.02 \mathrm{~g} / \mathrm{bhp}-\mathrm{hr} \mathrm{NO}_{\mathrm{x}}$ technology package outside of the direct upfront vehicle cost increase. The life-cycle cost analysis sought to incorporate costs associated with the following elements: initial incremental purchase cost, fuel consumption changes (changes in fuel economy), diesel exhaust fluid (DEF) consumption changes, and the maximum FUL of the aftertreatment package (major overhaul intervals). Thus, the life-cycle costs depend on the vehicle type (mileage), region, fuel, engine displacement, maximum useful life, fuel economy change, DEF consumption change, and discount rate.

Three scenarios were defined to evaluate the bounds of the life-cycle costs across all parameters evaluated. For the three scenarios evaluated (Low-Cost, Mid-Cost, High-Cost), the life-cycle costs were evaluated for each EMission FACtor (EMFAC) model vehicle type (CARB 2018b), aggregated to a representative average and calculated across the vehicle fleet for the MY 2027 vehicles. The analysis showed that EMFAC vehicles can have significantly different life-cycle costs and that the spread depends on the scenario evaluated: approximately a $\$ 4,000$ spread across vehicle types in the Low-Cost scenario, while the High-Cost scenario had nearly a $\$ 40,000$ difference. This large spread was found to be due to the number of aftertreatment package replacements needed throughout the vehicle lifetime. The aggregated, representative average life-cycle costs for the Mid-Cost scenario were estimated to be $\$ 12,700$ for the 6-L diesel engine, $\$ 13,200$ for the 12-L diesel engine, $\$ 4,800$ for the 12-L natural gas engine, and $\$ 800$ for the 6-L gasoline engine. The total life-cycle costs to California vehicle owners for the MY 2027 vehicles were estimated to range between \$92 million and \$1.2 billion, depending on the scenario (Low-Cost or High-Cost) realized.

The sensitivity analysis indicated that the manufacturing volume may be the most important parameter impacting the life-cycle cost; however, limited data were received from the external stakeholders surveyed. The next most important parameter was the assumption of extended FUL and extended warranty, as the increase in aftertreatment lifetime may not exceed the vehicle's travel requirement, which results in larger replacement costs over the vehicle's life. However, one may expect that the higher upfront purchase incurred by the vehicle owner should effectively be offset by the repair savings over the lifetime of the vehicle. Next, the aftertreatment cost bound (low/high error bars on the incremental cost data), fuel economy improvement, and 
discount rate were found to have a moderate impact on the life-cycle cost. Lastly, the region and DEF consumption change were found to have minimal influence on the life-cycle cost.

The results of this cost analysis reflect the specific technology and aftertreatment FUL assumptions on which the study was based. In particular, the incremental cost of moving from a $0.2 \mathrm{~g} / \mathrm{bhp}$-hr to $0.02 \mathrm{~g} / \mathrm{bhp}-\mathrm{hr}$ standard is expected to be non-linear due to diminishing returns on technology performance. Extrapolating the results beyond this specific study and outside of these specific assumptions is not recommended and should only be done with careful attention to the scope and limits of this study. 


\section{Table of Contents}

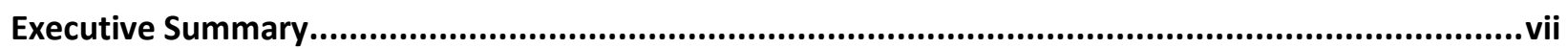

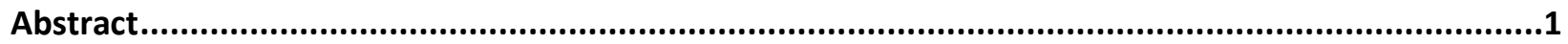

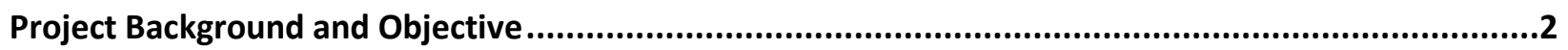

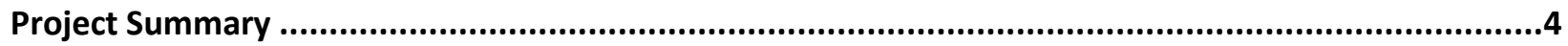

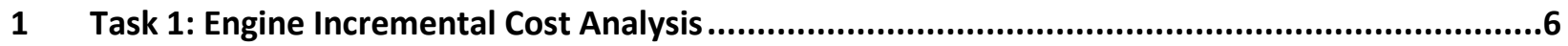

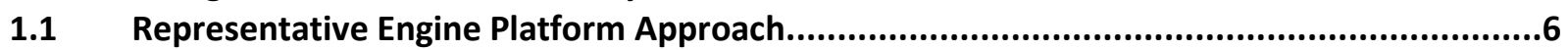

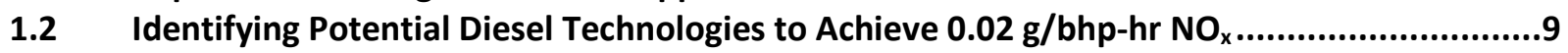

1.3 Identifying Potential Gasoline and Natural Gas Technologies to Achieve $0.02 \mathrm{~g} / \mathrm{bhp}-\mathrm{hr} \mathrm{NO}_{\mathrm{x} . .}$

NREL Survey of Potential Technologies to Achieve 0.02 g/bhp-hr NO

1.4.1 Definition of Baseline Costs of Current Technologies With 2018 EPA Certification ..............12

1.4.2 NREL Initial Incremental Cost Estimates .......................................................................... 13

1.4.3 First Survey Responses for Incremental Costs of Potential Diesel Technologies................. 19

1.4.4 Incremental Costs of Potential Technologies with Extended FUL and Warranty, and

California-Only Volumes. 25

1.4.5 Incremental Cost Survey Response Observations............................................................. 31

1.4.6 Incremental Costs for Natural Gas and Gasoline Technology Packages ..............................32

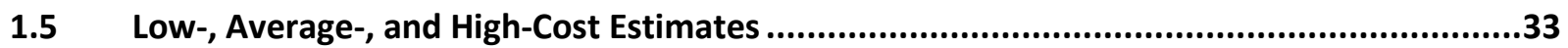

1.5.1 Low-, Average-, and High-Cost Estimates for MY 2023 with Current FUL and Warranty..... 33

1.5.2 Low-, Average-, and High-Cost Estimates for MY 2027 with Extended Warranty and

Extended Useful Life. 35

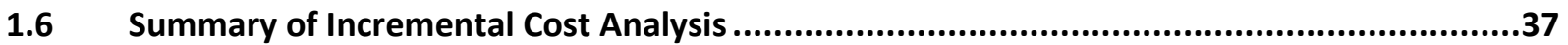

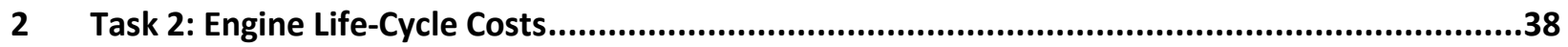

2.1 Maximum Full Useful Life Analysis.....................................................................38

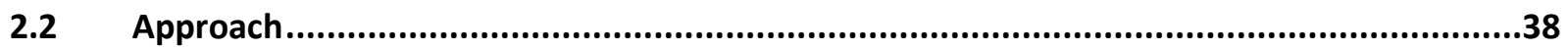

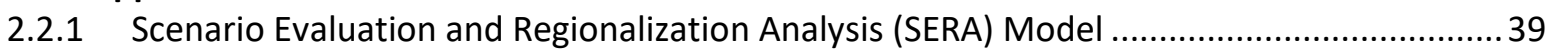

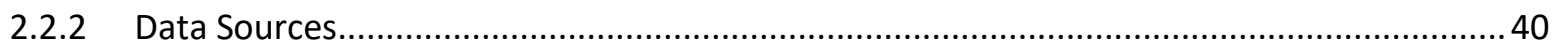

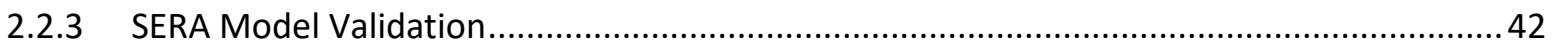

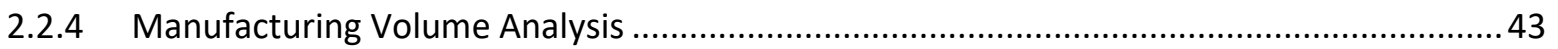

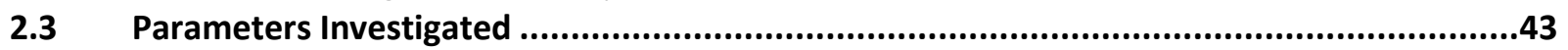

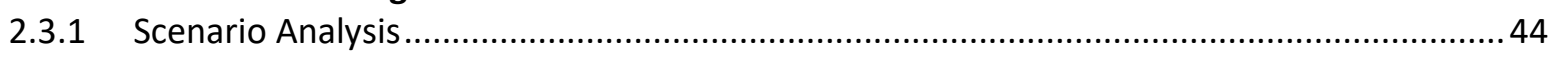

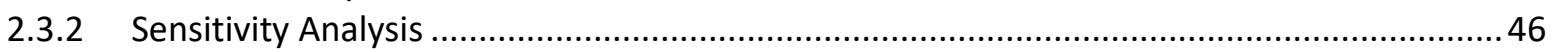

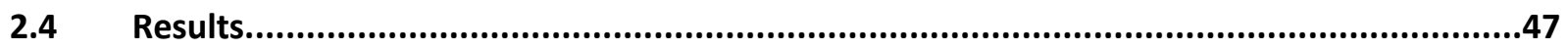

2.4.1 Case Study: T7 Tractor and T6 OOS Small Vehicle Life-Cycle Costs .................................. 47

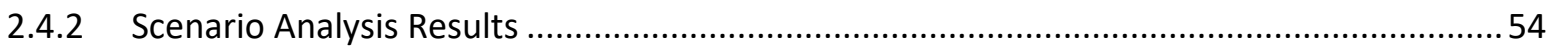

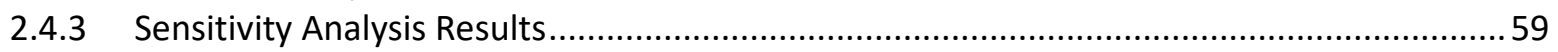

2.5 Life-Cycle Cost Analysis Summary and Conclusions .................................................60

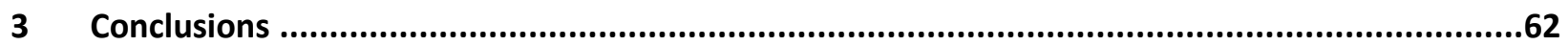

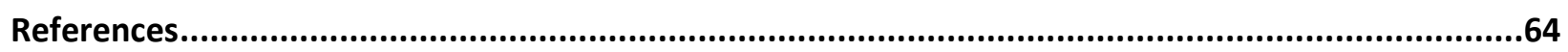

Appendix A. Selected Results for Specific EMFAC Vehicles of Interest to CARB ...........................65

Appendix B. EMFAC Vehicle Disaggregation ..............................................................................67 


\section{List of Figures}

Figure 1. Schematic of proposed low- and average-cost diesel aftertreatment technology ...................... 10

Figure 2. Schematic of proposed high-cost diesel aftertreatment technology ........................................ 11

Figure 3. Summary of 6-7-L potential technology packages for MY 2023 with current FUL ................. 34

Figure 4. Summary of 12-13-L potential technology packages for MY 2023 with current FUL .............. 35

Figure 5. Summary of 6-7-L potential technology packages for MY 2027 with extended FUL and

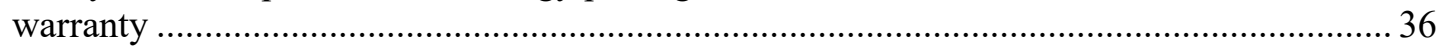

Figure 6. Summary of 12-13-L potential technology packages for MY 2027 with extended FUL and

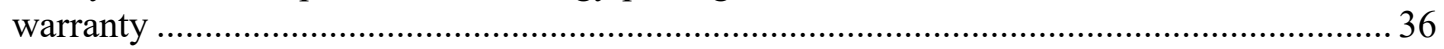

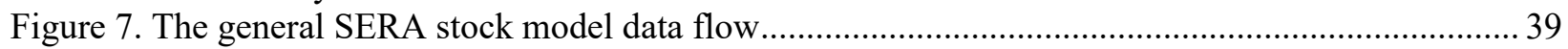

Figure 8. Data flow and analysis using the SERA model for life-cycle cost analysis .............................. 42

Figure 9. SERA model validation against the CA Vision 2.1 model..................................................... 43

Figure 10. Annual present value cost for a T7 Tractor 12-L diesel engine designed for current full useful life (435,000 miles; top) and extended full useful life (1,000,000 miles; bottom) for MY

2027 in the South Coast Air Basin with a 2.5\% increase in DEF consumption, a discount rate of $7 \%$, and national manufacturing volumes.

Figure 11. Annual present value cost for a T6 OOS small 6-7-L diesel engine designed for current full useful life (110,000 miles; top) and extended full useful life (550,000 miles; bottom) for MY 2027 in the South Coast Air Basin with a 2.5\% increase in DEF consumption, a discount rate of $7 \%$, and national manufacturing volumes. 48

Figure 12. Total present value cost for the T7 Tractor and T6 OOS small vehicles with diesel engine aftertreatment technology as a function of incremental steps between current FUL and extended FUL for two scenarios: replacements at end of FUL (orange) and no replacements

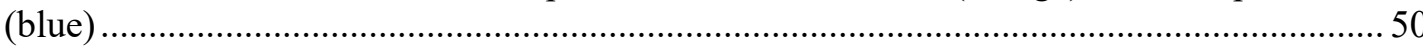

Figure 13. Present value cost for different Class 6 and Class 8 diesel engine aftertreatment technologies with current full useful life.

Figure 14. Present value cost for different Class 6 and Class 8 diesel engine aftertreatment technologies with extended full useful life....

Figure 15. Present value cost for the T7 Tractor and T6 OOS small trucks with diesel engines designed for current full useful life at both California and national manufacturing volumes.

Figure 16. Present value cost for the T7 Tractor and T7 OOS small trucks with diesel engine aftertreatment technologies designed for current FUL as a function of region.

Figure 17. Present value cost for the T7 Tractor and T7 OOS small trucks with diesel engine aftertreatment technologies designed for extended FUL and warranty as a function of region

Figure 18. Present value life-cycle cost for all EMFAC vehicles in the low-cost scenario, segmented by

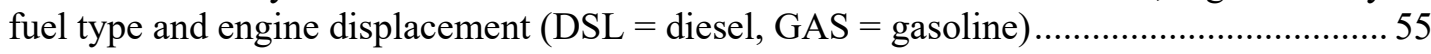

Figure 19. Present value life-cycle cost for all EMFAC vehicles in the mid-cost scenario, segmented by fuel type and engine displacement $(\mathrm{DSL}=$ diesel, $\mathrm{GAS}=$ gasoline, $\mathrm{CNG}=$ compressed

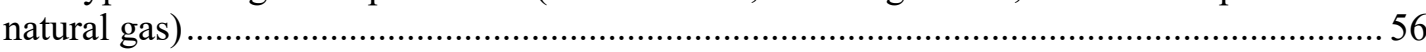

Figure 20. Present value life-cycle cost for all EMFAC vehicles in the high-cost scenario, segmented by fuel type and engine displacement $(\mathrm{DSL}=$ diesel) ................................................... 57

Figure 21. EMFAC vehicle sales-weighted average present value cost for 6-L and 12-L diesel engine

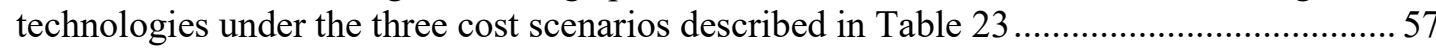

Figure 22. Scenario analysis for a 12-liter compressed natural-gas and 6-liter gasoline engine ................ 58 Figure 23. Total California fleet life-cycle cost for the MY 2027 vehicles for each scenario analyzed..... 58 Figure 24. Sensitivity diagram for the diesel 6-7-L and 12-13-L engines relative to the mid-cost scenario .

Figure 25. Sensitivity diagram for the gasoline 6-L engine relative to the mid-cost scenario.

Figure 26. Sensitivity diagram for the natural-gas $12-\mathrm{L}$ engine relative to the mid-cost scenario 60 


\section{List of Tables}

Table 1. Current and Proposed Extended Full Useful Life and Warranty for Engine Life-Cycle Cost

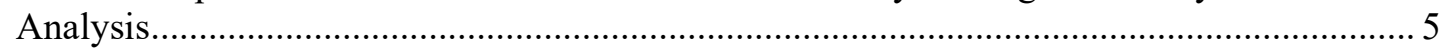

Table 2. Engine Platform Analysis for Incremental Cost Analysis ...................................................... 7

Table 3. NREL Estimates of Potential Low-Cost Diesel Technology Package 6-7 L ............................. 14

Table 4. NREL Estimates of Potential Low-Cost Diesel Technology Package 12-13 L ......................... 15

Table 5. NREL Estimate of Potential Average-Cost Diesel Technology Package 6-7 L........................ 16

Table 6. NREL Estimates of Potential Average-Cost Diesel Technology Package 12-13 L .................... 17

Table 7. NREL Estimates of Potential High-Cost Diesel Technology Package 6-7 L ........................... 18

Table 8. NREL Estimates of Potential High-Cost Diesel Technology Package 12-13 L ....................... 19

Table 9. Survey Responses for Potential Low-Cost Diesel Technology Package 6-7 L......................... 20

Table 10. Survey Responses for Potential Low-Cost Diesel Technology Package 12-13 L................... 21

Table 11. Survey Responses for Potential Average-Cost Diesel Technology Package 6-7 L ................. 22

Table 12. Survey Responses for Potential Average-Cost Diesel Technology Package 12-13 L .............. 23

Table 13. Survey Responses for Potential High-Cost Diesel Technology Package 6-7 L ....................... 24

Table 14. Survey Responses for Potential High-Cost Diesel Technology Package 12-13 L ................... 25

Table 15. Survey Responses for Potential Low-Cost Diesel Technology Package 6-7 L with Extended FUL, Extended Warranty, and California-Only Volumes ...................................................26

Table 16. Survey Responses for Potential Low-Cost Diesel Technology Package 12-13 L with Extended FUL, Extended Warranty, and CA Volumes ...................................................................... 27

Table 17. Survey Responses for Potential Average-Cost Diesel Technology Package 6-7 L with Extended FUL, Extended Warranty, and California-Only Volumes .....................................................28

Table 18. Survey Responses for Potential Average-Cost Diesel Technology Package 12-13 L with Extended FUL, Extended Warranty, and California-Only Volumes ....................................2 29

Table 19. Survey Responses for Potential High-Cost Diesel Technology Package 6-7 L with Extended FUL, Extended Warranty, and California-Only Volumes .................................................... 30

Table 20. Survey Responses for Potential High-Cost Diesel Technology Package 12-13 L with Extended FUL, Extended Warranty, and California-Only Volumes .................................................... 31

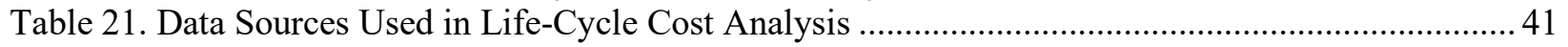

Table 22. Life-Cycle Cost Parameters Investigated in this Study ....................................................... 44

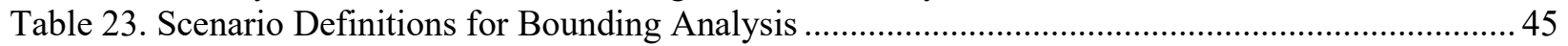

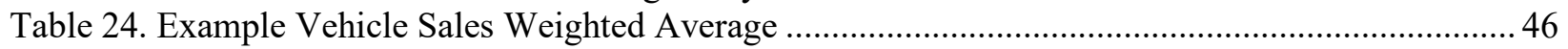




\section{Abstract}

The National Renewable Energy Laboratory (NREL) conducted a cost analysis for emission control technologies under contract to the California Air Resources Board (CARB). CARB sought incremental cost analysis for emission control technologies for on-road heavy-duty (HD) engines used in vehicles greater than 14,000 pounds $(\mathrm{lb})$ gross vehicle weight rating (GVWR) to achieve oxides of nitrogen $\left(\mathrm{NO}_{\mathrm{x}}\right)$ emissions rates significantly lower than those required by current emissions standards. Specifically, incremental costs (without any retail price markup) were estimated for representative diesel, natural gas, and gasoline engine and emission aftertreatment systems that were selected to represent potential technology packages that could achieve 0.02 grams per brake horsepower-hour $(\mathrm{g} / \mathrm{bhp}-\mathrm{hr}) \mathrm{NO}_{\mathrm{x}}$ on certification test cycles, including a proposed updated certification test cycle that includes additional low-load operating conditions. NREL surveyed stakeholders including industry association groups, Tier 1 suppliers, and engine original equipment manufacturers (OEMs) to estimate incremental direct and indirect costs. Incremental costs were considered for current engine full useful life (FUL) definitions, as well as with proposed increased FUL and warranty periods. The incremental costs were subsequently incorporated in life-cycle cost analyses examining the incremental engine and aftertreatment costs along with life-cycle costs over the various engine FUL scenarios. Life-cycle costs analysis included the incremental upfront cost, fuel consumption changes (changes in fuel economy), diesel exhaust fluid (DEF) consumption changes, and the maximum FUL of the aftertreatment package (major overhaul intervals). 


\section{Project Background and Objective}

Current emission standards for heavy-duty diesel engines, established by the United States Environmental Protection Agency (EPA) for 2010, specify a limit of 0.20 grams per brake horsepower-hour (g/bhp-hr) $\mathrm{NO}_{\mathrm{x}}$. This standard represents a 90\% reduction from the previous benchmark of $2.0 \mathrm{~g} / \mathrm{bhp}$-hr and applies to both heavy-duty diesel engines and heavy-duty Ottocycle engines used in vehicles greater than 14,000-lb GVWR.

Diesel-engine manufacturers utilize a variety of technologies in order to meet these standards, primarily among them being selective catalytic reduction (SCR). Natural-gas engine manufacturers use SCR for lean-burn engines and three-way catalysts (TWCs) for stoichiometric engines. Both of these methods reduce $\mathrm{NO}_{\mathrm{x}}$ emissions by removing them from the engine-out exhaust prior to exiting the tailpipe. These manufacturers have used lessons learned from other applications such as stationary-source and light-duty vehicles to meet current $\mathrm{NO}_{\mathrm{x}}$ emission requirements, and as these technologies mature there are opportunities to reduce emissions even further.

The California Air Resources Board (CARB), together with the Southwest Research Institute (SwRI), is currently funding several research programs to investigate the feasibility of achieving $\mathrm{NO}_{\mathrm{x}}$ emissions less than the 2010 limit of $0.20 \mathrm{~g} / \mathrm{bhp}$-hr. The first ("Stage 1") project is a $\$ 1.6$ million research contract between CARB and SwRI to evaluate improved engine emission control calibration, enhanced aftertreatment technologies and configurations, improved aftertreatment thermal management, urea dosing strategies, and engine management practices for two heavy-duty engines: one natural-gas engine with a TWC and one diesel engine with a diesel particulate filter (DPF) and SCR. The target emission rate for this project, which was finalized in December 2016, is $0.02 \mathrm{~g} / \mathrm{bhp}-\mathrm{hr} \mathrm{NO}_{\mathrm{x}}$.

CARB is also contracting a $\$ 1.05$ million "Stage 2" project with SwRI to further optimize the diesel engine aftertreatment system for low engine-load duty cycles typical of city driving. Stage 2 objectives are to develop a supplemental low-load certification test cycle that will, along with the Federal Test Procedure (FTP), ensure $\mathrm{NO}_{x}$ control under nearly all driving conditions and evaluate metrics for in-use testing under low-load operations. The "Stage 3" project, currently in the planning stage, will complement the Stage 1 and Stage 2 efforts with testing on an additional engine that is representative of likely future engine configurations.

Alongside current emission standards, CARB and EPA both require that heavy-duty engines meet these standards throughout their entire useful life. The useful life period is defined according to a vehicle's GVWR, and for heavy-duty engines ranges from 110,000-435,000 miles. The useful life period for Otto-cycle and light heavy-duty diesel engines $(14,001-19,500$ lb GVWR) is 110,000 miles/10 years; for medium heavy-duty diesel engines (19,501-33,000-lb GVWR) 185,000 miles/10 years; and for heavy heavy-duty diesel engines (greater than 33,000lb GVWR) 435,000 miles/10 years, or 22,000 hours.

Well-maintained on-road diesel engines can operate significantly beyond their currently defined useful life periods (e.g., many heavy-duty diesel engines currently operate upwards of 800,000 miles to over a million miles), and CARB is taking this reality into consideration as it evaluates the consequences of lowering its $\mathrm{NO}_{\mathrm{x}}$ emission targets. Engine durability becomes a critical 
factor with longer useful life definitions, particularly in preventing "upstream" engine component failures that can damage "downstream" emission control system components and cause excess emissions of criteria pollutants such as particulate matter (PM) and $\mathrm{NO}_{\mathrm{x}}$. Therefore, manufacturers will need to improve the durability of their engines and emission control systems by developing higher-quality parts and assembly methods and replacement of components and/or subsystems.

CARB is expected to propose new standards to be implemented by 2024, which will set even lower $\mathrm{NO}_{\mathrm{x}}$ emission standards and add new certification test cycles to ensure emission control at low-load operations. Adding this new test cycle to the certification requirement is expected to drive further improvements to aftertreatment hardware and engine control and calibration.

With these new emission standards of approximately $0.02 \mathrm{~g} / \mathrm{bhp}-\mathrm{hr} \mathrm{NO}$ in mind, it is important to examine the direct and indirect costs of implementing new technologies, both the incremental costs to original equipment manufacturers and the costs of using the technology packages throughout the engines' useful life. These costs can be divided by category, including the specific technologies for achieving the $\mathrm{NO}_{\mathrm{x}}$ standard, the costs to increase durability (extended useful life), and the costs of the on-board diagnostics (OBD) hardware and calibration works impacted by the changes. This cost analysis will use specific emission control and engine technologies identified by SwRI in Stages 1 and 2, along with testing that is representative of likely future engine configurations. 


\section{Project Summary}

This project was defined by two tasks - Task 1: Engine Incremental Cost Analysis and Task 2: Engine Life-Cycle Costs. For Task 1, NREL reviewed current technologies and technology packages that are being examined as part of the SwRI projects, Stages 2 and 3, as provided by CARB. NREL identified and reviewed likely emission control and engine technologies to meet $0.02 \mathrm{~g} / \mathrm{bhp}-\mathrm{hr} \mathrm{NO}_{\mathrm{x}}$ requirements with CARB staff based on Stage 2 and 3 efforts from SwRI testing of potential future engine configurations. These technologies were then defined as the potential technologies and the starting point of developing a low- $\mathrm{NO}_{\mathrm{x}}$ technology incremental cost analysis from 2018 baseline costs.

NREL then evaluated these potential technologies and technology packages for engine plus aftertreatment incremental cost analysis via a series of surveys sent to Tier 1 suppliers, trade organizations, and engine OEMs. The surveys defined the potential technologies broken into engine components, emission control components, subsystems, and indirect costs. The combination of incremental costs (over the 2018 baseline) associated with developing and integrating the specified lower $\mathrm{NO}_{\mathrm{x}}$ emission control technologies into the engines, the costs of increasing the durability of these engines and their emission control systems, and the costs of directly impacted OBD hardware and calibration works of these specified technology packages were then examined to understand the total incremental cost implications to Tier 1 suppliers and engine OEMs of the potential technologies.

The evaluation of costs was dependent on cooperation from Tier 1 suppliers, trade organizations and engine OEMs, as well as the availability of direct and indirect cost information for engine and emission control technologies. NREL utilized existing relationships with industry partners in order to perform a thorough cost assessment but could not guarantee full cooperation or sharing of confidential cost information from Tier 1 suppliers, trade organizations, and engine OEMs.

After accounting for the initial incremental cost implications to Tier 1 suppliers (both collectively through the Manufacturers of Emission Controls Association [MECA] and individually) and engine OEMs, NREL conducted a life-cycle cost analysis as Task 2 to examine the costs of using the specified technology packages during the engines' certification full useful life (FUL). NREL utilized a range of FUL values for each heavy-duty vehicle category, Classes 4 through 8. The current FUL mileage - for heavy-duty engines of 110,000 miles up to 435,000 miles, depending on a vehicle's GVWR; 110,000 miles/10 years for heavy-duty Otto-cycle (HDO) and light heavy-duty diesel (LHDD) engines (14,001-19,500-lb GVWR); 185,000 miles/10 years for medium heavy-duty diesel (MHDD) engines (19,501-33,000-lb GVWR); and 435,000 miles/10 years or 22,000 hours for heavy heavy-duty diesel (HHDD) engines (greater than 33,000-lb GVWR) - was defined as the low-end value of the range for each specific vehicle class. For the high-end value of the range, NREL utilized input from CARB for proposed extended FUL targets as the upper-bound levels for each specific vehicle class: 250,000 miles/15 years for HDO engines (14,001-19,500-lb GVWR), 550,000 miles/15 years for LHDD engines (14,001-19,500-lb GVWR) and MHDD engines (14,001-19,500-lb GVWR), and 1,000,000 miles/15 years for HHDD engines (greater than 33,000-lb GVWR). Additionally, per CARB's guidance, the high-end value with extended FUL also includes the provision that warranty periods will increase to $80 \%$ of the extended FUL, both in mileage and time, except for heavy- 
duty Otto-cycle, which was specified as 220,000 miles/12 years. The current FUL defining the lower bound and the extended FUL defining the upper bound are summarized in Table 1.

Table 1. Current and Proposed Extended Full Useful Life and Warranty for Engine Life-Cycle Cost Analysis

\begin{tabular}{|c|c|c|c|c|c|}
\hline & LHDD & MHDD & HHDD & $\begin{array}{c}\text { Natural } \\
\text { Gas - Otto }\end{array}$ & $\begin{array}{c}\text { Heavy-Duty - } \\
\text { Otto }\end{array}$ \\
\hline GVWR (Ib) & $14,001-19,500$ & $19,501-33,000$ & $>33,000$ & $>33,000$ & 14,000 \\
\hline $\begin{array}{l}\text { Current full } \\
\text { useful life }\end{array}$ & $\begin{array}{c}110,000 \\
\text { miles/10 years }\end{array}$ & $\begin{array}{c}185,000 \\
\text { miles/10 years }\end{array}$ & $\begin{array}{l}435,000 \\
\text { miles } / 10 \\
\text { years, } \\
22,000 \\
\text { hours }\end{array}$ & $\begin{array}{c}435,000 \\
\text { miles } / 10 \\
\text { years, } \\
22,000 \\
\text { hours }\end{array}$ & $\begin{array}{c}110,000 \\
\text { miles/15 years }\end{array}$ \\
\hline $\begin{array}{l}\text { Proposed } \\
\text { extended } \\
\text { full useful } \\
\text { life }\end{array}$ & $\begin{array}{c}550,000 \\
\text { miles/15 years }\end{array}$ & $\begin{array}{c}550,000 \\
\text { miles/15 years }\end{array}$ & $\begin{array}{c}1,000,000 \\
\text { miles } / 15 \\
\text { years }\end{array}$ & $\begin{array}{c}1,000,000 \\
\text { miles } / 15 \\
\text { years }\end{array}$ & $\begin{array}{c}250,000 \\
\text { miles } / 15 \text { years }\end{array}$ \\
\hline $\begin{array}{l}\text { Proposed } \\
\text { warranty } \\
\text { period with } \\
\text { extended } \\
\text { full useful } \\
\text { life }\end{array}$ & $\begin{array}{c}440,000 \\
\text { miles/12 years }\end{array}$ & $\begin{array}{c}440,000 \\
\text { miles/12 years }\end{array}$ & $\begin{array}{c}800,000 \\
\text { miles } / 12 \\
\text { years }\end{array}$ & $\begin{array}{c}800,000 \\
\text { miles } / 12 \\
\text { years }\end{array}$ & $\begin{array}{c}220,000 \\
\text { miles/12 years }\end{array}$ \\
\hline
\end{tabular}

After accounting for the initial incremental costs of the technologies, as determined in Task 1, the life-cycle cost assessment of Task 2 then took into account the aftertreatment technologies' effects on fuel consumption, DEF consumption, major overhaul intervals (full useful life estimates), manufacturing volume, and financial discount rates. The life-cycle cost modeled for each vehicle is specific to the EMission FACtor (EMFAC) model's vehicle definition of vehicle miles traveled, which depends on the specific region, vocation, model year, fuel type, and age.

For the life-cycle cost analysis in Task 2, the aftertreatment full useful life mileage was used to set the equipment overhaul schedule. For all scenarios in the life-cycle cost analysis, the incremental cost associated with the aftertreatment package was assumed to be incurred after the truck mileage exceeded the stated maximum FUL. This assumption is expected to be conservative, as not all aftertreatment packages will fail immediately after they exceed their stated maximum FUL and statistical analysis of failure rates combined with data on aftertreatment technology operating and maintenance costs were not available. To understand the impact of this assumption on the life-cycle cost, a sensitivity analysis was completed assuming the aftertreatment package would not need to be replaced over the vehicle's lifetime, as that provides the lower bound on the life-cycle cost. 


\section{Task 1: Engine Incremental Cost Analysis}

\subsection{Representative Engine Platform Approach}

The engine and aftertreatment incremental cost analysis began with a review of 54 model year (MY) 2018 medium- and heavy-duty engine family CARB certification summaries, covering Class 4-8 vehicle applications. The review provided background on the fuels used, range of engine displacements for each service class (i.e., LHDD, MHDD, HHDD, HDO), current technologies utilized, and certification levels versus Federal Test Procedure (FTP) and heavyduty Supplemental Emissions Test with Ramped Mode Cycles (SET-RMC) standards for $\mathrm{NO}_{\mathrm{x}}$. Because the majority of Class 4-8 engines are diesel fueled, incremental costs for diesel engines was the primary focus of the study. Natural gas and gasoline were also studied, but liquified petroleum gas/propane was not. A limited number of engine platforms were initially selected to represent the Class 4-8 vehicle population, based on engine displacement. This down-selection was necessary to come up with a reasonable number of representative engine platforms to use for the incremental cost analysis that could subsequently be used in the Task 2 life-cycle cost analysis over large vehicle populations, while keeping manageable the burden of calculating incremental cost for surveys conducted with Tier 1 suppliers, trade organizations, and engine OEMs. The initial engine platforms included: 6-L LHDD, 9-L MHDD, 12-L HHDD, 15-L HHDD, 12-L natural gas, and 6-L HDO (gasoline). Initial reviews with industry provided feedback that this number of engine platforms was still too large, and the diesel engine platforms could be consolidated and referenced to approximate horsepower levels. As a result, the diesel engine platforms were reduced to $\sim 6-7 \mathrm{~L}$ with $\sim 300$ horsepower (hp) and $\sim 12-13 \mathrm{~L}$ with $\sim 475$ hp. This reduction would still provide incremental costs with appropriate discrete levels. The inbetween calculation for a 9-L engine was agreed to not be worth the additional burden for industry survey responses. The elimination of the $15-\mathrm{L}$ engine was agreed to be covered by increased power density from $\sim 12-13$-L engines with future trends.

Current technologies were reviewed to benchmark the baseline for the $0.02 \mathrm{~g} / \mathrm{bhp}-\mathrm{hr} \mathrm{NO}_{\mathrm{x}}$ incremental cost. The industry surveys were designed to collect direct and indirect cost information for engine and aftertreatment subsystems from a 2018 baseline, with a $0.20 \mathrm{~g} / \mathrm{bhp}-\mathrm{hr}$ standard, as well as multiple technology packages assumed to meet a potential future $0.02 \mathrm{~g} / \mathrm{bhp}$ $\mathrm{hr} \mathrm{NO}_{\mathrm{x}}$ standard under a proposed new low-load certification (LLC), in addition to FTP and SET-RMC. The incremental costs would form the basis of Task 1. While the surveys were designed to allow industry respondents to start with their own 2018 baseline and did not explicitly define a common set of identical technologies, the CARB certification review showed most diesel engines in the 6-7-L and 12-13-L ranges were common in having direct diesel injection, cooled exhaust gas recirculation (EGR), turbocharging, a diesel oxidation catalyst (DOC), a diesel particulate filter (DPF), and selective catalytic reduction (SCR) using DEF. The technology packages supporting $0.02 \mathrm{~g} / \mathrm{bhp}-\mathrm{hr} \mathrm{NO}_{\mathrm{x}}$ selected for incremental cost study are described in more detail below.

A single natural-gas engine platform was selected at $12 \mathrm{~L}$ to align with the $\sim 12-13$-L diesel platform. The CARB certification review showed a number of natural-gas engines (in various displacements, meeting MHDD and HHDD requirements) sharing the same technologies: stoichiometric Otto-cycle operation, spark ignition (SI), throttle body fuel injection, turbocharging, cooled EGR, and a three-way catalyst (TWC). 
A single gasoline-fueled HDO platform was selected at $6 \mathrm{~L}$ to align with the $\sim 6-7$-L diesel platform. The CARB certification review showed HDO gasoline is approaching $0.02 \mathrm{~g} / \mathrm{bhp}-\mathrm{hr}$ $\mathrm{NO}_{\mathrm{x}}$ on the current certification cycles using stoichiometric, SI, naturally aspirated, EGR technologies with a TWC technology package.

Utilizing the results and recommendations from Stage 2 and 3 efforts from SwRI testing of potential future diesel-engine configurations, NREL identified three diesel technology packages to evaluate the total incremental cost implications for an MY 2023 release nationwide. These identified diesel technology packages were intended to represent potential low-, average-, and high-cost options to meet a $0.02 \mathrm{~g} / \mathrm{bhp}-\mathrm{hr} \mathrm{NO}_{\mathrm{x}}$ standard and were meant to provide a broader assessment of potential incremental costs than a single option. As previously referenced, no natural-gas technology package was surveyed for incremental costs related to $0.02 \mathrm{~g} / \mathrm{bhp}-\mathrm{hr} \mathrm{NO}_{\mathrm{x}}$, and the HDO gasoline technology package only included TWC and calibration upgrades. The resulting engine platforms defined for the incremental cost study are summarized in Table 2.

Table 2. Engine Platform Analysis for Incremental Cost Analysis

\begin{tabular}{lcccc}
\hline & LHDD & HHDD & $\begin{array}{c}\text { Natural Gas }- \\
\text { HHDD standard }\end{array}$ & Gasoline - HDO \\
\hline Engines & $\sim 6-7 \mathrm{~L}$ & $\sim 12-13 \mathrm{~L}$ & $12 \mathrm{~L}$ & $6 \mathrm{~L}$ \\
& $\sim 300 \mathrm{hp}$ & $\sim 475 \mathrm{hp}$ & & \\
$\begin{array}{l}\text { Current full } \\
\text { useful life }\end{array}$ & $\begin{array}{c}110,000 \mathrm{miles} / 10 \\
\text { years }\end{array}$ & $\begin{array}{c}435,000 \mathrm{miles} / 10 \\
\text { years, } \\
22,000 \text { hours }\end{array}$ & $\begin{array}{c}435,000 \text { miles } / 10 \\
\text { years, } \\
22,000 \text { hours }\end{array}$ & $\begin{array}{c}110,000 \text { miles } / 10 \\
\text { years }\end{array}$ \\
Low-Cost Tech. & $\$ \$ \$$ & $\$ \$ \$$ & Not applicable & Not applicable \\
Avg.-Cost Tech. & $\$ \$ \$$ & $\$ \$ \$$ & Not applicable & $\$ \$ \$$ \\
High-Cost Tech. & $\$ \$ \$$ & $\$ \$ \$$ & Not applicable & Not applicable \\
\hline
\end{tabular}

NREL then directly surveyed heavy-duty engine OEMs, Tier 1 suppliers, emission control technology manufacturers, and industry trade organizations to obtain the most accurate and current cost information for the identified likely technology packages to meet $0.02 \mathrm{~g} / \mathrm{bhp}-\mathrm{hr} \mathrm{NO}_{\mathrm{x}}$ requirements and the cost implications for using these specific technologies. The cost survey included a definition of the potential technologies as engine components, emission control components, subsystems and strategies, and indirect costs broken into categories of research and development (R\&D) costs, certification costs, and warranty costs. The combination of costs associated with developing and integrating the specified lower $\mathrm{NO}_{\mathrm{x}}$ emission control technologies into the engines, the costs of increasing the durability of these engines and their emission control systems, and the costs of impacted OBD hardware and calibration of these specified technology package were then examined to understand the total incremental cost implications to Tier 1 suppliers and engine OEMs of the potential technologies in two different surveys. Any incremental costs associated with future OBD requirements unrelated to meeting $0.02 \mathrm{~g} / \mathrm{bhp}-\mathrm{hr} \mathrm{NO}_{\mathrm{x}}$ were excluded from this study. Similarly, incremental costs related to future greenhouse gas (GHG) or fuel efficiency requirements and not specifically to meeting 0.02 $\mathrm{g} / \mathrm{bhp}-\mathrm{hr} \mathrm{NO}_{\mathrm{x}}$ were also excluded. 
The first survey assumed that the $0.02 \mathrm{~g} / \mathrm{bhp}-\mathrm{hr} \mathrm{NO}_{\mathrm{x}}$ regulation beginning MY 2023 included current FTP and SET-RMC steady-state test cycles, as well as a proposed new LLC for mediumand heavy-duty engine system certification. While not finalized and currently the topic of ongoing research, the new LLC engine cycle was assumed to last approximately 90 minutes, including a combination of motoring, sustained low load, and high-power transients. This first survey considered FUL hours/miles to remain the same as the current regulation. The survey was designed to allow industry respondents to start with their own 2018 baseline and did not explicitly define a common set of identical technologies. As a reference point, NREL provided internally generated estimates (from research, literature review, and engineering judgement) for the 2018 current technology costs (Posada, Chambliss, and Blumberg 2016; Posada Sanchez, Bandivadekar, and German 2012; Ou et al. 2019). Direct costs for both a 2018 baseline and 0.02 $\mathrm{g} / \mathrm{bhp}$-hr technology packages were surveyed on discrete engine and aftertreatment subsystem levels, along with indirect costs. The level of discrete subsystems was kept as small as possible to provide insight for where the costs accumulate while also being kept large enough to prevent identification of proprietary or confidential cost information from an individual respondent. Furthermore, only incremental costs are reported in this report and preliminary reviews with CARB to prevent identifying proprietary or confidential 2018 baseline costs. The survey requested future costs be calculated in 2018 dollars. The first survey asked for production volumes to be identified and to provide guidance on cost impacts for $0.02 \mathrm{~g} / \mathrm{bhp}$-hr incremental costs if regulation were to include all of the United States or California only.

The second survey was a follow-up survey sent to those Tier 1 suppliers, trade organization, and engine OEMs that responded to the first survey. The technology packages remained the same as the first survey, but instead assumed $0.02 \mathrm{~g} / \mathrm{bhp}-\mathrm{hr} \mathrm{NO}_{\mathrm{x}}$ regulation beginning MY 2027 and again included current FTP and SET-RMC steady-state test cycles, as well as a new LLC. This second survey also considered extended useful life hours/miles as proposed by CARB in Table 1. The second survey asked for costing information to consider $0.02 \mathrm{~g} / \mathrm{bhp}$-hr regulation if only California were included, representing lower production volumes than a scenario where all of the U.S. were included.

NREL then aggregated all of the data from the cost survey responses and the initial estimates derived by NREL from research, literature review, and engineering judgement. The incremental costs were not adjusted to reflect a retail markup due to the complexity with which pricing decisions are made. In responding to NREL's surveys, trade organizations, Tier 1 suppliers, and OEMs did provide feedback that they did not agree or conclude that these technologies would be feasible for meeting the $0.02 \mathrm{~g} / \mathrm{bhp}-\mathrm{hr} \mathrm{NO}_{\mathrm{x}}$ requirements by MY 2023. Their valuable input was strictly a costing exercise and not a technology feasibility assessment. The diesel incremental cost information resulted in a range of costs due to the format of the provided data from the responses received. This range consisted of a low, average, and high estimate for engine technology costs, aftertreatment technology costs, OBD-related direct costs, and indirect costs. The survey results for the diesel engine and aftertreatment technology packages were then defined as three total incremental costs of low, average, and high estimates based on the identified potential technology packages to achieve $0.02 \mathrm{~g} / \mathrm{bhp}-\mathrm{hr} \mathrm{NO}_{\mathrm{x}}$ requirements.

Fewer responses were received for the natural gas (HHDD standard) engine platform, preventing NREL from sufficiently aggregating incremental cost information to protect proprietary information. Therefore, NREL reported the total integrated incremental cost as an order of 
magnitude in comparison to the diesel engine with similar displacement results; the subsystemlevel engine, aftertreatment, and OBD system direct costs as well as the indirect costs were not broken out or reported.

Similarly, few responses were received for the gasoline HDO engine platform. Some aggregation was possible for direct costs, but only NREL estimates were available for indirect costs. As a result, only total integrated incremental costs are reported.

\subsection{Identifying Potential Diesel Technologies to Achieve $0.02 \mathrm{~g} / \mathrm{bhp}-$ $\mathrm{hr} \mathrm{NO}_{\mathrm{x}}$}

CARB is currently funding several research programs with SwRI to investigate the feasibility of achieving $0.02 \mathrm{~g} / \mathrm{bhp}-\mathrm{hr} \mathrm{NO}_{\mathrm{x}}$ emissions with a diesel engine and is in the Stage 3 process of testing specific emission control and diesel engine technologies. Based on SwRI's research and results from Stages 1 and 2 (Sharp et al., "Thermal Management," 2017; Sharp et al., "Comparison of Advanced," 2017; Sharp et al., "NO Management," 2017), NREL identified different engine and emission control technologies that showed potential capabilities of achieving $0.02 \mathrm{~g} / \mathrm{bhp}-\mathrm{hr} \mathrm{NO}_{\mathrm{x}}$ emissions during current FTP and SET-RMC steady-state test cycles, as well as a proposed new LLC cycle by MY 2023. These diesel engine and emission control technologies were grouped into three different diesel technology packages to represent a range of potential low-, average-, and high-costing diesel technology package solutions.

The potential low-cost diesel technology package consisted of an EPA 2017 certificationcompliant engine with a variable-geometry turbo charger, no turbo compounding, and a combined engine thermal management strategy of EGR cooler bypass, charge air cooler bypass, and a turbine bypass. In addition to the engine system, the emission control technologies included two points of DEF dosing and DEF mixers, one light-off SCR (LO-SCR), one DOC, one DPF, two SCRs, and one ammonia slip catalyst (ASC). The aftertreatment system also contained a $\mathrm{NO}_{x}$ sensor upstream of the first DEF dosing system and mixer, a temperature sensor upstream of the LO-SCR, a second temperature sensor downstream of the LO-SCR, a second $\mathrm{NO}_{\mathrm{x}}$ sensor downstream LO-SCR and upstream of the DOC, a third temperature sensor downstream of the LO-SCR and upstream of the DOC, a fourth temperature sensor downstream of the DOC and upstream of the DPF, a fifth temperature sensor downstream of the DPF and upstream of the first second DEF dosing system and mixer, an ammonia $\left(\mathrm{NH}_{3}\right)$ sensor downstream the first SCR and upstream the second SCR, a sixth temperature sensor downstream of the ASC, and a third $\mathrm{NO}_{x}$ sensor downstream of the ASC. An example of the aftertreatment technology system with sensors is illustrated in Figure 1. 


$$
\llbracket=\mathrm{NO}_{\mathrm{x}} \text { Sensor } \frac{\pi}{\square}=\mathrm{DEF} \text { Dosing } \llbracket=\mathrm{NH}_{3} \text { Sensor }
$$

$=$ Temp Sensor

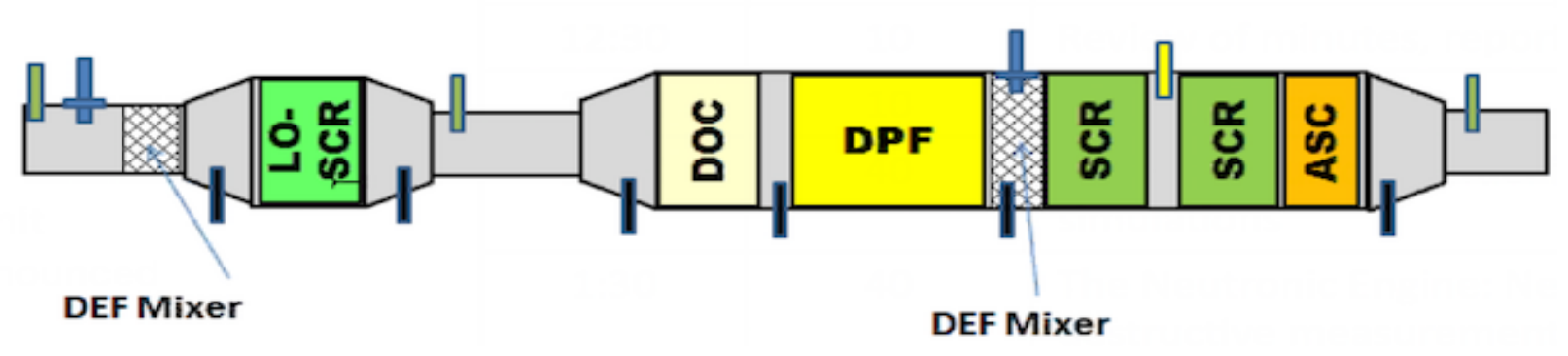

Figure 1. Schematic of proposed low- and average-cost diesel aftertreatment technology Figure from SwRI

The potential average-cost diesel technology package consisted of an EPA 2017 certificationcompliant engine with a variable-geometry turbo charger, no turbo compounding, and an engine thermal management strategy and technology for cylinder deactivation. In addition to the engine system, the emission control technologies again included the same aftertreatment system as the low-cost diesel technology package with two points of DEF dosing and DEF mixers, one LOSCR, one DOC, one DPF, two SCRs, and one ASC, as shown in Figure 1. The aftertreatment system also contained a $\mathrm{NO}_{\mathrm{x}}$ sensor upstream of the first DEF dosing system and mixer, a temperature sensor upstream of the LO-SCR, a second temperature sensor downstream of the LO-SCR, a second $\mathrm{NO}_{\mathrm{x}}$ sensor downstream LO-SCR and upstream of the DOC, a third temperature sensor downstream of the LO-SCR and upstream of the DOC, a fourth temperature sensor downstream of the DOC and upstream of the DPF, a fifth temperature sensor downstream of the DPF and upstream of the first second DEF dosing system and mixer, an $\mathrm{NH}_{3}$ sensor downstream of the first SCR and upstream of the second SCR, a sixth temperature sensor downstream of the ASC, and a third $\mathrm{NO}_{\mathrm{x}}$ sensor downstream of the ASC.

The proposed high-cost diesel technology package consisted of an EPA 2017 certificationcompliant engine with a variable-geometry turbo charger, no turbo compounding, and a combined engine thermal management strategy of EGR cooler bypass, charge air cooler bypass, and a turbine bypass. In addition to the engine system, the emission control technologies included a passive $\mathrm{NO}_{\mathrm{x}}$ absorber (PNA), one DOC, one DEF doser and DEF mixer, one selective catalytic reduction on filter (SCRF), one SCR, and one ASC. The aftertreatment system also contained a $\mathrm{NO}_{\mathrm{x}}$ sensor upstream of the PNA, a second $\mathrm{NO}_{\mathrm{x}}$ sensor downstream of the PNA, an $\mathrm{NH}_{3}$ sensor downstream of the SCRF and upstream of the SCR, and a third $\mathrm{NO}_{x}$ sensor downstream of the ASC. An example of the aftertreatment technology is illustrated in Figure 2. 


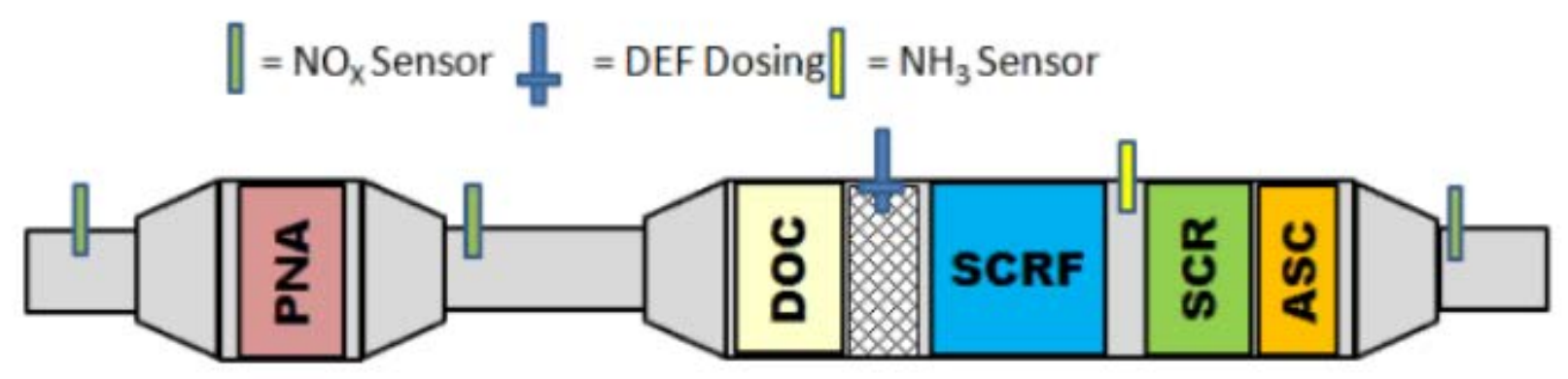

Figure 2. Schematic of proposed high-cost diesel aftertreatment technology

Figure from SwRI

Note that the proposed technology packages that were initially designed to represent low-, average-, and high-cost combinations. It was assumed that the PNA, as a very new technology, would drive incremental costs to be higher than other packages. Likewise, cylinder deactivation was assumed to have a higher incremental cost than cooler bypasses for charge air, EGR, and turbine given the same aftertreatment package. However, once incremental cost information became available, the relative incremental costs did not necessarily turn out in that order. Nevertheless, to maintain consistency in the study, the proposed technology packages continued to be referred by their initial naming convention.

\subsection{Identifying Potential Gasoline and Natural Gas Technologies to Achieve $0.02 \mathrm{~g} / \mathrm{bhp}-\mathrm{hr} \mathrm{NO}_{\mathrm{x}}$}

The single natural-gas 12 -L engine platform was selected to align with the $\sim 12-13$-L diesel platform. The CARB certification review showed a number of natural-gas engines (in various displacements, meeting MHDD and HHDD requirements) sharing the same technologies: stoichiometric Otto-cycle operation, SI, throttle body fuel injection, turbocharging, cooled EGR, and a TWC. Notably, most of the natural-gas engines already meet CARB's optional low- $\mathrm{NO}_{\mathrm{x}}$ standard at $0.02 \mathrm{~g} / \mathrm{bhp}-\mathrm{hr}$ under the current certification cycles. Because the proposed LLC certification was assessed to be less challenging for a stoichiometric SI engine than a diesel engine, it was assumed that the current 2018 "baseline" technology package would already meet the new $0.02 \mathrm{~g} / \mathrm{bhp}-\mathrm{hr} \mathrm{NO}_{\mathrm{x}}$ requirement. Incremental cost for $0.02 \mathrm{~g} / \mathrm{bhp}-\mathrm{hr} \mathrm{NO}_{\mathrm{x}}$ was therefore not calculated, but cost increases related to extending FUL were considered. As noted later in this report, industry feedback identified this assumption as incorrect.

The single gasoline-fueled HDO platform was selected at $6 \mathrm{~L}$ to align with the $\sim 6-7$-L diesel platform. The CARB certification review showed HDO gasoline is approaching $0.02 \mathrm{~g} / \mathrm{bhp}-\mathrm{hr}$ $\mathrm{NO}_{\mathrm{x}}$ on the current certification cycles, and similar technology (stoichiometric, SI, naturally aspirated, EGR technologies with a TWC) with liquified petroleum gas fuel has recently been certified at $0.05 \mathrm{~g} / \mathrm{bhp}-\mathrm{hr}$ and $0.02 \mathrm{~g} / \mathrm{bhp}-\mathrm{hr}$ under CARB's optional low-NO $\mathrm{N}_{\mathrm{x}}$ standards. The base engine was assumed to need no significant upgrades for the $0.02 \mathrm{~g} / \mathrm{bhp}-\mathrm{hr}$ standard with proposed LLC certification cost study, but TWC direct cost upgrades and indirect costs for engineering, certification, and warranty were surveyed, as well as extended FUL impacts. Vehicle packaging impacts were noted to also potentially be required to enable close coupling of the TWCs. 


\subsection{NREL Survey of Potential Technologies to Achieve $0.02 \mathrm{~g} / \mathrm{bhp}-\mathrm{hr}$ $\mathrm{NO}_{\mathrm{x}}$}

NREL created a cost survey with a baseline price of an MY 2018 system representing an EPA 2018 certification-compliant engine and aftertreatment system in 2018 dollars and asked trade organizations, Tier 1 suppliers, and engine OEMs to provide incremental cost estimates in comparison to the above-defined technologies with the potential to achieve $0.02 \mathrm{~g} / \mathrm{bhp}-\mathrm{hr} \mathrm{NO}_{\mathrm{x}}$ requirements. The cost survey was reviewed with CARB and EPA staff and approved by CARB before submitting for requested responses. The survey consisted of two technology packages for diesel engine and aftertreatment systems, one technology package for natural-gas engines and aftertreatment, and one technology package for gasoline engines and aftertreatment systems. To simplify the survey for stakeholder input and avoid asking for input on three separate combinations of engine and aftertreatment technology packages, the two unique diesel engine technology packages (charge air, EGR, and turbine cooler bypass vs. cylinder deactivation) were surveyed with the two unique aftertreatment technology packages (Figure 1 and Figure 2). From these incremental cost inputs, NREL could construct the proposed low-, average-, and high-cost combined engine and aftertreatment technology packages.

The first survey assumed that the $0.02 \mathrm{~g} / \mathrm{bhp}-\mathrm{hr} \mathrm{NO}_{\mathrm{x}}$ regulation beginning MY 2023 included current FTP and SET-RMC steady-state test cycles, as well as a new LLC cycle. While not finalized and currently the topic of ongoing research, the LLC was assumed as a new engine certification cycle lasting approximately 90 minutes and included a combination of motoring, sustained low load, and high-power transients. This first survey also considered FUL hours/miles to remain the same as the current regulation. NREL also prefaced the likely follow-up survey seeking additional guidance on how increasing FUL hour/mile requirements may further affect the provided costs.

The second survey was a follow-up survey sent to the same Tier 1 suppliers, trade organizations, and engine OEMs that responded to the first survey. The technology packages remained the same and instead assumed $0.02 \mathrm{~g} / \mathrm{bhp}-\mathrm{hr} \mathrm{NO}_{\mathrm{x}}$ regulation beginning MY 2027 and again included current FTP and SET-RMC steady-state test cycles, as well as a proposed new LLC cycle. Again, while not finalized and currently the topic of ongoing research, the LLC was assumed as a new engine certification cycle lasting approximately 90 minutes and included a combination of motoring, sustained low load, and high-power transients. This second survey considered extended FUL hours/miles as proposed by CARB's Stage 2 definitions defined in Table 1. Additionally, per CARB's guidance, the extended FUL also included the assumption that warranty periods will increase to $80 \%$ of the extended FUL, both in mileage and time, except for heavy-duty Otto cycle, which was specified as 220,000 miles/ 12 years.

\subsubsection{Definition of Baseline Costs of Current Technologies With 2018 EPA Certification}

As a starting point for the incremental cost definition of potential technologies to meet 0.02 $\mathrm{g} / \mathrm{bhp}-\mathrm{hr} \mathrm{NO}_{\mathrm{x}}$ requirements, NREL estimated the direct manufacturing costs and indirect costs for an EPA 2018-certified engine and aftertreatment system production costs of current technology to meet $0.20 \mathrm{~g} / \mathrm{bhp}-\mathrm{hr} \mathrm{NO}_{\mathrm{x}}$ in 2018 dollars for the U.S. market based on literature reviews and engineering judgement (Posada, Chambliss, and Blumberg, 2016; Posada Sanchez, Bandivadekar, and German 2012; Ou 2019). These estimates were defined for two diesel 
platforms, 6-7 L and 12-13 L, based on the majority of current market offerings. NREL then estimated the incremental cost of MY 2023 technologies to meet a $0.02 \mathrm{~g} / \mathrm{bhp}-\mathrm{hr} \mathrm{NO}_{\mathrm{x}}$ requirement based on literature review, engineering judgement, and feedback from SwRI to provide a baseline estimate of the incremental costs for the two potential diesel technology packages for each of the two engine platforms. The NREL estimates for EPA 2018-certified $\left(0.20 \mathrm{~g} / \mathrm{bhp}-\mathrm{hr} \mathrm{NO}_{\mathrm{x}}\right)$ engine and aftertreatment direct and indirect costs, as well as NREL estimates for incremental direct and indirect costs for MY $20230.02 \mathrm{~g} / \mathrm{bhp}-\mathrm{hr} \mathrm{NO}_{\mathrm{x}}$ were generated as starting points for stakeholders to consider in the survey. NREL requested survey responses to utilize the baseline estimates, if accurate, or to correct NREL's incremental cost estimates as necessary. Only incremental costs are revealed in this report.

The baseline technology packages for the diesel engine and aftertreatment technology consisted of an EPA 2018-certified engine, a DOC, a DPF, a DEF dosing system and mixer (with a single doser), am SCR with $\mathrm{ASC}$, one $\mathrm{NO}_{\mathrm{x}}$ sensor, three $\mathrm{NH}_{3}$ sensors, and four temperature sensors. These components were the same for the two platforms of 6-7 L and 12-13 L. The baseline costs and resulting incremental costs were scaled accordingly. The baseline technology package for the gasoline HDO engine platform consisted of stoichiometric, SI, naturally aspirated, EGR technologies with a TWC. The baseline technology package for the natural-gas system consisted of stoichiometric Otto-cycle operation, SI, throttle body fuel injection, turbocharging, cooled EGR, and a TWC.

\subsubsection{NREL Initial Incremental Cost Estimates}

NREL's initial estimated incremental costs of the potential diesel technology package likely to be the lowest incremental cost to meet $0.02 \mathrm{~g} / \mathrm{bhp}-\mathrm{hr} \mathrm{NO}_{\mathrm{x}}$ for the 6-7- $\mathrm{L}$ platform are depicted in Table 3. This technology package consisted of an EPA 2017 certification-compliant engine with a variable-geometry turbo charger, no turbo compounding, and a combined engine thermal management strategy of EGR cooler bypass, charge air cooler bypass, and a turbine bypass. In addition to the engine system, the emission control technologies included two points of DEF dosing and DEF mixers, one LO-SCR, one DOC, one DPF, two SCRs, and one ASC. In the following tables, note that negative incremental costs mean the cost for that component/subsystem reduce from the 2018 baseline. 
Table 3. NREL Estimates of Potential Low-Cost Diesel Technology Package 6-7 L

\begin{tabular}{ll}
\hline Cost Component & Incremental Cost Estimate \\
\hline EGR Cooler Bypass & $\$ 330$ \\
Charge Air Cooler Bypass & $\$ 200$ \\
Turbine Bypass & $\$ 220$ \\
\hline Total Engine Technology Incremental Cost & $\$ 750$ \\
LO-SCR & $\$ 530$ \\
DOC & $(\$ 15)$ \\
DPF & $(\$ 45)$ \\
SCR+ASC and DEF Dosing System & $\$ 751$ \\
OBD Sensors and Controllers (NOx, NH, and Temp Sensors) & $(\$ 66)$ \\
\hline Total Aftertreatment Technology Incremental Cost & $\$ 1,155$ \\
\hline R\&D Engineering Incremental Cost & $\$ 100$ \\
\hline Certification Incremental Costs & $\$ 0$ \\
\hline Warranty Incremental Costs & $\$ 0$ \\
\hline Total Indirect Incremental Costs to Manufacturer & $\$ 100$ \\
\hline Total Incremental Cost Comparison & $\$ 2,005$ \\
\hline
\end{tabular}

NREL's initial estimated incremental costs of the potential diesel technology package, likely to be the lowest incremental cost to meet $0.02 \mathrm{~g} / \mathrm{bhp}-\mathrm{hr} \mathrm{NO}_{\mathrm{x}}$ for the 12-13-L platform, are depicted in Table 4. 
Table 4. NREL Estimates of Potential Low-Cost Diesel Technology Package 12-13 L

\begin{tabular}{ll}
\hline Cost Component & Incremental Cost Estimate \\
\hline EGR Cooler Bypass & $\$ 330$ \\
Charge Air Cooler Bypass & $\$ 200$ \\
Turbine Bypass & $\$ 220$ \\
$\begin{array}{l}\text { Total Engine Technology } \\
\text { Incremental Cost }\end{array}$ & $\$ 750$ \\
\hline LO-SCR & $\$ 750$ \\
$\begin{array}{l}\text { DOC } \\
\text { DPF }\end{array}$ & $\$ 504$ \\
$\begin{array}{l}\text { SCR+ASC and DEF Dosing } \\
\text { System }\end{array}$ & $\$ 1,277$ \\
$\begin{array}{l}\text { OBD Sensors and Controllers } \\
\text { (NOx, NH }\end{array}$, and Temp Sensors) & $(\$ 66)$ \\
$\begin{array}{l}\text { Total Aftertreatment } \\
\text { Technology Incremental Cost }\end{array}$ & $\$ 2,367$ \\
$\begin{array}{l}\text { R\&D Engineering Incremental } \\
\text { Cost } \\
\text { Certification Incremental Costs }\end{array}$ & $\$ 100$ \\
$\begin{array}{l}\text { Warranty Incremental Costs } \\
\text { Total Indirect Incremental } \\
\text { Costs to Manufacturer }\end{array}$ & $\$ 0$ \\
\hline $\begin{array}{l}\text { Total Incremental Cost } \\
\text { Comparison }\end{array}$ & $\$ 100$ \\
\hline
\end{tabular}

NREL's initial estimated incremental costs of the potential diesel technology package, likely to

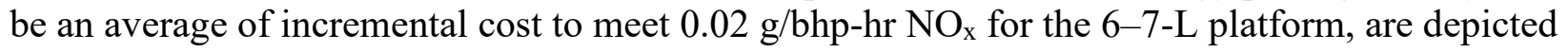
in Table 5. The potential average-cost diesel technology package consisted of an EPA 2017 certification-compliant engine with a variable-geometry turbo charger, no turbo compounding, and an engine thermal management strategy and technology for cylinder deactivation. In addition to the engine system, the emission control technologies again included the same aftertreatment system as the low-cost diesel technology package with two points of DEF dosing and DEF mixers, one LO-SCR, one DOC, one DPF, two SCRs, and one ASC. 
Table 5. NREL Estimate of Potential Average-Cost Diesel Technology Package 6-7 L

\begin{tabular}{ll}
\hline Cost Component & Incremental Cost Estimate \\
\hline Cylinder Deactivation & $\$ 1,050$ \\
\hline Total Engine Technology Incremental Cost & $\$ 1,050$ \\
\hline LO-SCR & $\$ 530$ \\
DOC & $(\$ 15)$ \\
DPF & $(\$ 45)$ \\
SCR+ASC and DEF Dosing System & $\$ 751$ \\
OBD Sensors and Controllers (NOx, NH, and Temp Sensors) & $(\$ 66)$ \\
\hline Total Aftertreatment Technology Incremental Cost & $\$ 1,155$ \\
\hline R\&D Engineering Incremental Cost & $\$ 100$ \\
Certification Incremental Costs & $\$ 0$ \\
\hline Warranty Incremental Costs & $\$ 0$ \\
\hline Total Indirect Incremental Costs to Manufacturer & $\$ 100$ \\
\hline Total Incremental Cost Comparison & $\$ 2,305$ \\
\hline
\end{tabular}

NREL's initial estimated incremental costs of the potential diesel technology package, likely to be the average incremental cost to meet $0.02 \mathrm{~g} / \mathrm{bhp}-\mathrm{hr} \mathrm{NO}_{\mathrm{x}}$ for the 12-13-L platform, are depicted in Table 6. 
Table 6. NREL Estimates of Potential Average-Cost Diesel Technology Package 12-13 L

\begin{tabular}{ll}
\hline Cost Component & Incremental Cost Estimate \\
\hline Cylinder Deactivation & $\$ 1,050$ \\
Total Engine Technology Incremental Cost & $\$ 1,050$ \\
LO-SCR & $\$ 750$ \\
DOC & $\$ 504$ \\
DPF & $\$ 98$ \\
SCR+ASC and DEF Dosing System & $\$ 1,277$ \\
OBD Sensors and Controllers (NO, $\mathrm{NH}_{3}$, and Temp Sensors) & $(\$ 66)$ \\
Total Aftertreatment Technology Incremental Cost & $\$ 2,563$ \\
R\&D Engineering Incremental Cost & $\$ 100$ \\
Certification Incremental Costs & $\$ 0$ \\
Warranty Incremental Costs & $\$ 0$ \\
\hline Total Indirect Incremental Costs to Manufacturer & $\$ 100$ \\
\hline Total Incremental Cost Comparison & $\$ 3,713$ \\
\hline
\end{tabular}

NREL's initial estimated incremental costs of the potential diesel technology package, likely to be the highest incremental cost to meet $0.02 \mathrm{~g} / \mathrm{bhp}-\mathrm{hr} \mathrm{NO}_{\mathrm{x}}$ for the 6-7-L platform, are depicted in Table 7. The potential high-cost diesel technology package consisted of an EPA 2017 certification-compliant engine with a variable-geometry turbo charger, no turbo compounding, and a combined engine thermal management strategy of EGR cooler bypass, charge air cooler bypass, and a turbine bypass. In addition to the engine system, the emission control technologies included a PNA, one DOC, one DEF doser and DEF mixer, one SCRF, one SCR, and one ASC. 
Table 7. NREL Estimates of Potential High-Cost Diesel Technology Package 6-7 L

\begin{tabular}{ll}
\hline Cost Component & Incremental Cost Estimate \\
\hline EGR Cooler Bypass & $\$ 330$ \\
Charge Air Cooler Bypass & $\$ 200$ \\
Turbine Bypass & $\$ 220$ \\
\hline Total Engine Technology Incremental Cost & $\$ 750$ \\
\hline PNA & $\$ 730$ \\
DOC & $(\$ 15)$ \\
DPF (2018 baseline system only) & $(\$ 759)$ \\
SCRF & $\$ 714$ \\
SCR+ASC and DEF Dosing System & $\$ 74$ \\
OBD Sensors and Controllers (NOx, NH ${ }_{3}$ and Temp Sensors) & $\$ 314$ \\
\hline Total Aftertreatment Technology Incremental Cost & $\$ 1,058$ \\
\hline R\&D Engineering Incremental Cost & $\$ 0$ \\
\hline Certification Incremental Costs & $\$ 0$ \\
\hline Warranty Incremental Costs & $\$ 0$ \\
\hline Total Indirect Incremental Costs to Manufacturer & $\$ 0$ \\
\hline Total Incremental Cost Comparison & $\$ 1,808$ \\
\hline
\end{tabular}

NREL's initial estimated incremental costs of the potential diesel technology package, likely to be the highest incremental cost to meet $0.02 \mathrm{~g} / \mathrm{bhp}-\mathrm{hr} \mathrm{NO}$ for the 12-13-L platform, are depicted in Table 8 . 
Table 8. NREL Estimates of Potential High-Cost Diesel Technology Package 12-13 L

\begin{tabular}{ll}
\hline Cost Component & Incremental Cost Estimate \\
\hline EGR Cooler Bypass & $\$ 330$ \\
Charge Air Cooler Bypass & $\$ 200$ \\
Turbine Bypass & $\$ 220$ \\
\hline Total Engine Technology Incremental Cost & $\$ 750$ \\
\hline PNA & $\$ 1,256$ \\
DOC & $\$ 4$ \\
DPF (2018 baseline system only) & $(\$ 1,398)$ \\
SCRF & $\$ 1,300$ \\
SCR+ASC and DEF Dosing System & $\$ 227$ \\
OBD Sensors and Controllers (NOx, NH ${ }_{3}$ and Temp Sensors) & $\$ 314$ \\
\hline Total Aftertreatment Technology Incremental Cost & $\$ 1,703$ \\
\hline R\&D Engineering Incremental Cost & $\$ 0$ \\
\hline Certification Incremental Costs & $\$ 0$ \\
\hline Warranty Incremental Costs & $\$ 0$ \\
\hline Total Indirect Incremental Costs to Manufacturer & $\$ 0$ \\
\hline Total Incremental Cost Comparison & $\$ 2,453$ \\
\hline
\end{tabular}

\subsubsection{First Survey Responses for Incremental Costs of Potential Diesel Technologies}

NREL received a total of five survey responses from a mix of advanced engine technology and emission control technology trade organizations, Tier 1 suppliers, and engine OEMs. As referenced in the Acknowledgements, MECA responded to the survey in a single, aggregated response (to protect confidential cost information). NREL does not know how many MECA member companies are included in that aggregated response.

As a reminder, the first survey specified:

- $0.02 \mathrm{~g} / \mathrm{bhp}-\mathrm{hr} \mathrm{NO}_{\mathrm{x}}$ on FTP, RMC-SET, in addition to the new proposed LLC

- MY 2023 introduction

- Current FUL

- Current warranty offered by the OEMs (whatever that may be)

- Production volumes for all of the United States, with guidance for changes for Californiaonly adoption. 
NREL received feedback for U.S. volumes, with very little information regarding impacts for California-only adoption. As NREL was unable to aggregate California-only adoption incremental costs, only incremental costs for U.S. volumes are reported.

After receiving the responses to the first survey request, NREL aggregated the incremental cost data into a range of low, average, and high responses for the potential low-cost diesel technology package, as summarized below for 6-7 L in Table 9 and 12-13 L in Table 10. Note that these low, average, and high incremental cost responses are not to be confused with the proposed low-, average-, and high-cost technology packages. Also, note that the low, average, and high responses for each component/subsystem (row) were calculated so that the total low, average, and high incremental cost may not directly reflect any single survey response.

Table 9. Survey Responses for Potential Low-Cost Diesel Technology Package 6-7 L

\begin{tabular}{llll}
\hline 6-7 L & Low & Avg. & High \\
\hline EGR Cooler Bypass & $\$ 170$ & $\$ 243$ & $\$ 330$ \\
Charge Air Cooler Bypass & $\$ 128$ & $\$ 167$ & $\$ 200$ \\
Turbine Bypass & $\$ 170$ & $\$ 207$ & $\$ 230$ \\
\hline Total Engine Technology Incremental Cost & $\$ 468$ & $\$ 617$ & $\$ 760$ \\
\hline LO-SCR & $\$ 401$ & $\$ 944$ & $\$ 2,200$ \\
DOC & $(\$ 15)$ & $\$ 10$ & $\$ 30$ \\
DPF & $(\$ 45)$ & $(\$ 17)$ & $\$ 0$ \\
SCR+ASC and DEF Dosing System & $\$ 300$ & $\$ 621$ & $\$ 823$ \\
OBD Sensors and Controllers (NO, NH $_{3}$, and Temp Sensors) & $\$ 141$ & $\$ 333$ & $\$ 800$ \\
Other & $\$ 50$ & $\$ 175$ & $\$ 300$ \\
\hline Total Aftertreatment Technology Incremental Cost & $\$ 832$ & $\$ 2,066$ & $\$ 4,153$ \\
\hline R\&D Engineering Incremental Cost & $\$ 70$ & $\$ 85$ & $\$ 100$ \\
Certification Incremental Costs & $\$ 0$ & $\$ 25$ & $\$ 50$ \\
Warranty Incremental Costs & $\$ 750$ & $\$ 1,875$ & $\$ 3,000$ \\
\hline Total Indirect Incremental Costs to Manufacturer & $\$ 820$ & $\$ 1,985$ & $\$ 3,150$ \\
\hline Total Incremental Cost Comparison & $\$ 2,120$ & $\$ 4,668$ & $\$ 8,063$ \\
\hline
\end{tabular}


Table 10. Survey Responses for Potential Low-Cost Diesel Technology Package 12-13 L

\begin{tabular}{llll}
\hline 12-13 L & Low & Avg. & High \\
\hline EGR Cooler Bypass & $\$ 170$ & $\$ 302$ & $\$ 408$ \\
Charge Air Cooler Bypass & $\$ 128$ & $\$ 185$ & $\$ 240$ \\
Turbine Bypass & $\$ 170$ & $\$ 215$ & $\$ 240$ \\
\hline Total Engine Technology Incremental Cost & $\$ 468$ & $\$ 702$ & $\$ 888$ \\
\hline LO-SCR & $\$ 574$ & $\$ 1,120$ & $\$ 2,450$ \\
DOC & $\$ 0$ & $\$ 89$ & $\$ 250$ \\
DPF & $(\$ 98)$ & $(\$ 44)$ & $\$ 0$ \\
SCR+ASC and DEF Dosing System & $\$ 500$ & $\$ 784$ & $\$ 1,100$ \\
OBD Sensors and Controllers (NOx, NH ${ }^{3}$, and Temp Sensors) & $\$ 158$ & $\$ 330$ & $\$ 600$ \\
Other & $\$ 50$ & $\$ 150$ & $\$ 300$ \\
\hline Total Aftertreatment Technology Incremental Cost & $\$ 1,184$ & $\$ 2,429$ & $\$ 4,700$ \\
\hline R\&D Engineering Incremental Cost & $\$ 110$ & $\$ 354$ & $\$ 503$ \\
Certification Incremental Costs & $\$ 0$ & $\$ 21$ & $\$ 50$ \\
Warranty Incremental Costs & $\$ 1,500$ & $\$ 1,833$ & $\$ 2,500$ \\
\hline Total Indirect Incremental Costs to Manufacturer & $\$ 1,610$ & $\$ 2,208$ & $\$ 3,053$ \\
\hline Total Incremental Cost Comparison & $\$ 3,262$ & $\$ 5,339$ & $\$ 8,641$ \\
\hline
\end{tabular}

After receiving the responses to the first survey request, NREL aggregated the incremental cost data into a range of low, average, and high estimates for the potential average-cost diesel technology package, as summarized for 6-7 L in Table 11 and $12-13 \mathrm{~L}$ in Table 12. 
Table 11. Survey Responses for Potential Average-Cost Diesel Technology Package 6-7 L

\begin{tabular}{llll}
\hline 6-7 L & Low & Avg. & High \\
\hline Cylinder Deactivation & $\$ 480$ & $\$ 790$ & $\$ 1,140$ \\
Other & $\$ 150$ & $\$ 505$ & $\$ 860$ \\
\hline Total Engine Technology Incremental Cost & $\$ 630$ & $\$ 1,295$ & $\$ 2,000$ \\
\hline LO-SCR & $\$ 401$ & $\$ 944$ & $\$ 2,200$ \\
DOC & $(\$ 15)$ & $\$ 10$ & $\$ 30$ \\
DPF & $(\$ 45)$ & $(\$ 17)$ & $\$ 0$ \\
SCR+ASC and DEF Dosing System & $\$ 300$ & $\$ 621$ & $\$ 823$ \\
OBD Sensors and Controllers (NOx, NH3, and Temp Sensors) & $\$ 141$ & $\$ 333$ & $\$ 800$ \\
Other & $\$ 50$ & $\$ 175$ & $\$ 300$ \\
\hline Total Aftertreatment Technology Incremental Cost & $\$ 832$ & $\$ 2,064$ & $\$ 4,153$ \\
\hline R\&D Engineering Incremental Cost & $\$ 70$ & $\$ 85$ & $\$ 100$ \\
Certification Incremental Costs & $\$ 0$ & $\$ 25$ & $\$ 50$ \\
\hline Warranty Incremental Costs & $\$ 750$ & $\$ 1,875$ & $\$ 3,000$ \\
\hline Total Indirect Incremental Costs to Manufacturer & $\$ 820$ & $\$ 1,985$ & $\$ 3,150$ \\
\hline Total Incremental Cost Comparison & $\$ 2,282$ & $\$ 5,344$ & $\$ 9,303$ \\
\hline
\end{tabular}


Table 12. Survey Responses for Potential Average-Cost Diesel Technology Package 12-13 L

\begin{tabular}{llll}
\hline 12-13 L & Low & Avg. & High \\
\hline Cylinder Deactivation & $\$ 561$ & $\$ 952$ & $\$ 1,550$ \\
Other & $\$ 150$ & $\$ 625$ & $\$ 1,100$ \\
\hline Total Engine Technology Cost & $\$ 711$ & $\$ 1,577$ & $\$ 2,650$ \\
\hline LO-SCR & $\$ 574$ & $\$ 1,120$ & $\$ 2,450$ \\
DOC & $\$ 0$ & $\$ 89$ & $\$ 250$ \\
DPF & $(\$ 98)$ & $(\$ 44)$ & $\$ 0$ \\
SCR+ASC and DEF Dosing System & $\$ 500$ & $\$ 784$ & $\$ 1,100$ \\
OBD Sensors and Controllers (NOx, NH 3 , and Temp Sensors) & $\$ 158$ & $\$ 330$ & $\$ 600$ \\
Other & $\$ 50$ & $\$ 150$ & $\$ 300$ \\
\hline Total Aftertreatment Technology Incremental Cost & $\$ 1,184$ & $\$ 2,429$ & $\$ 4,700$ \\
\hline R\&D Engineering Incremental Cost & $\$ 110$ & $\$ 354$ & $\$ 503$ \\
\hline Certification Incremental Costs & $\$ 0$ & $\$ 21$ & $\$ 50$ \\
\hline Warranty Incremental Costs & $\$ 1,500$ & $\$ 1,833$ & $\$ 2,500$ \\
\hline Total Indirect Incremental Costs to Manufacturer & $\$ 1,610$ & $\$ 2,209$ & $\$ 3,053$ \\
\hline Total Incremental Cost Comparison & $\$ 3,505$ & $\$ 6,214$ & $\$ 10,403$ \\
\hline
\end{tabular}

After receiving the responses to the first survey request, NREL aggregated the incremental cost data into a range of low, average, and high estimates for the potential high-cost diesel technology package, as summarized for 6-7 $\mathrm{L}$ in Table 13 and 12-13 $\mathrm{L}$ in Table 14. 
Table 13. Survey Responses for Potential High-Cost Diesel Technology Package 6-7 L

\begin{tabular}{|c|c|c|c|}
\hline $6-7 \mathrm{~L}$ & Low & Avg. & High \\
\hline EGR Cooler Bypass & $\$ 170$ & $\$ 243$ & $\$ 330$ \\
\hline Charge Air Cooler Bypass & $\$ 128$ & $\$ 167$ & $\$ 200$ \\
\hline Turbine Bypass & $\$ 170$ & $\$ 207$ & $\$ 230$ \\
\hline $\begin{array}{l}\text { Total Engine Technology } \\
\text { Incremental Cost }\end{array}$ & $\$ 468$ & $\$ 617$ & $\$ 760$ \\
\hline PNA & $\$ 701$ & $\$ 883$ & $\$ 1,000$ \\
\hline DOC & $(\$ 15)$ & $(\$ 12)$ & $(\$ 9)$ \\
\hline $\begin{array}{l}\text { DPF ( } 2018 \text { baseline system } \\
\text { only) }\end{array}$ & $(\$ 759)$ & $(\$ 549)$ & $(\$ 377)$ \\
\hline SCRF & $\$ 500$ & $\$ 559$ & $\$ 677$ \\
\hline $\begin{array}{l}\text { SCR+ASC and DEF Dosing } \\
\text { System }\end{array}$ & $\$ 584$ & $\$ 722$ & $\$ 793$ \\
\hline $\begin{array}{l}\text { OBD Sensors and Controllers } \\
\text { (NOx, } \mathrm{NH}_{3} \text {, and Temp } \\
\text { Sensors) }\end{array}$ & $\$ 141$ & $\$ 214$ & $\$ 313$ \\
\hline Other & $\$ 50$ & $\$ 50$ & $\$ 50$ \\
\hline $\begin{array}{l}\text { Total Aftertreatment } \\
\text { Technology Incremental } \\
\text { Cost }\end{array}$ & $\$ 1,202$ & $\$ 1,868$ & $\$ 2,447$ \\
\hline $\begin{array}{l}\text { R\&D Engineering Incremental } \\
\text { Cost }\end{array}$ & $\$ 400$ & $\$ 400$ & $\$ 400$ \\
\hline $\begin{array}{l}\text { Certification Incremental } \\
\text { Costs }\end{array}$ & $\$ 50$ & $\$ 50$ & $\$ 50$ \\
\hline Warranty Incremental Costs & $\$ 750$ & $\$ 750$ & $\$ 750$ \\
\hline $\begin{array}{l}\text { Total Indirect Incremental } \\
\text { Costs to Manufacturer }\end{array}$ & $\$ 1,200$ & $\$ 1,200$ & $\$ 1,200$ \\
\hline $\begin{array}{l}\text { Total Incremental Cost } \\
\text { Comparison }\end{array}$ & $\$ 2,870$ & $\$ 3,685$ & $\$ 4,407$ \\
\hline
\end{tabular}


Table 14. Survey Responses for Potential High-Cost Diesel Technology Package 12-13 L

\begin{tabular}{llll}
\hline 12-13 L & Low & Avg. & High \\
\hline EGR Cooler Bypass & $\$ 170$ & $\$ 302$ & $\$ 408$ \\
Charge Air Cooler Bypass & $\$ 128$ & $\$ 185$ & $\$ 240$ \\
Turbine Bypass & $\$ 170$ & $\$ 215$ & $\$ 240$ \\
\hline Total Engine Technology Incremental Cost & $\$ 468$ & $\$ 702$ & $\$ 888$ \\
\hline PNA & $\$ 1,147$ & $\$ 2,270$ & $\$ 3,880$ \\
DOC & $\$ 0$ & $\$ 11$ & $\$ 22$ \\
DPF (2018 baseline system only) & $(\$ 881)$ & $(\$ 673)$ & $(\$ 560)$ \\
SCRF & $\$ 800$ & $\$ 930$ & $\$ 1,162$ \\
SCR+ASC and DEF Dosing System & $(\$ 209)$ & $\$ 387$ & $\$ 723$ \\
OBD Sensors and Controllers (NO, NH $_{3}$, and Temp Sensors) & $\$ 158$ & $\$ 254$ & $\$ 330$ \\
Other & $\$ 50$ & $\$ 75$ & $\$ 100$ \\
\hline Total Aftertreatment Technology Incremental Cost & $\$ 1,065$ & $\$ 3,253$ & $\$ 5,657$ \\
\hline R\&D Engineering Incremental Cost & $\$ 350$ & $\$ 427$ & $\$ 503$ \\
Certification Incremental Costs & $\$ 13$ & $\$ 32$ & $\$ 50$ \\
Warranty Incremental Costs & $\$ 1,500$ & $\$ 1,650$ & $\$ 1,800$ \\
\hline Total Indirect Incremental Costs to Manufacturer & $\$ 1,863$ & $\$ 2,108$ & $\$ 2,353$ \\
\hline Total Incremental Cost Comparison & $\$ 3,396$ & $\$ 6,063$ & $\$ 8,898$ \\
\hline
\end{tabular}

\subsubsection{Incremental Costs of Potential Technologies with Extended FUL and Warranty, and California-Only Volumes}

After receiving the responses to the first survey request, NREL aggregated the incremental cost data into a range of low, average, and high estimates, as summarized previously. NREL then followed up with an additional survey to identify incremental costs from the MY 2018 baseline, but also to add extended FUL and warranty per Table 1. Lower production volumes representing California only (instead of all of the United States) were also incorporated. The survey assumed implementation for MY 2027 (instead of MY 2023, as in the first survey), as additional time would be necessary to engineer for extended FUL and warranty. Table 15 through Table 20 summarize these additional survey responses. 
Table 15. Survey Responses for Potential Low-Cost Diesel Technology Package 6-7 L with Extended FUL, Extended Warranty, and California-Only Volumes

\begin{tabular}{llll}
\hline 6-7 L & Low & Avg. & High \\
\hline EGR Cooler Bypass & $\$ 289$ & $\$ 390$ & $\$ 490$ \\
Charge Air Cooler Bypass & $\$ 191$ & $\$ 225$ & $\$ 259$ \\
Turbine Bypass & $\$ 255$ & $\$ 296$ & $\$ 345$ \\
\hline Total Engine Technology Incremental Cost & $\$ 735$ & $\$ 911$ & $\$ 1,094$ \\
\hline LO-SCR & $\$ 513$ & $\$ 1135$ & $\$ 2,200$ \\
DOC & $\$ 0$ & $\$ 99$ & $\$ 171$ \\
DPF & $\$ 0$ & $\$ 95$ & $\$ 164$ \\
SCR+ASC and DEF Dosing System & $\$ 300$ & $\$ 1161$ & $\$ 1829$ \\
OBD Sensors and Controllers (NOx, NH, and Temp Sensors) & $\$ 738$ & $\$ 845$ & $\$ 997$ \\
Other & $\$ 300$ & $\$ 300$ & $\$ 300$ \\
\hline Total Aftertreatment Technology Incremental Cost & $\$ 1,851$ & $\$ 3,635$ & $\$ 5,661$ \\
\hline R\&D Engineering Incremental Cost & $\$ 70$ & $\$ 70$ & $\$ 70$ \\
Certification Incremental Costs & $\$ 0$ & $\$ 0$ & $\$ 0$ \\
Warranty Incremental Costs & $\$ 10,800$ & $\$ 10,800$ & $\$ 10,800$ \\
\hline Total Indirect Incremental Costs to Manufacturer & $\$ 10,870$ & $\$ 10,870$ & $\$ 10,870$ \\
\hline Total Incremental Cost Comparison & $\$ 13,456$ & $\$ 15,416$ & $\$ 17,625$ \\
\hline
\end{tabular}


Table 16. Survey Responses for Potential Low-Cost Diesel Technology Package 12-13 L with Extended FUL, Extended Warranty, and CA Volumes

\begin{tabular}{llll}
\hline 12-13 L & Low & Avg. & High \\
\hline EGR Cooler Bypass & $\$ 289$ & $\$ 390$ & $\$ 490$ \\
Charge Air Cooler Bypass & $\$ 191$ & $\$ 246$ & $\$ 288$ \\
Turbine Bypass & $\$ 255$ & $\$ 296$ & $\$ 345$ \\
Total Engine Technology Incremental Cost & $\$ 735$ & $\$ 932$ & $\$ 1,123$ \\
LO-SCR & $\$ 736$ & $\$ 1,330$ & $\$ 2,450$ \\
DOC & $\$ 0$ & $\$ 144$ & $\$ 330$ \\
DPF & $\$ 0$ & $\$ 83$ & $\$ 191$ \\
SCR+ASC and DEF Dosing System & $\$ 500$ & $\$ 1,240$ & $\$ 1,892$ \\
OBD Sensors and Controllers (NOx, NH3, and Temp Sensors) & $\$ 476$ & $\$ 765$ & $\$ 997$ \\
Other & $\$ 300$ & $\$ 950$ & $\$ 1,600$ \\
\hline Total Aftertreatment Technology Incremental Cost & $\$ 2,012$ & $\$ 4,512$ & $\$ 7,460$ \\
\hline R\&D Engineering Incremental Cost & $\$ 110$ & $\$ 357$ & $\$ 603$ \\
Certification Incremental Costs & $\$ 10$ & $\$ 7$ & $\$ 13$ \\
Warranty Incremental Costs & $\$ 1,640$ & $\$ 23,061$ & $\$ 38,282$ \\
Total Indirect Incremental Costs to Manufacturer & $\$ 7,950$ & $\$ 23,424$ & $\$ 38,898$ \\
\hline Total Incremental Cost Comparison & $\$ 28,868$ & $\$ 47,481$ \\
\hline & & & \\
\hline
\end{tabular}


Table 17. Survey Responses for Potential Average-Cost Diesel Technology Package 6-7 L with Extended FUL, Extended Warranty, and California-Only Volumes

\begin{tabular}{llll}
\hline 6-7 L & Low & Avg. & High \\
\hline Cylinder Deactivation & $\$ 638$ & $\$ 880$ & $\$ 1,140$ \\
Other & $\$ 860$ & $\$ 860$ & $\$ 860$ \\
\hline Total Engine Technology Incremental Cost & $\$ 1,498$ & $\$ 1,740$ & $\$ 2,000$ \\
\hline LO-SCR & $\$ 513$ & $\$ 1,135$ & $\$ 2,200$ \\
DOC & $\$ 0$ & $\$ 99$ & $\$ 171$ \\
DPF & $\$ 0$ & $\$ 95$ & $\$ 164$ \\
SCR+ASC and DEF Dosing System & $\$ 300$ & $\$ 1,161$ & $\$ 1,829$ \\
OBD Sensors and Controllers (NOx, NH3, and Temp Sensors) & $\$ 738$ & $\$ 845$ & $\$ 997$ \\
Other & $\$ 300$ & $\$ 300$ & $\$ 300$ \\
\hline Total Aftertreatment Technology Incremental Cost & $\$ 1,851$ & $\$ 3,635$ & $\$ 5,661$ \\
\hline R\&D Engineering Incremental Cost & $\$ 70$ & $\$ 70$ & $\$ 70$ \\
Certification Incremental Costs & $\$ 0$ & $\$ 0$ & $\$ 0$ \\
\hline Warranty Incremental Costs & $\$ 10,800$ & $\$ 10,800$ & $\$ 10,800$ \\
\hline Total Indirect Incremental Costs to Manufacturer & $\$ 10,870$ & $\$ 10,870$ & $\$ 10,870$ \\
\hline Total Incremental Cost Comparison & $\$ 14,219$ & $\$ 16,245$ & $\$ 18,531$ \\
\hline
\end{tabular}


Table 18. Survey Responses for Potential Average-Cost Diesel Technology Package 12-13 L with Extended FUL, Extended Warranty, and California-Only Volumes

\begin{tabular}{llll}
\hline $\mathbf{1 2 - 1 3}$ L & Low & Avg. & High \\
\hline Cylinder Deactivation & $\$ 724$ & $\$ 1,176$ & $\$ 1,860$ \\
Other & $\$ 1,100$ & $\$ 1,100$ & $\$ 1,100$ \\
\hline Total Engine Technology Cost & $\$ 1,824$ & $\$ 2,276$ & $\$ 2,960$ \\
\hline LO-SCR & $\$ 736$ & $\$ 1,330$ & $\$ 2,450$ \\
DOC & $\$ 0$ & $\$ 144$ & $\$ 330$ \\
DPF & $\$ 0$ & $\$ 83$ & $\$ 191$ \\
SCR+ASC and DEF Dosing System & $\$ 500$ & $\$ 1,240$ & $\$ 1,892$ \\
OBD Sensors and Controllers (NOx, NH3, and Temp Sensors) & $\$ 476$ & $\$ 765$ & $\$ 997$ \\
Other & $\$ 300$ & $\$ 950$ & $\$ 1,600$ \\
\hline Total Aftertreatment Technology Incremental Cost & $\$ 2,012$ & $\$ 4,512$ & $\$ 7,460$ \\
\hline R\&D Engineering Incremental Cost & $\$ 110$ & $\$ 357$ & $\$ 603$ \\
Certification Incremental Costs & $\$ 0$ & $\$ 7$ & $\$ 13$ \\
\hline Warranty Incremental Costs & $\$ 7,840$ & $\$ 23,061$ & $\$ 38,282$ \\
\hline Total Indirect Incremental Costs to Manufacturer & $\$ 7,950$ & $\$ 23,424$ & $\$ 38,898$ \\
\hline Total Incremental Cost Comparison & $\$ 11,786$ & $\$ 30,212$ & $\$ 49,318$ \\
\hline
\end{tabular}


Table 19. Survey Responses for Potential High-Cost Diesel Technology Package 6-7 L with Extended FUL, Extended Warranty, and California-Only Volumes

\begin{tabular}{|c|c|c|c|}
\hline $6-7 \mathrm{~L}$ & Low & Avg. & High \\
\hline EGR Cooler Bypass & $\$ 289$ & $\$ 340$ & $\$ 391$ \\
\hline Charge Air Cooler Bypass & $\$ 191$ & $\$ 225$ & $\$ 259$ \\
\hline Turbine Bypass & $\$ 255$ & $\$ 296$ & $\$ 345$ \\
\hline $\begin{array}{l}\text { Total Engine Technology } \\
\text { Incremental Cost }\end{array}$ & $\$ 735$ & $\$ 865$ & $\$ 995$ \\
\hline PNA & $\$ 924$ & $\$ 1,097$ & $\$ 1,250$ \\
\hline DOC & $\$ 101$ & $\$ 119$ & $\$ 136$ \\
\hline DPF (2018 baseline system only) & $(\$ 511)$ & $(\$ 444)$ & $(\$ 377)$ \\
\hline SCRF & $\$ 679$ & $\$ 799$ & $\$ 919$ \\
\hline SCR+ASC and DEF Dosing System & $\$ 1,374$ & $\$ 1,616$ & $\$ 1,858$ \\
\hline $\begin{array}{l}\text { OBD Sensors and Controllers ( } \mathrm{NO}_{\mathrm{x}} \\
\mathrm{NH}_{3} \text {, and Temp Sensors) }\end{array}$ & $\$ 738$ & $\$ 868$ & $\$ 997$ \\
\hline Other & $\$ 0$ & $\$ 0$ & $\$ 0$ \\
\hline $\begin{array}{l}\text { Total Aftertreatment Technology } \\
\text { Incremental Cost }\end{array}$ & $\$ 3,305$ & $\$ 4,044$ & $\$ 4,783$ \\
\hline R\&D Engineering Incremental Cost & $\$ x x$ & $\$ x x$ & $\$ x x$ \\
\hline Certification Incremental Costs & $\$ x x$ & $\$ x x$ & $\$ x x$ \\
\hline Warranty Incremental Costs & $\$ x x$ & $\$ x x$ & $\$ x x$ \\
\hline $\begin{array}{l}\text { Total Indirect Incremental Costs to } \\
\text { Manufacturer }\end{array}$ & $\$ x x$ & $\$ x x$ & $\$ x x$ \\
\hline Total Incremental Cost Comparison & $\$ x x$ & $\$ x x$ & $\$ x x$ \\
\hline
\end{tabular}

Note for Table 19 that insufficient responses were received for this technology package with respect to indirect costs to allow sufficient aggregation. Therefore, indirect and total incremental costs were not calculated. 
Table 20. Survey Responses for Potential High-Cost Diesel Technology Package 12-13 L with Extended FUL, Extended Warranty, and California-Only Volumes

\begin{tabular}{llll}
\hline 12-13 L & Low & Avg. & High \\
\hline EGR Cooler Bypass & $\$ 289$ & $\$ 390$ & $\$ 490$ \\
Charge Air Cooler Bypass & $\$ 191$ & $\$ 246$ & $\$ 288$ \\
Turbine Bypass & $\$ 255$ & $\$ 296$ & $\$ 345$ \\
\hline Total Engine Technology Incremental Cost & $\$ 735$ & $\$ 932$ & $\$ 1,123$ \\
\hline PNA & $\$ 1,592$ & $\$ 2,801$ & $\$ 4,656$ \\
DOC & $\$ 0$ & $\$ 153$ & $\$ 263$ \\
DPF (2018 baseline system only) & $(\$ 881)$ & $(\$ 698)$ & $(\$ 560)$ \\
SCRF & $\$ 960$ & $\$ 1,220$ & $\$ 1,553$ \\
SCR+ASC and DEF Dosing System & $(\$ 209)$ & $\$ 1,077$ & $\$ 1,977$ \\
OBD Sensors and Controllers (NOx, NH3, and Temp Sensors) & $\$ 426$ & $\$ 720$ & $\$ 997$ \\
Other & $\$ 1,600$ & $\$ 1,600$ & $\$ 1,600$ \\
\hline Total Aftertreatment Technology Incremental Cost & $\$ 3,488$ & $\$ 6,873$ & $\$ 10,486$ \\
\hline R\&D Engineering Incremental Cost & $\$ 603$ & $\$ 603$ & $\$ 603$ \\
Certification Incremental Costs & $\$ 13$ & $\$ 13$ & $\$ 13$ \\
Warranty Incremental Costs & $\$ 38,621$ & $\$ 38,621$ & $\$ 38,621$ \\
\hline Total Indirect Incremental Costs to Manufacturer & $\$ 39,237$ & $\$ 39,237$ & $\$ 39,273$ \\
\hline Total Incremental Cost Comparison & $\$ 43,460$ & $\$ 47,042$ & $\$ 50,846$ \\
\hline It & $\$ 130 u$ \\
\hline
\end{tabular}

It should be noted that the total indirect incremental cost estimates by manufacturers, and the total incremental costs in Table 15 to Table 20, are dominated by the warranty incremental costs. In some cases, the high estimate of incremental warranty costs is over $\$ 38,000$. As discussed in Section 1.4 .5 , the warranty incremental costs were based on a very small sample size, and may be biased high due to the OEMs' uncertainty regarding covering warranty for unfamiliar technology needed to meet a $0.02 \mathrm{~g} / \mathrm{bhp}-\mathrm{hr}$ NOx standard at the same time with much longer FULs than current FULs.

\subsubsection{Incremental Cost Survey Response Observations}

The following general observations can be made regarding the incremental costs reported in Table 3 through Table 20.

- The initial NREL estimates for total incremental costs were fairly close to the lower end of survey responses for the first survey (MY 2023, U.S. volume, current FUL).

- Indirect costs are a significant portion of the total cost. 
- Total costs are not necessarily tied to engine displacement/power but are heavily dependent on indirect costs. Production volumes of various engine displacements have more of an impact than engine "size" on indirect cost, and therefore total incremental cost.

- High engineering, certification, and warranty costs spread over relatively small volumes are the drivers of indirect costs. Survey respondents did not share amortization strategies or exact volumes, so those effects are unknown.

- Only OEMs responded with indirect costs, as Tier 1 and MECA responses included only direct costs. Due to the limited number of OEM responses, the indirect costs may have a high level of variation and may not necessarily represent indirect costs for all OEMs.

- $\quad$ The second survey (MY 2027, California-only volume, extended FUL and warranty) was intended to present "worst case" in many parameters, and the survey results reflect that.

- The second survey results report very high incremental indirect costs, especially for warranty. The OEMs did not break that warranty down into how much was attributed to extended FUL versus the extension of the warranty period. Feedback from OEMs indicated high levels of uncertainty in projected warranty costs for this scenario.

- The second survey results assumed CA-only volumes, but OEMs were free to interpret that assumption on their own. OEMs did not report how these CA-only volumes differed from U.S. volumes in the first survey. They did not explicitly state different assumptions regarding market share or changes in CA-only volume due to potential increased prepurchases ahead of new emissions regulations or potential reduced purchases due to new emissions regulations.

- Some apparent anomalies in the survey responses may be attributed to the limited number of responses. As noted above, not all respondents reported incremental cost estimates for all proposed technology combinations. The aggregated data reported is the best NREL has available that still protects individual confidential costing information.

\subsubsection{Incremental Costs for Natural Gas and Gasoline Technology Packages}

As previously referenced, few responses were received for the natural gas (HHDD standard) engine platform, preventing NREL from sufficiently aggregating incremental cost information to protect proprietary information. The study assumption that natural-gas engine technology meeting CARB's current optional low- $\mathrm{NO}_{\mathrm{x}}$ certification at $0.02 \mathrm{~g} / \mathrm{bhp}$-hr would require no significant upgrades to meet a proposed $0.02 \mathrm{~g} / \mathrm{bhp}-\mathrm{hr}$ standard with a new LLC was flawed, based on industry feedback. The feedback focused on changes needed to meet the new LLC cycle and the potential that a moving average window method for emission compliance may be necessary. Based on NREL's analysis and research from literature review, trade organization feedback, and OEM feedback, the anticipated incremental cost of both indirect and direct incremental costs for natural-gas engines and aftertreatment technology to meet an MY 2023 target of $0.02 \mathrm{~g} / \mathrm{bhp}$-hr utilizing the moving average window method to assess emission compliance is within $10 \%$ of the low-cost diesel technology package for equivalent 
displacement. A round number estimate total of $\$ 3,000$ incremental cost was subsequently used for the Task 2: Engine Life-Cycle Costs study.

Similarly, few responses were received for the gasoline HDO engine platform. Some aggregation was possible for direct costs, but only NREL estimates were available for indirect costs. As a result, only total integrated (including direct and indirect) incremental costs ranging from $\$ 353$ to \$468 for MY 2023 were calculated with current FUL.

\subsection{Low-, Average-, and High-Cost Estimates}

Because NREL received a range of values in response to both surveys, the diesel incremental cost analysis results in nine different points of costs, with low-, average-, and high-cost responses to each of the potential low-, average-, and high-cost diesel technology packages.

\subsubsection{Low-, Average-, and High-Cost Estimates for MY 2023 with Current FUL and Warranty}

These different points of cost defining the range of data received in response to the first survey for MY 2023 and current full useful life as defined in Table 1 are depicted by error bars within the summary graphs in Figure 3 and Figure 4. The incremental cost variance within any one package is larger than the differences between the engine and aftertreatment packages. In addition, the range of costs seem to have a greater impact on the larger displacement platforms, resulting in a large variance within the individual technology packages. 


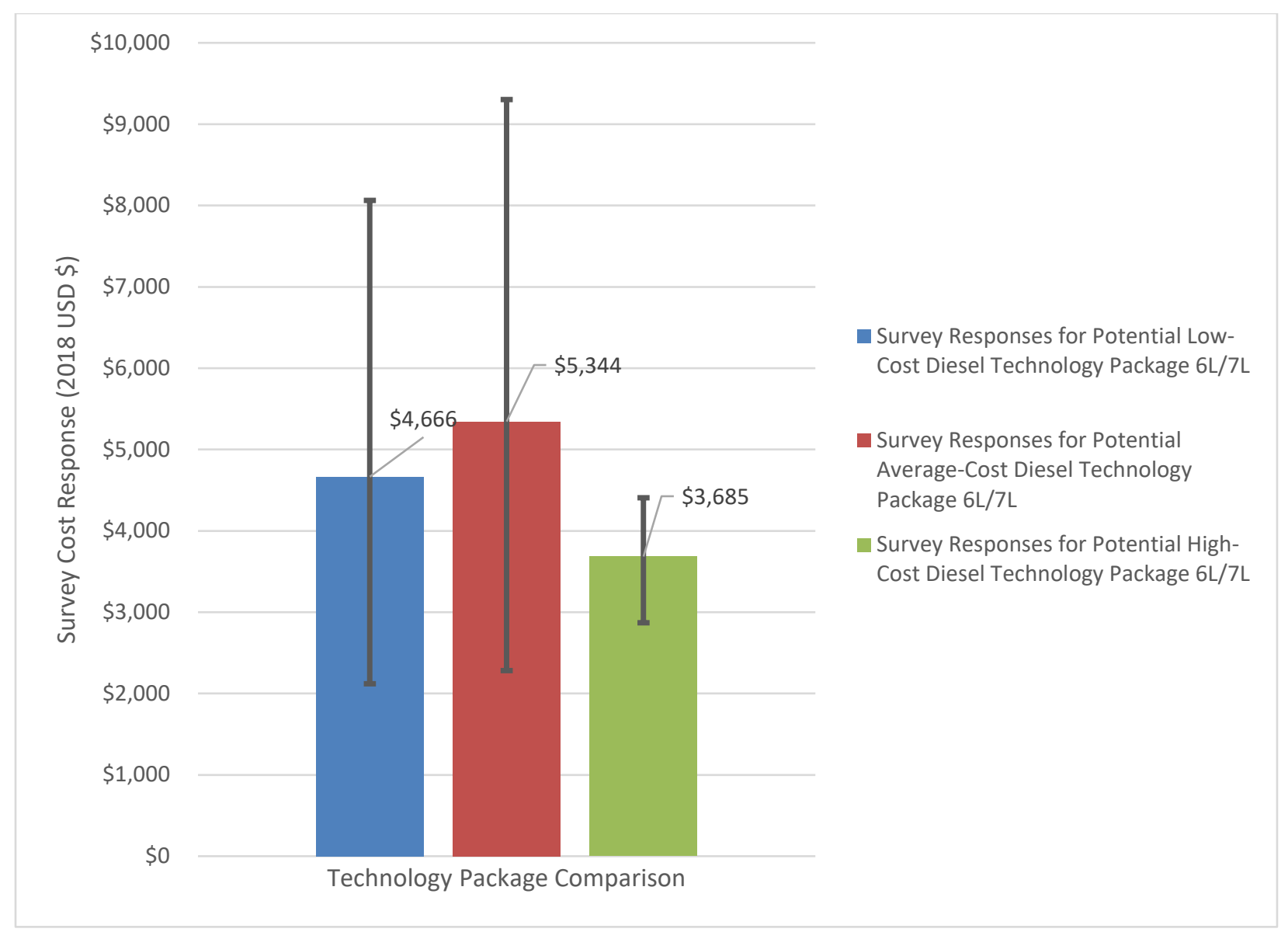

Figure 3. Summary of 6-7-L potential technology packages for MY 2023 with current FUL 


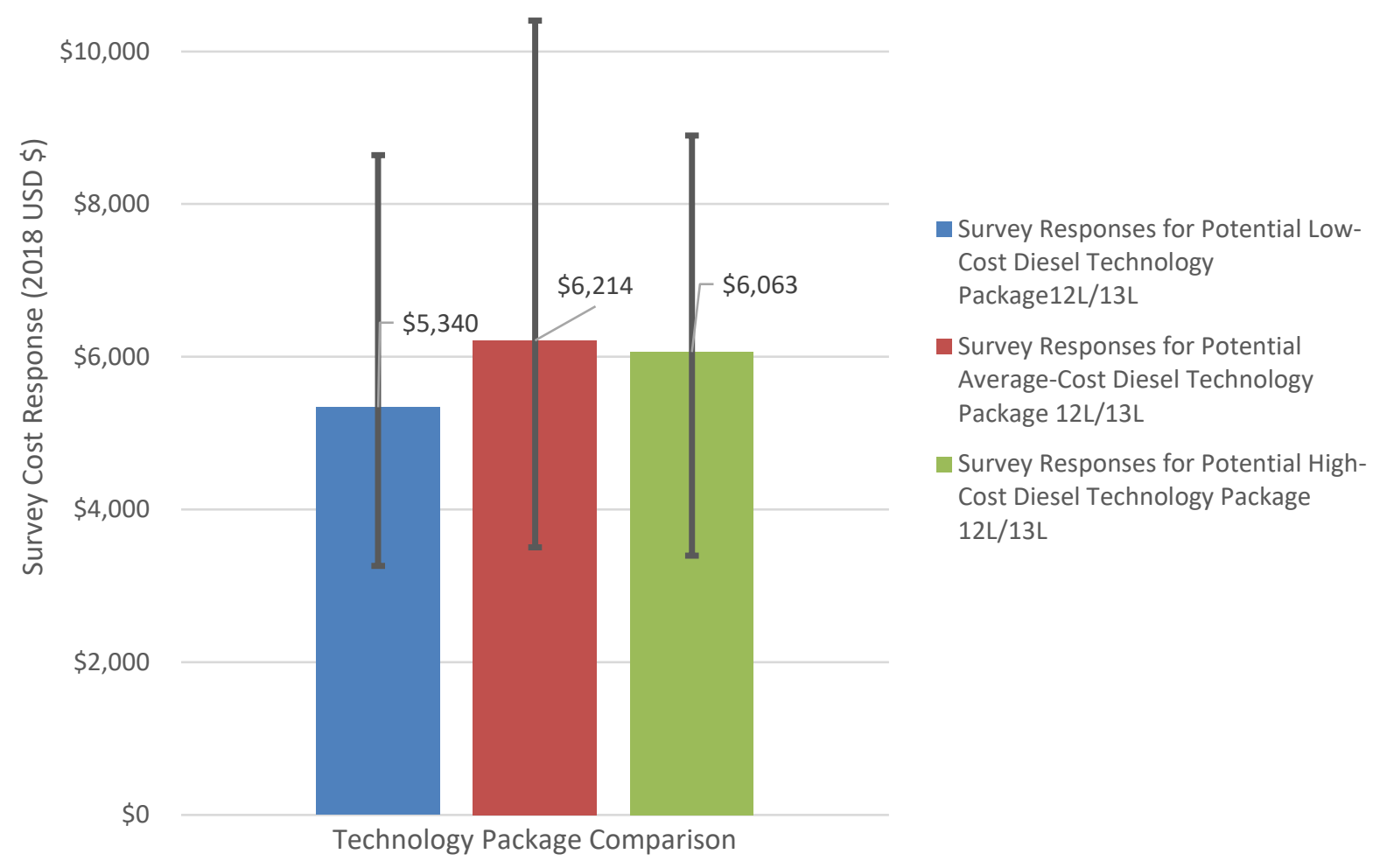

Figure 4. Summary of 12-13-L potential technology packages for MY 2023 with current FUL

\subsubsection{Low-, Average-, and High-Cost Estimates for MY 2027 with Extended Warranty and Extended Useful Life}

The range of incremental costs received in response to the second survey for MY 2027 with extended useful life and warranty as defined in Table 1 are depicted by error bars within the summary graphs in Figure 5 and Figure 6. NREL did not receive enough responses for the third technology package of the potential high-cost diesel technology to aggregate and therefore did not include the estimates received in order to protect the source of the data. 


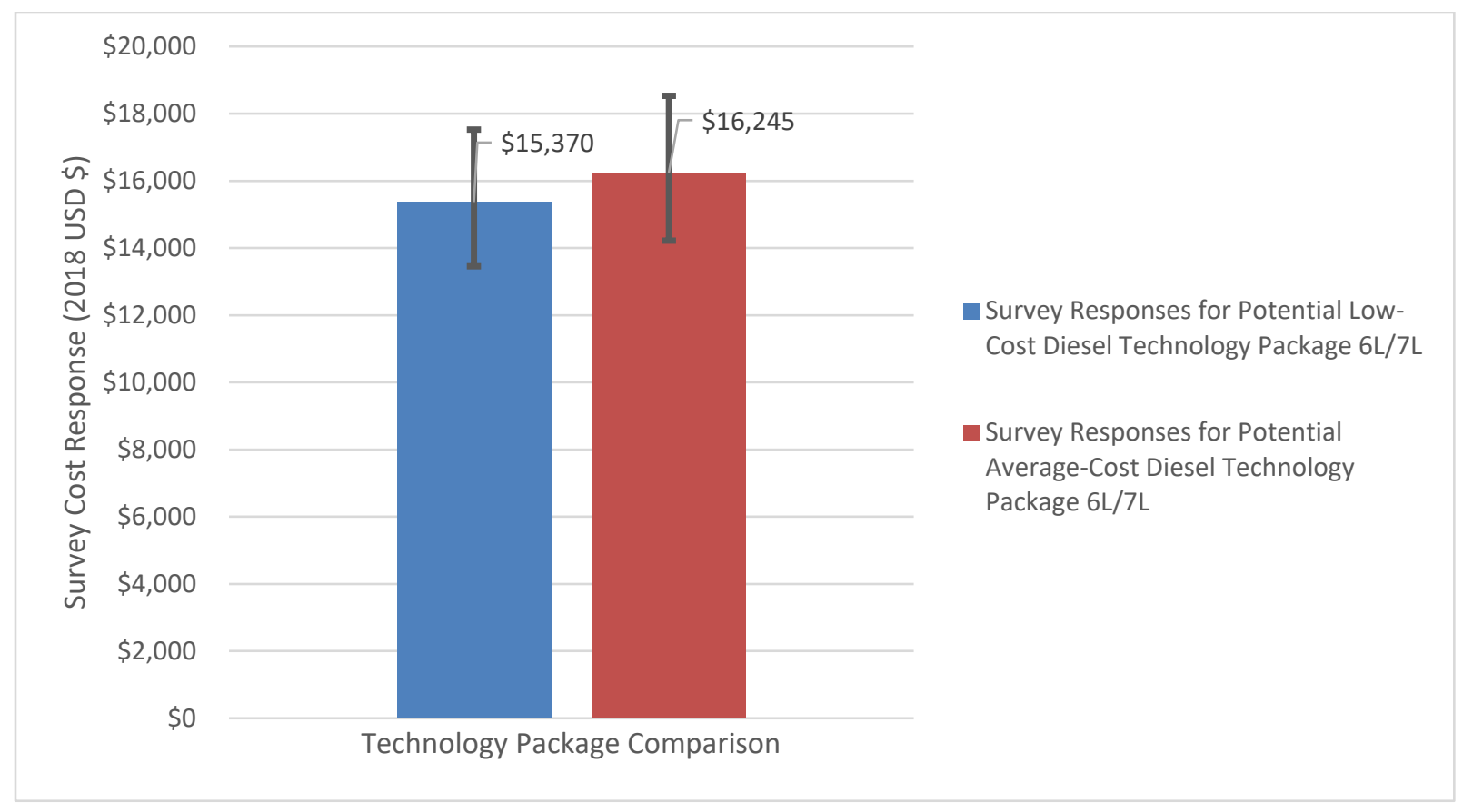

Figure 5. Summary of 6-7-L potential technology packages for MY 2027 with extended FUL and warranty

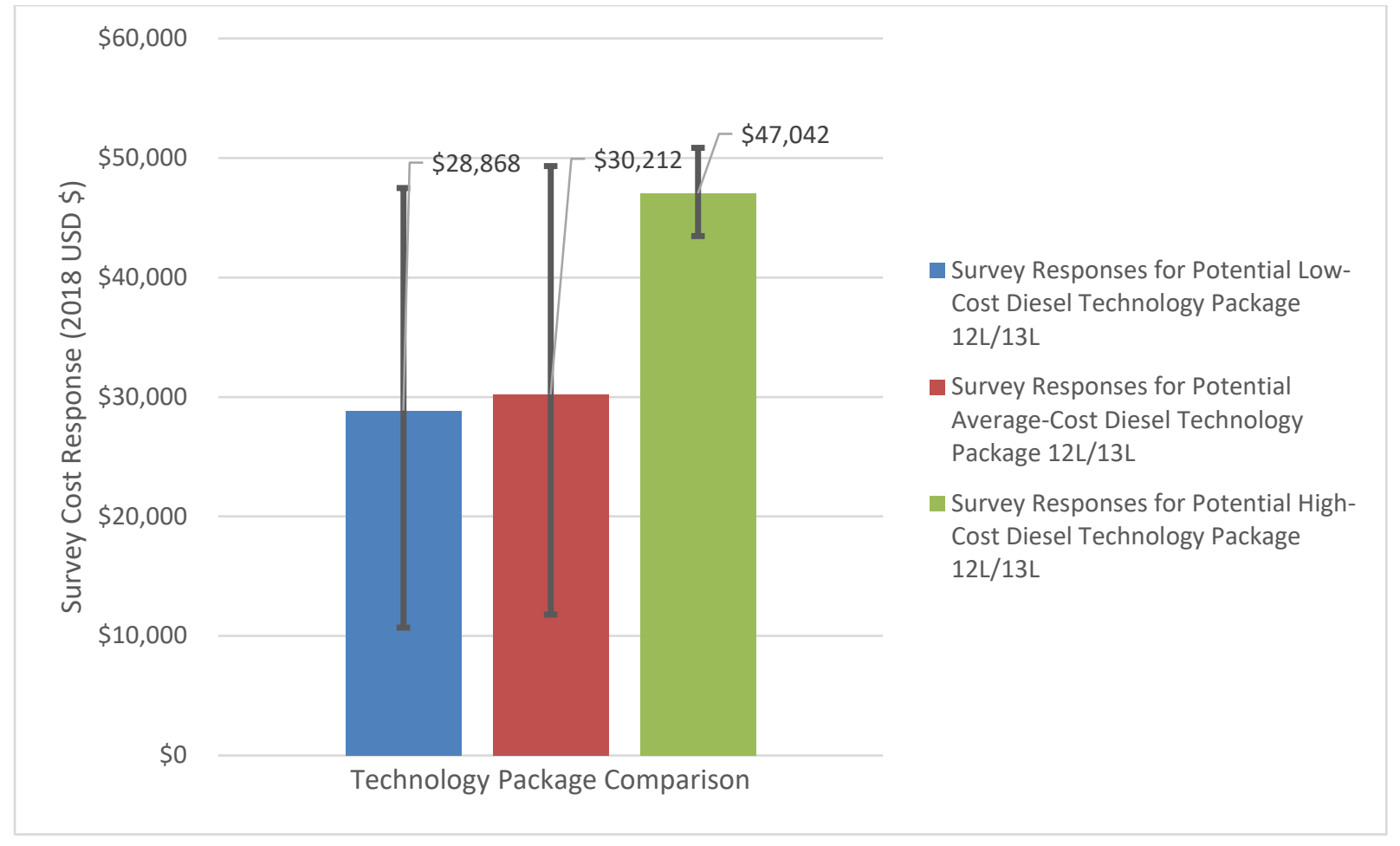

Figure 6. Summary of 12-13-L potential technology packages for MY 2027 with extended FUL and warranty 


\subsection{Summary of Incremental Cost Analysis}

NREL received a total of five survey responses from a mix of advanced engine technology and emission control technology trade organizations, Tier 1 suppliers, and engine OEMs. Data were aggregated with the incremental cost estimates NREL derived from literature review and engineering judgments. The survey responses included incremental cost estimates in a range of values, creating variance for each potential low-, average-, and high-cost technology package. The wide variance in the SCR + ASC and DEF dosing system costs drive most of the variance within the total aftertreatment costs. The cost variance is also much greater in larger displacements due to the high costs of the aftertreatment components and the variance within each of those. Indirect costs are a significant portion of the combined hardware costs of the engine and aftertreatment. Lastly, the incremental costs were not adjusted to reflect a retail markup due to the complexity with which pricing decisions are made. 


\section{Task 2: Engine Life-Cycle Costs}

This section details a life-cycle cost analysis completed to understand the true costs to the owner of a vehicle with a $0.02 \mathrm{~g} / \mathrm{bhp}-\mathrm{hr} \mathrm{NO}_{\mathrm{x}}$ aftertreatment package outside of the direct upfront vehicle cost increase. The life-cycle cost analysis sought to incorporate costs associated with the following elements:

- Initial purchase cost

- Fuel consumption changes (changes in fuel economy)

- DEF consumption

- Maximum useful life of the aftertreatment package (major overhaul intervals)

- Other operating and maintenance costs.

To complete the life-cycle cost analysis, two main tasks were completed: assessing the maximum useful life for the aftertreatment packages and computing the life-cycle costs. Section 2.1 reviews the maximum useful life analysis in detail, Section 2.2 reviews the life-cycle cost approach, Section 2.3 outlines the scenarios evaluated in this study, and Section 2.4 summarizes the results of the life-cycle cost analysis.

\subsection{Maximum Full Useful Life Analysis}

The maximum useful life for the aftertreatment system determines the mileage at which costs to the owner may be incurred if the system begins to fail. For all scenarios in the life-cycle cost analysis, the incremental cost associated with the aftertreatment package was assumed to be incurred after the truck mileage exceeded the stated maximum useful life. This assumption is expected to be conservative as not all aftertreatment packages will fail immediately after they exceed their stated maximum useful life. Statistical analysis of failure rates combined with data on aftertreatment technology operating and maintenance costs could give a more accurate depiction of life-cycle costs. However, such data are not currently available.

The extended maximum useful life option was evaluated by considering the tradeoff between increased upfront costs due to improved durability needed for the extended maximum useful life ${ }^{1}$ and the decrease in owner-related replacement costs at the end of the maximum useful life.

The maximum useful life depends on both the displacement of the vehicle and the fuel type. The extended maximum useful life values were defined based on the CARB proposal in January 2019 and previously shown in Table 1 .

\subsection{Approach}

This analysis leverages the high-fidelity vehicle stock model within NREL's Scenario Evaluation and Regionalization Analysis (SERA) model. The SERA stock model tracks vehicle miles traveled, fuel consumption, and ownership costs throughout each vehicle's lifetime and is resolved temporally and spatially with high fidelity. The SERA model was complemented by

\footnotetext{
${ }^{1}$ It is important to note that the data received from the cost survey (Section 1.3) combined both an extended useful life and an extended warranty. Thus, the cost data used for the extended useful life scenarios couples both the extended useful life and extended warranty information together.
} 
additional data sets to effectively map the vehicles to the aftertreatment packages evaluated in this study.

The following sections provide a brief overview of the SERA stock model, the data sources used in this study, model validation, scenario design, and the life-cycle cost results.

\subsubsection{Scenario Evaluation and Regionalization Analysis (SERA) Model}

The SERA model's stock module capability provides a flexible framework for tracking vehicles over their life. The SERA's stock model has been used for a variety of U.S. Department of Energy and California Energy Commission projects and, in particular, is described in detail in Bush et al. (2019). The general data flow for the SERA stock model is shown in Figure 7, which shows how data for regional sales (total vehicles sold), market shares (disaggregation of vehicle sales by vehicle type), vehicle survival (salvage rate data), annual travel (vehicle-miles traveled), fuel consumption data (fuel economy and fuel types), and emission rate data are combined to track vehicle population, travel, and resulting energy consumption and emissions.

For this analysis, the SERA model was expanded to track vehicle life-cycle costs over the vehicle's lifetime. The model was updated to account for vehicle costs that could be incurred when purchasing a vehicle or driving the vehicle, as the model already has those data within it.

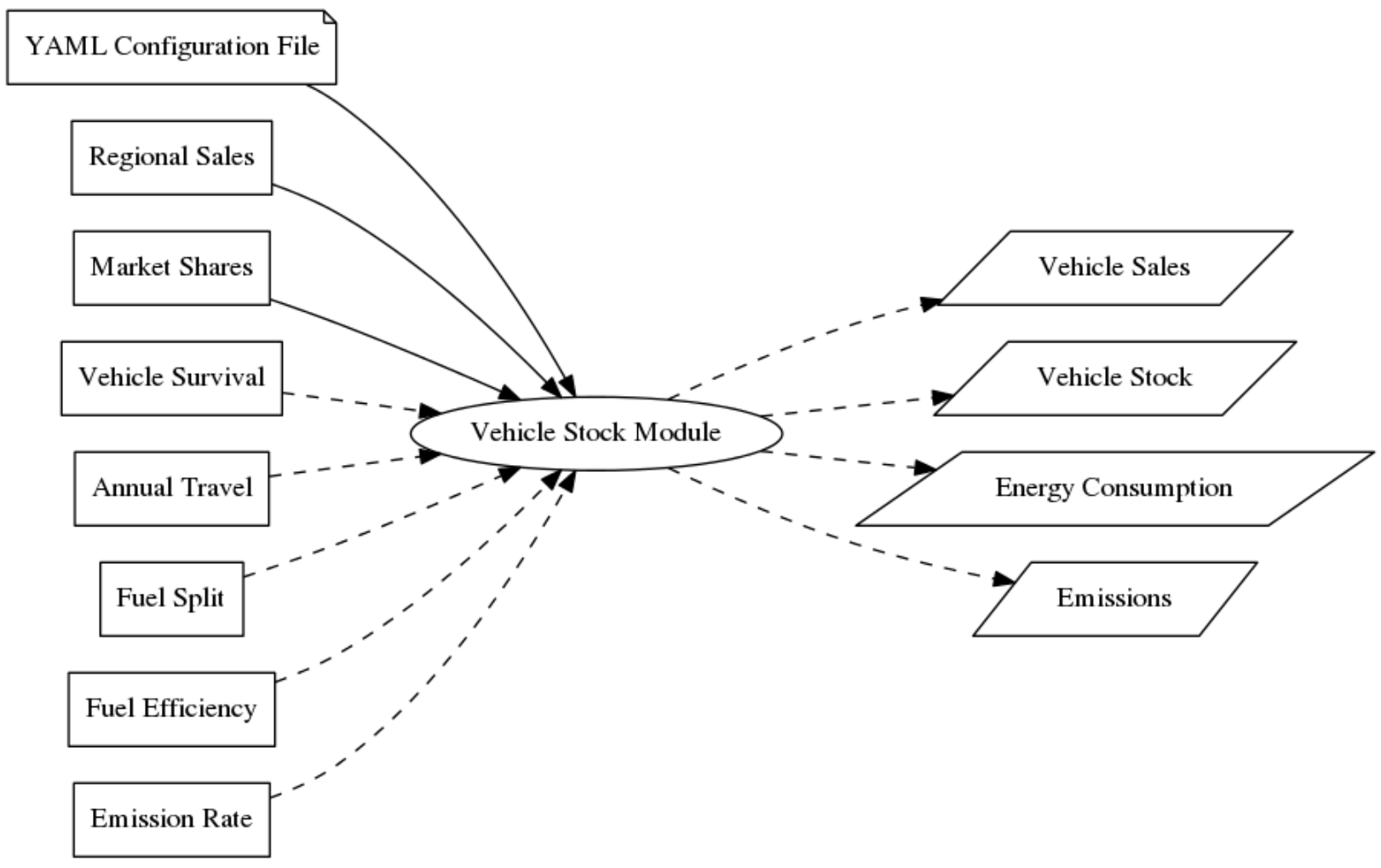

Figure 7. The general SERA stock model data flow 


\subsubsection{Data Sources}

The SERA model provides the analytic framework for a detailed stock model but is complemented by additional data sets to complete the life-cycle analysis required in this study. The data sources used in this analysis are summarized in Table 21. 
Table 21. Data Sources Used in Life-Cycle Cost Analysis

\begin{tabular}{|c|c|}
\hline Data Source & Description \\
\hline & $\begin{array}{l}\text { The EMFAC emissions model is } \\
\text { used by CARB to assess } \\
\text { emissions from on-road vehicles } \\
\text { (cars, trucks, and buses). }\end{array}$ \\
\hline $\begin{array}{l}\text { EMFAC/CA } \\
\text { Vision } 2.1\end{array}$ & $\begin{array}{l}\text { The CA Vision } 2.1 \text { model ( } 2017) \\
\text { is a scenario-planning model } \\
\text { and provides the detailed stock } \\
\text { data required for the SERA } \\
\text { model. It should be noted that } \\
\text { the CA Vision model is based on } \\
\text { the EMFAC } 2014 \text { results. }\end{array}$ \\
\hline $\begin{array}{l}\text { IHS Markit } \\
\text { (Polk) } \\
\text { Department } \\
\text { of Motor } \\
\text { Vehicles } \\
\text { Registration } \\
\text { Data }\end{array}$ & $\begin{array}{l}\text { The IHS Markit (formerly known } \\
\text { as Polk) Department of Motor } \\
\text { Vehicles registration database } \\
\text { (2013) provides data across the } \\
\text { United States on the quantity } \\
\text { and types of trucks registered in } \\
\text { each zip code. }\end{array}$ \\
\hline $\begin{array}{l}\text { Task } 1 \text { Cost } \\
\text { Data }\end{array}$ & $\begin{array}{l}\text { The Task } 1 \text { survey cost data } \\
\text { includes the incremental cost for } \\
\text { three different aftertreatment } \\
\text { packages, two engine } \\
\text { displacements, three different } \\
\text { fuel types, different maximum } \\
\text { useful life estimates, different } \\
\text { manufacturing volumes, and } \\
\text { different model years. }\end{array}$ \\
\hline
\end{tabular}

How it was used

The CA Vision 2.1 model data was used as the base stock model to create within SERA (e.g., vehicle sales, survival, vehicle miles traveled, and fuel economy were matched between SERA and the CA Vision 2.1 model).

Thus, the SERA stock model vehicles, population, total mileage, and fuel consumption match the EMFAC and CA Vision 2.1 models.

The IHS Markit data were used to disaggregate EMFAC vehicles by their engine displacement to compute fleet-wide costs.

For example, the T6 Instate Small truck comprises GVWR classes 4-7, which correspond to multiple engine displacements. The IHS Markit data were used to determine the fraction of T6 Instate Small trucks within each engine displacement class.

The Task 1 data were incorporated into the SERA model as upfront costs to the vehicle owner mapped to the appropriate vehicle (model year, engine displacement, fuel type).

The incremental upfront cost was also assumed to be incurred after the maximum useful life of the aftertreatment package was surpassed in most scenarios.

Scenario analysis was used to evaluate a $1.25 \%$ improvement in fuel economy. The marginal improvement in fuel economy results in fuel cost savings during the vehicle's life.

California

Energy

Commission

Fuel Prices
California Energy Commission's forecast of fuel prices (2017)
Preliminary data from SwRI indicates an improvement of $0 \%-4 \%$, depending on the engine cycle, with $1.25 \%$ as a good central estimate per SwRI feedback. No reductions in fuel economy were evaluated as the vehicles must still meet the existing GHG standards regulated by CARB.

Scenario analysis as completed to determine the life-cycle cost of increased DEF consumption.

Diesel
Exhaust Fluid
Price

Diesel Price
A constant $\$ 6 /$ gal DEF cost was assumed based on NREL's CoOptima analysis

As seen in Table 21, there are several data sources that combine within the SERA model to evaluate the life-cycle cost of the low- $\mathrm{NO}_{\mathrm{x}}$ fuel standard. Visually, these data sources are combined as seen in Figure 8. 


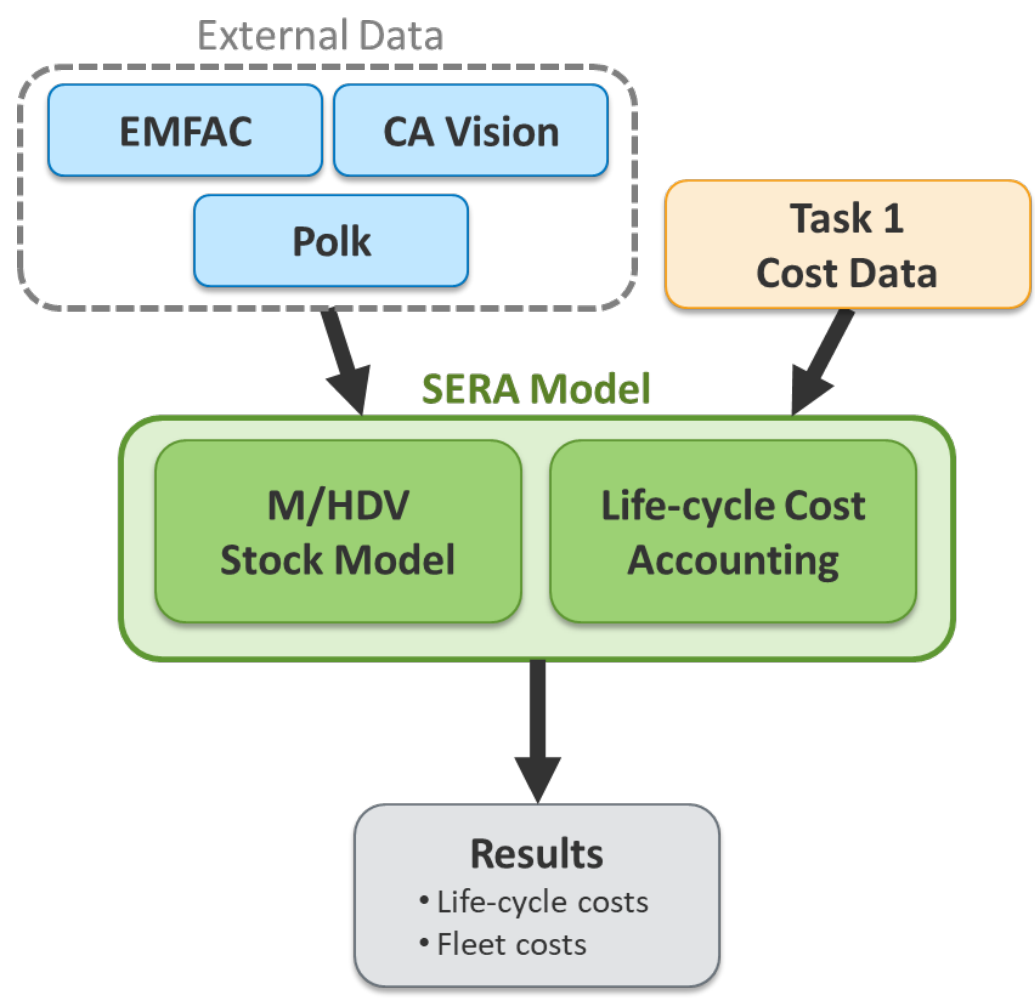

Figure 8. Data flow and analysis using the SERA model for life-cycle cost analysis

Due to the EMFAC and CA Vision 2.1 model spatial and temporal fidelity, each vehicle is defined by a specific region, vocation, model year, fuel type, and age. These vehicles are then further disaggregated by engine displacement using the IHS Markit (formerly Polk) Department of Motor Vehicles registration data. Thus, the life-cycle costs for each vehicle are a function of all of these parameters, and there is a distribution of life-cycle costs across the California fleet due to different vehicle types and travel profiles. For example, the life-cycle costs for a Class 8 long haul tractor will be very different than a Class 6 parcel delivery truck due to the different aftertreatment package costs (which vary by displacement), in addition to the different marginal fuel cost reductions, because they have very different travel requirements profiles and fuel economies.

The distribution in life-cycle costs will be analyzed across the California fleet vehicle types, engine technologies, displacements, and regions using multiple analytic methods, including scenario analysis and sensitivity analysis.

\subsubsection{SERA Model Validation}

The SERA model was validated against the CA Vision 2.1 model to ensure the starting point for the life-cycle cost analysis was accurate. Figure 9 summarizes the results of the model validation, which show very close agreement between the SERA model and the CA Vision model for predicting stock through 2050. Additionally, validating the model by region, Figure 9 shows there is a less than $1.2 \%$ error in predicting the California vehicle population through 2050 for each region. 
This model validation indicates that the SERA model matches the CA Vision 2.1 model closely through 2050. For this analysis, the life-cycle cost analysis is focused on model years 2023 and 2027, so this validation signifies that those vehicle sales and survival (lifetimes) will be accurately accounted for in the life-cycle analysis. Additionally, the vehicle travel and fuel consumption data influence the life-cycle costs for each vehicle, and this validation indicates that those costs will be accurately accounted for.

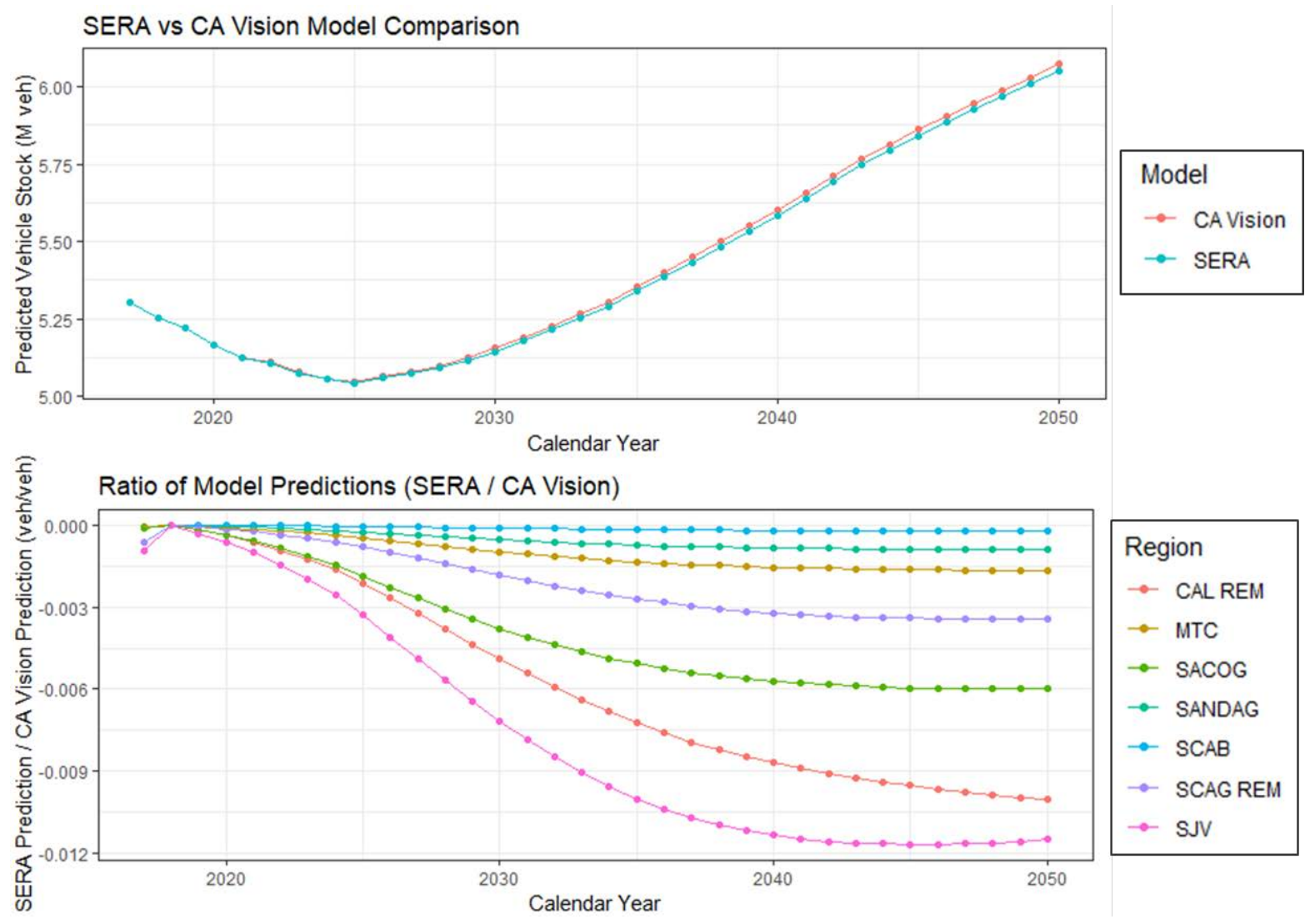

Figure 9. SERA model validation against the CA Vision 2.1 model

\subsubsection{Manufacturing Volume Analysis}

Manufacturing volume influences the upfront cost of aftertreatment systems, as large manufacturing volumes allow the firm to spread capital and fixed operating costs over more units sold, reducing the per-unit cost. As discussed in the Task 1 section of this report, most data collected from OEMs are for a national manufacturing volume. One OEM provided cost estimates for the 12-13-L diesel engine for a California-only manufacturing volume basis. These data were included in the sensitivity analysis to show its potential importance but not in the scenario analysis given the limited data set.

\subsection{Parameters Investigated}

The realized life-cycle cost to the vehicle owner depends on a variety of parameters that need to be evaluated. Some of the key parameters assessed in this study include:

- Aftertreatment design cost basis (Task 1) 
- Extended maximum useful life

- Manufacturing volume

- Engine displacement

- Vehicle type, region, model year

- Fuel economy impact

- DEF consumption impact.

These parameters and their analysis bounds are summarized in Table 22. Each parameter was varied independently of others to understand the life-cycle cost sensitivity to that parameter.

Table 22. Life-Cycle Cost Parameters Investigated in this Study

\begin{tabular}{ll}
\hline \multicolumn{1}{c}{ Parameter } & \multicolumn{1}{c}{ Description } \\
\hline Adoption Rate & 1) $100 \%$ compliance by 2023 (Current useful life, only) \\
& 2) $100 \%$ by 2027 (Extended full useful life, only) \\
Max Useful Life & 1) (Min) Current useful life \\
2) (Max) Extended useful life \\
3-5) $25 \% / 50 \% / 75 \%$ of min/max spread \\
1-3) Low/Avg/High cost basis from Task 1 \\
Will be needed to investigate life-cycle costs differences due to: \\
1) Varying aftertreatment packages (displacement) \\
2) Vehicle types (EMFAC definition) \\
3) Region (Seven CA Vision 2.1 Model Regions) \\
4) Model year (2023, 2027) \\
5) Fuel economy impacts (e.g., no change, 1.25\% improvement) \\
6) DEF consumption changes (e.g., 0\%, 2.5\%, 5\% change) \\
7) Discount rates (3\%, $7 \%$ ) \\
8) Manufacturing volume (U.S. vs. California-only) \\
\hline
\end{tabular}

Due to the large number of parameters, each with its own uncertainty around it, the results look at a scenario analysis (varying multiple parameters at one time) and a sensitivity analysis (varying one parameter at a time).

Adoption rate was originally intended to be a parameter of investigation. However, data were only available for current useful life with $100 \%$ compliance by 2023 and extended useful life with $100 \%$ compliance by 2027 . No data were available to determine learning curves or how costs might change depending on the adoption deadline. For this reason, it was assumed that the current full useful life costs for 2023 adoption would hold for 2027 adoption as well. This allows side-by-side comparison of current and extended full useful life life-cycle costs.

\subsubsection{Scenario Analysis}

Due to the large number of parameters that could influence the life-cycle cost of each vehicle, a scenario analysis approach was taken. Three scenarios were defined to understand the bounds on the life-cycle costs: low-cost scenario, mid-cost scenario, and high-cost scenario. These scenarios were defined to bound the life-cycle cost as well as provide a scenario evaluating a mid-cost lifecycle analysis; however, they do not represent the most likely scenarios that could be realized. 
The three scenarios are defined in Table 23 and outline the parameter assumptions used for each scenario. The scenarios were defined to look at the bounds of the life-cycle cost analysis, while the sensitivity analysis was completed to understand the critical parameters driving the life-cycle cost of the aftertreatment system. Because California manufacturing volume data were available from only one OEM for only one engine displacement, all scenarios consider U.S. manufacturing volumes.

Additionally, the upfront cost (Task 1 data) was based only on the average-cost technology package and used the low/average/high error bar bounds. This technology package was selected because the error bar bounds of the average-cost technology package effectively span the full spectrum of potential costs (as seen in Section 1.4). Additionally, the low-cost technology package and high-cost technology package may not actually represent the lowest-cost or highestcost packages, as found from the survey data in Task 1.

Table 23. Scenario Definitions for Bounding Analysis

\begin{tabular}{l|ccc}
\hline \multicolumn{1}{c|}{ Parameter } & Low-Cost Scenario & Mid-Cost Scenario & High-Cost Scenario \\
\hline Upfront Cost & Low & Mid & High \\
Manufacturing Scale & U.S. & U.S. & U.S. \\
& Current & Current & Extended \\
Useful Life & Full Useful Life & Full Useful Life & Full Useful Life \\
Fuel Economy Change & $1.25 \%$ improvement & No change & No change \\
DEF Consumption & No change & $2.5 \%$ increase & $5 \%$ increase \\
Impact & $7 \%$ & $7 \%$ & $3 \%$ \\
Discount Rate & & & \\
\hline
\end{tabular}

In addition to the above parameters, the life-cycle cost also depends on the model year of the vehicle (compliance rate), the engine displacement, the fuel type (diesel, gasoline, natural gas), the vehicle's vocation (defined by EMFAC, which affects the vehicle miles traveled over its lifetime), as well as the region the vehicle is operating in (vehicle miles traveled varies slightly by region within the EMFAC model). Thus, to explore the life-cycle costs across this parameter space, three primary metrics were evaluated for each scenario:

1. Life-cycle costs for each vehicle/displacement/fuel/vocation/region combination

2. A vehicle sales weighted-average life-cycle cost across all vehicle/displacement/fuel/vocation/region combinations

3. A life-cycle cost across the full California fleet.

First, the life-cycle cost was calculated for each vehicle, engine displacement, fuel technology, EMFAC vocation, and region within each of low-cost, mid-cost, and high-cost scenarios. This provides vehicle-specific data and can be used to demonstrate the potential life-cycle costs that could be realized for each vehicle owner.

Second, a sales-weighted average life-cycle cost was determined based on the CA Vision 2.1 predicted sales for the model year 2027. This average metric weights the regions and vocations more heavily if there are more vehicles sold in that aftertreatment definition. For example, 
assume there are only two vehicles in California and each has a different life-cycle cost and are sold in different proportions, as seen in Table 24.

Table 24. Example Vehicle Sales Weighted Average

\begin{tabular}{lcc}
\hline Vehicle/Vocation & $\begin{array}{c}\text { Example } \\
\text { Life-Cycle Cost }\end{array}$ & $\begin{array}{c}\text { Example } \\
\text { Sales (vehicles) }\end{array}$ \\
\hline T7 Tractor & $\$ 1,000$ & 100 \\
T7 Single & $\$ 2,000$ & 50 \\
\hline
\end{tabular}

One estimate of representative life-cycle costs for vehicles in California may be a simple average of the two life-cycle costs $(\$ 1,500)$. However, a more accurate and representative life-cycle cost would be a vehicle sales weighted average that accounts for the relative proportion of vehicles within each vocation $(\$ 1,333){ }^{2}$ This approach was used to estimate a single life-cycle cost across all vehicles in California, which would represent an approximate cost for all vehicle owners in the state.

To complete the sales-weighted average, the EMFAC vehicles must be disaggregated into specific vocation, fuel, and engine displacement categories. IHS Markit (formerly Polk) Department of Motor Vehicles registration data were used to disaggregate the EMFAC vehicles into the appropriate vocation, fuel, and engine displacement categories. A summary of the breakdown can be found in Appendix B, while the full data file is provided as an attachment to the report.

In addition to the vehicle-specific life-cycle costs discussed previously, the life-cycle costs of all vehicles sold across California in 2027 were assessed for each scenario. This metric accounts for the relative proportion of vehicle types sold in California and the total cost California fleet owners would be expected to bear for each scenario. This calculation also accounts for the fact that not all vehicles survive the full expected lifetime (e.g., some Class 8 tractors will last only three years while others will last seven). These survival data are important, as vehicles may be retired before they travel more than the aftertreatment package's maximum useful life and thus would not incur those future replacement costs.

\subsubsection{Sensitivity Analysis}

To better understand the relative importance of each parameter affecting the life-cycle cost of the aftertreatment package, a sensitivity analysis was completed. A sensitivity analysis varies one single parameter and then shows the impact of that parameter on the life-cycle cost of the vehicle. For this analysis, the mid-cost scenario was used as the starting point for the sensitivity analysis, and the variation in each parameter either increases or decreases the life-cycle cost. By varying each parameter independently, one can determine which parameters are the key cost drivers for the life-cycle cost.

\footnotetext{
${ }^{2}$ Calculated as: $\$ 1,000 *(100 /(100+50))+\$ 2,000 *(50 /(100+50))=\$ 1,333 /$ vehicle
} 


\subsection{Results}

The results are presented in three sections: a case study to demonstrate life-cycle cost methodologies, scenario analysis results, and a sensitivity analysis.

The case study section illustrates the calculation methodologies that are described above and ultimately used in both the scenario and sensitivity analyses. The case study looks at the calculation methods and assumptions through the lens of two specific vehicles of interest to CARB: the T7 Tractor (heavy heavy-duty tractor truck) and the T6 OOS small (medium heavyduty out-of-state truck with GVWR $\leq 26,000 \mathrm{lb}$ ) (CARB 2018b). The case-study graphics aim to systematically depict some of the key calculation assumptions, limitations, and findings in an easier-to-understand format than when aggregated across all the California vehicles, vocations, displacements, regions, and scenario descriptions. Additional, single-vehicle results for EMFAC vehicles of specific interest to CARB can be found in Appendix A.

The Scenario Analysis and Sensitivity Analysis sections then summarize the core findings of the study, as discussed in Section 2.3.

\subsubsection{Case Study: T7 Tractor and T6 OOS Small Vehicle Life-Cycle Costs}

The life-cycle cost analysis methodologies are most easily understood through a specific example. Figure 10 shows the present value annual costs ${ }^{3}$ for a T7 Tractor (Class 8 line-haul) equipped with a 12-13-L diesel engine for two aftertreatment scenarios: (1) current FUL and (2) extended FUL. Life-cycle costs include the incremental replacement costs after full useful life is achieved (vehicle costs) and potential fuel economy improvements associated with the aftertreatment technology discounted back to present value (fuel costs). For the T7 Tractor 1213-L engine, the current full useful life is 435,000 miles. If designed for this lifespan, the aftertreatment technology would require two replacements. Extending the aftertreatment's full useful life to 1,000,000 miles significantly increases the upfront cost of the aftertreatment technology but eliminates the need for replacements through 2050, as seen in Figure 10.

\footnotetext{
${ }^{3}$ The present value annual costs for future years are determined using the discount rate (7\% for Figure 10). All values are reported in 2018 dollars, consistent with the Task 1 data, and the first year for discounting is assumed to be in 2027. Using this convention, the incremental vehicle costs (i.e., those due directly to the aftertreatment package) incurred in year 2027 exactly match the Task 1 incremental cost data, while future years are lower due to discounting.
} 


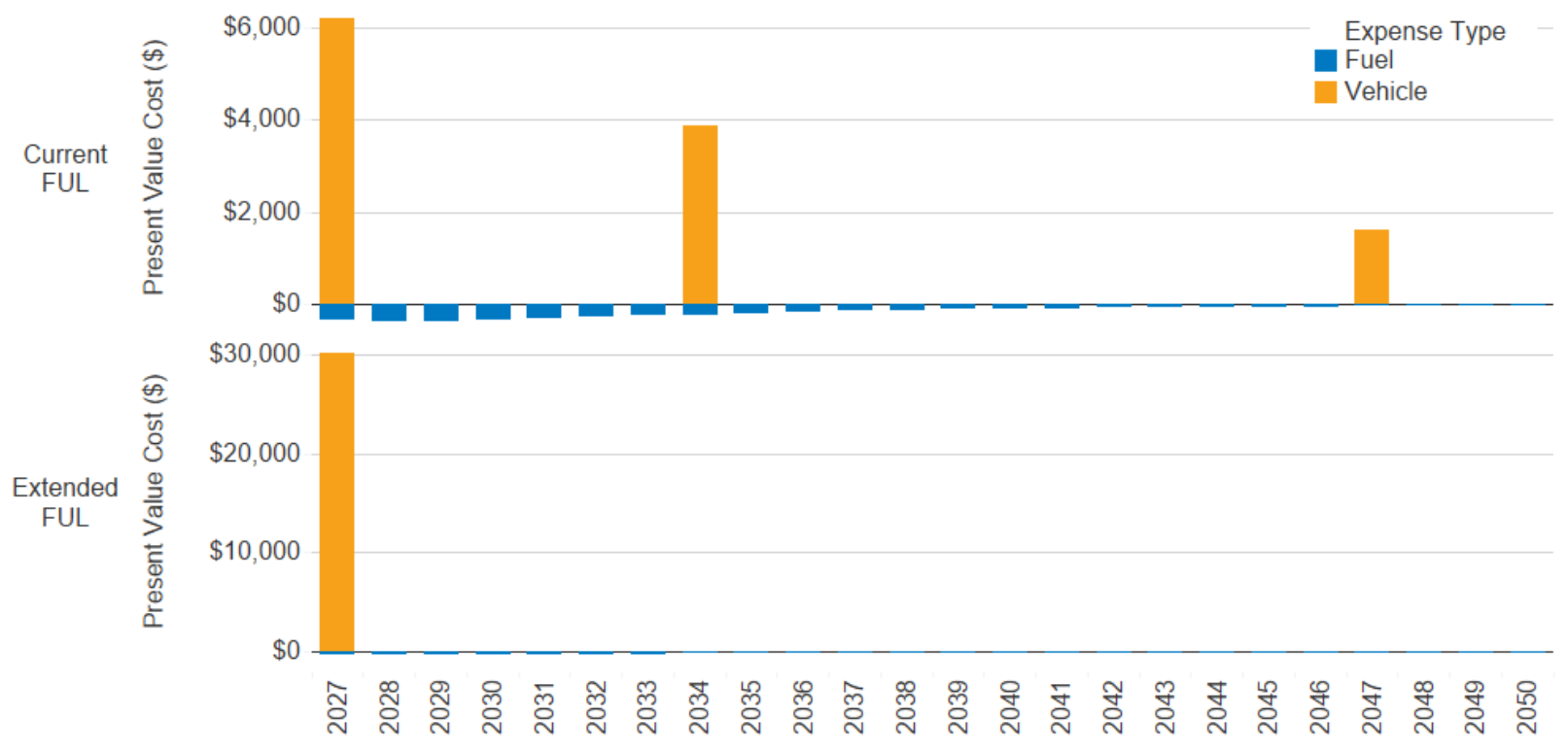

Figure 10. Annual present value cost for a T7 Tractor 12-L diesel engine designed for current full useful life (435,000 miles; top) and extended full useful life (1,000,000 miles; bottom) for MY 2027 in the South Coast Air Basin with a $2.5 \%$ increase in DEF consumption, a discount rate of $7 \%$, and national manufacturing volumes

Figure 11 shows annual costs for a T6 OOS small truck with a 6-7-L diesel engine. For the current full useful life design scenario of 110,000 miles, the aftertreatment technology must be replaced three times through 2050. Designing the aftertreatment technology for an extended full useful life of 550,000 miles results in no aftertreatment replacements through 2050.

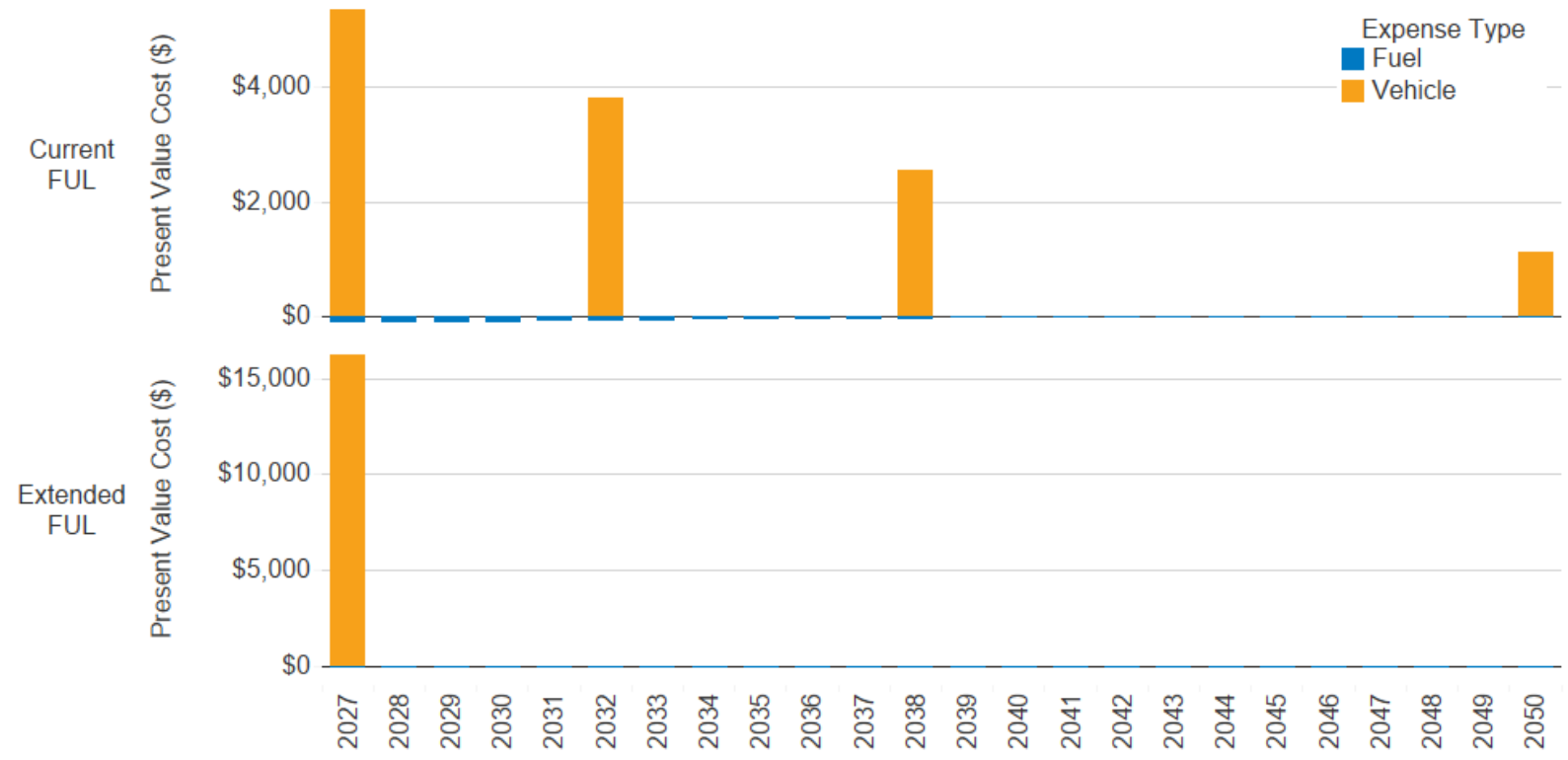

Figure 11. Annual present value cost for a T6 OOS small 6-7-L diesel engine designed for current full useful life (110,000 miles; top) and extended full useful life (550,000 miles; bottom) for MY 2027 in the South Coast Air Basin with a $2.5 \%$ increase in DEF consumption, a discount rate of $7 \%$, and national manufacturing volumes 
The previous two plots assume that replacement costs are incurred to the owner immediately upon termination of full useful life. In practice, full useful life might be extended by routine maintenance. ${ }^{4}$ As a result, Figure 10 and Figure 11 likely represent the upper bound on actual life-cycle costs. Statistical analysis of failure rates combined with data on aftertreatment technology operating and maintenance costs could give a more accurate depiction of life-cycle costs. However, such data were not available for these potential future systems.

To explore the full useful life replacement assumption, the life-cycle costs of a vehicle can be compared assuming either no replacements are completed after vehicle mileage exceeds the aftertreatment's maximum useful life or that replacements are completed. The lower bound on life-cycle costs is set by the condition in which no replacements or maintenance are performed on the aftertreatment package regardless of vehicle mileage. This is unlikely for the current full useful life design but could be realistic for an extended full useful life scenario in which the full useful life of the aftertreatment technology is met near the end of life of the entire truck.

Figure 12 shows total present value cost for the T7 Tractor and T6 OOS small diesel engines as a function of the aftertreatment package's maximum useful life. The orange markers represent the upper-cost bound that assumes the aftertreatment package will be replaced after the vehicle mileage exceeds the maximum useful life. The blue markers reflect the lower-cost bound of no aftertreatment package replacements over the vehicle lifetime. This analysis assumes linear increments in aftertreatment cost as the designed full useful life increases from current to extended. The actual total present value cost lies somewhere between these two bounds, which are typically less than $\sim \$ 5,000-\$ 7,000$ but depend on the vehicle being evaluated. As the aftertreatment package maximum useful life increases, the spread between the two conditions (orange and blue markers) typically decreases as the number of replacements decreases to zero over the lifetime of the vehicle.

Interestingly, for the T7 Tractor, designing for $75 \%$ of extended FUL is slightly more expensive than designing for $100 \%$ of extended FUL, as the one replacement that would be necessary in 2047 costs more than the incremental step in upfront cost associated with a 25\% longer FUL. However, it is unlikely that the truck owner will replace the entire aftertreatment system that close to the end of life, indicating that the true cost is likely lower than the value estimated here.

\footnotetext{
${ }^{4}$ It should be noted that rather than incurring the replacement cost at the end of the full useful life, one could amortize those costs throughout each year of the vehicle's operation. This would effectively add incremental routine maintenance for each year and the cost would be mathematically equivalent to the end-of-full-useful-life assumption calculated here. The true incremental lifetime repair cost depends on the expected failure rates for these new aftertreatment packages which were not obtained within this study.
} 


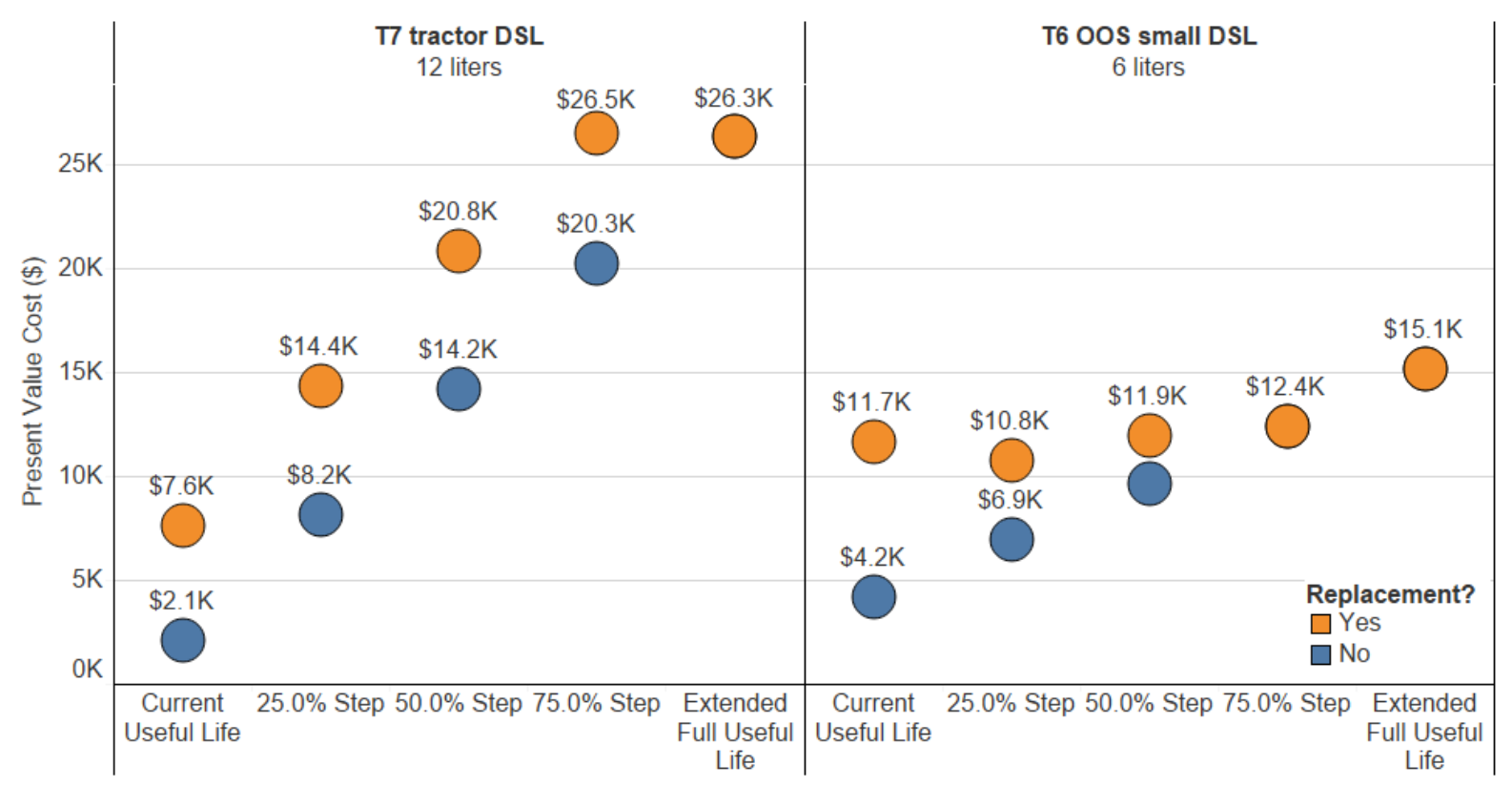

Figure 12. Total present value cost for the T7 Tractor and T6 OOS small vehicles with diesel engine aftertreatment technology as a function of incremental steps between current FUL and extended FUL for two scenarios: replacements at end of FUL (orange) and no replacements (blue)

Because aftertreatment package repair costs are either paid by the vehicle owner or the vehicle manufacturer through the warranty (if applicable), one may expect the higher upfront cost incurred to the vehicle owner for an aftertreatment package with extended full useful life and extended warranty to be offset by the aftertreatment repair cost savings over the life of the vehicle. CARB staff made this assumption when estimating costs for CARB's 2018 Step 1 warranty rulemaking, and CARB's Initial Statement of Reasons (staff report) for this rulemaking (CARB 2018a) assumes that the cost of the warranty packages is equivalent to the lifetime repair savings that the vehicle owner would realize.

The incremental upfront purchase cost that one could estimate based on the survey responses for extended FUL and warranty, and CA-only volumes, as described in Section 1.4.4, would be significantly higher than the repair cost savings that vehicle owners would realize. However, as described more fully in Section 1.4.5, the total incremental costs are dominated by the warranty incremental costs which were based on an extremely small sample size, which may be biased high because of the OEMs' uncertainty regarding covering warranty for unfamiliar technology and much longer useful lives than today's useful lives. These warranty costs may be interpreted to represent "worst case" due to these uncertainties.

While NREL does not know the method used by each OEM to determine their incremental warranty cost estimates and it is beyond the scope of this study to evaluate them in detail, a few additional potential reasons for the vehicle owner upfront costs (driven by the high warranty costs) being higher than the lifetime marginal repair savings could include:

- Failure uncertainty - Because the OEMs will not perfectly estimate the probability of failure for their aftertreatment packages, they may charge more than needed initially to ensure they have enough capital to cover any future liabilities. This would be an amount 
in excess of what the vehicle owners would actually incur but would be expected to decrease over time as the failure rates on new technologies become known with more certainty.

- Cost of capital - The OEMs have higher costs of capital than individual vehicle owners. Thus, their cost to reserve funding to cover future warranty liabilities would be more than what a vehicle owner would realize in lifetime repair costs on average.

- Soft costs - The OEMs may have embedded additional "soft" costs into the cost estimate for the extended full useful life and extended warranty to account for costs associated with warranty administration (tracking warranty data, contacting vehicle owners, processing payments), legal liability (increased legal staffing in the event of fraud), and potentially others.

- Customer relationships - Some manufacturers may reduce the price of the aftertreatment package with extended warranty for some customers with long-standing relationships or high volumes of purchases. These discounts may need to be offset with the "typical" aftertreatment cost, which may be reflected in the values reported from NREL's survey

The previous plots assumed medium-cost aftertreatment technologies, U.S. manufacturing volumes, up to a $1.25 \%$ improvement in fuel economy, a $2.5 \%$ increase in DEF consumption, and vehicle sales/operation in the South Coast Air Basin region. The next series of plots illustrates some sensitivity of present value cost to some of these assumptions.

Figure 13 shows present value cost of the T7 Tractor and T6 OOS small diesel trucks for the three aftertreatment cost scenarios presented in Task 1 for current full useful life. This graphic suggests that for a T7 Tractor with a 12-13-L diesel engine with current FUL, the present value cost could be $\sim 42 \%$ lower or $\sim 65 \%$ higher than the average, depending on which aftertreatment technology cost is realized. For the T6 OOS small truck with a 6-7-L diesel engine, the cost could potentially be $57 \%$ lower or $74 \%$ higher.

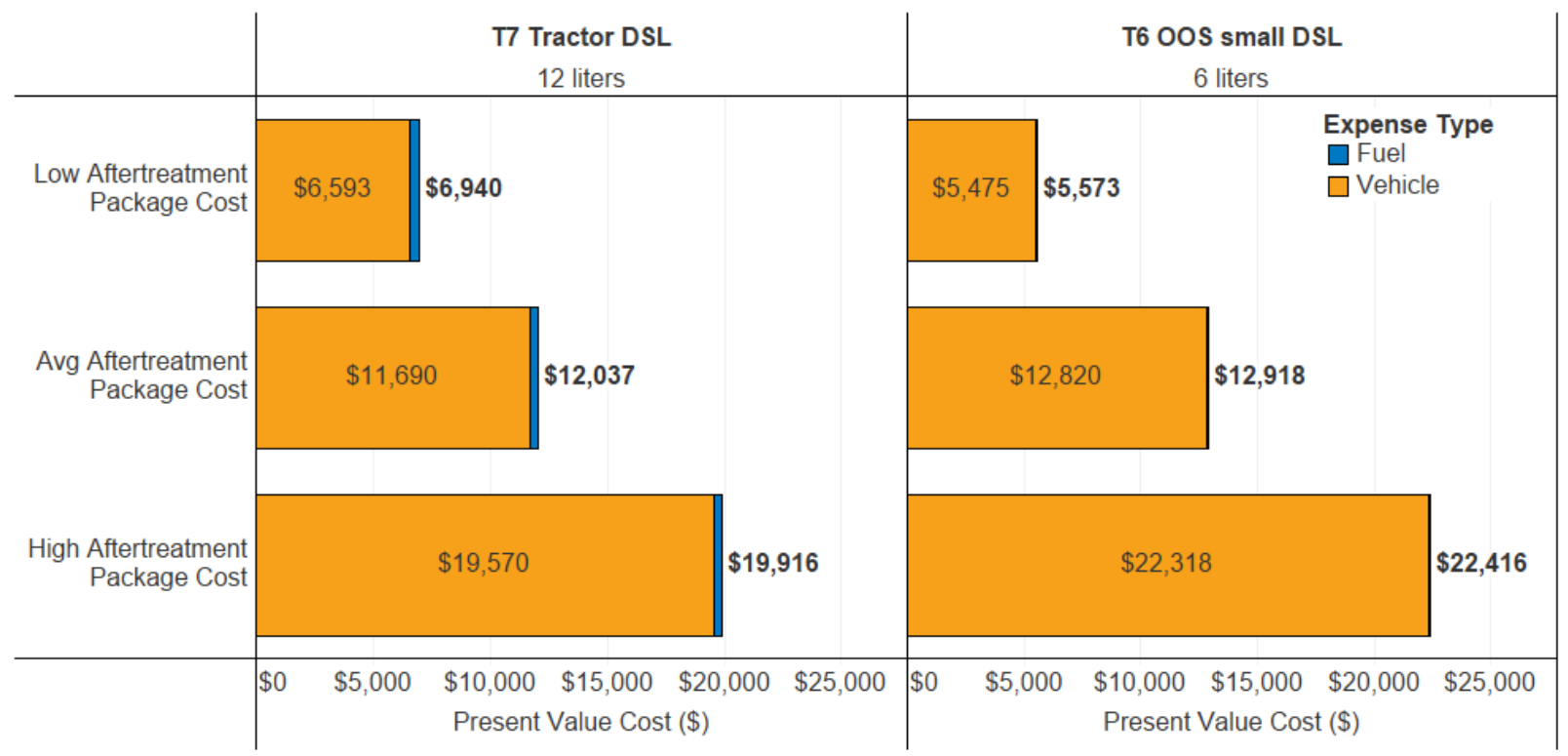

Figure 13. Present value cost for different Class 6 and Class 8 diesel engine aftertreatment technologies with current full useful life 
Figure 14 shows present value cost for different aftertreatment technologies with extended full useful life. For this condition, the T6 OOS small truck with a 6-7-L diesel engine could have a life-cycle cost $12 \%$ lower or higher. For the T7 Tractor with a 12-13-L diesel engine, the range in present value cost spans $60 \%$ lower or $63 \%$ higher, about the average aftertreatment cost technology present value.

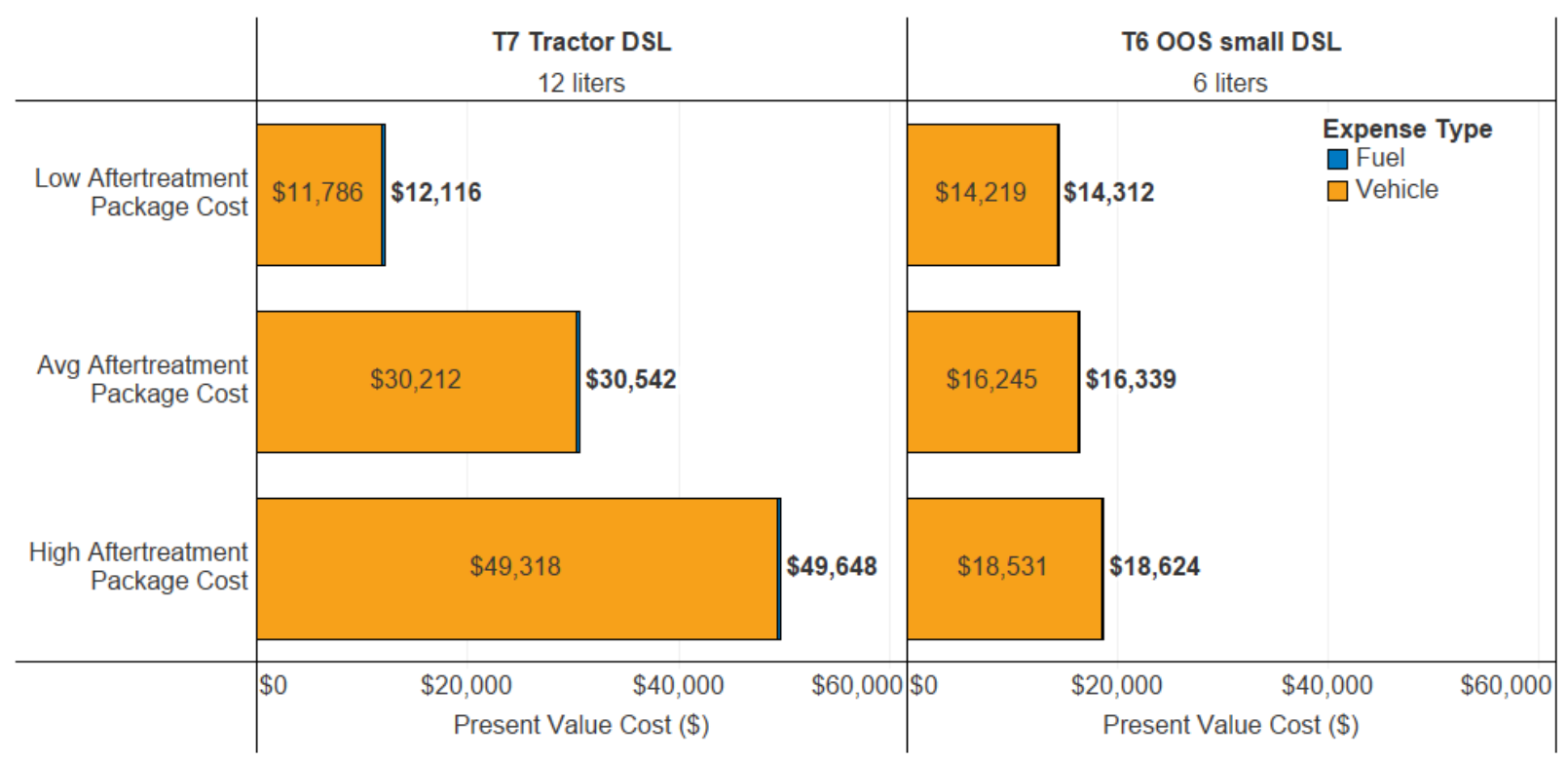

Figure 14. Present value cost for different Class 6 and Class 8 diesel engine aftertreatment technologies with extended full useful life

Figure 15 shows the present value cost for the T7 Tractor with a 12-13-L diesel engine aftertreatment technology manufactured at California and national volumes for current full useful life. No OEM data were available for California manufacturing volumes for extended full useful life. However, this figure suggests that reducing manufacturing volumes to California scales could increase the present value cost by a factor of approximately four to five. 


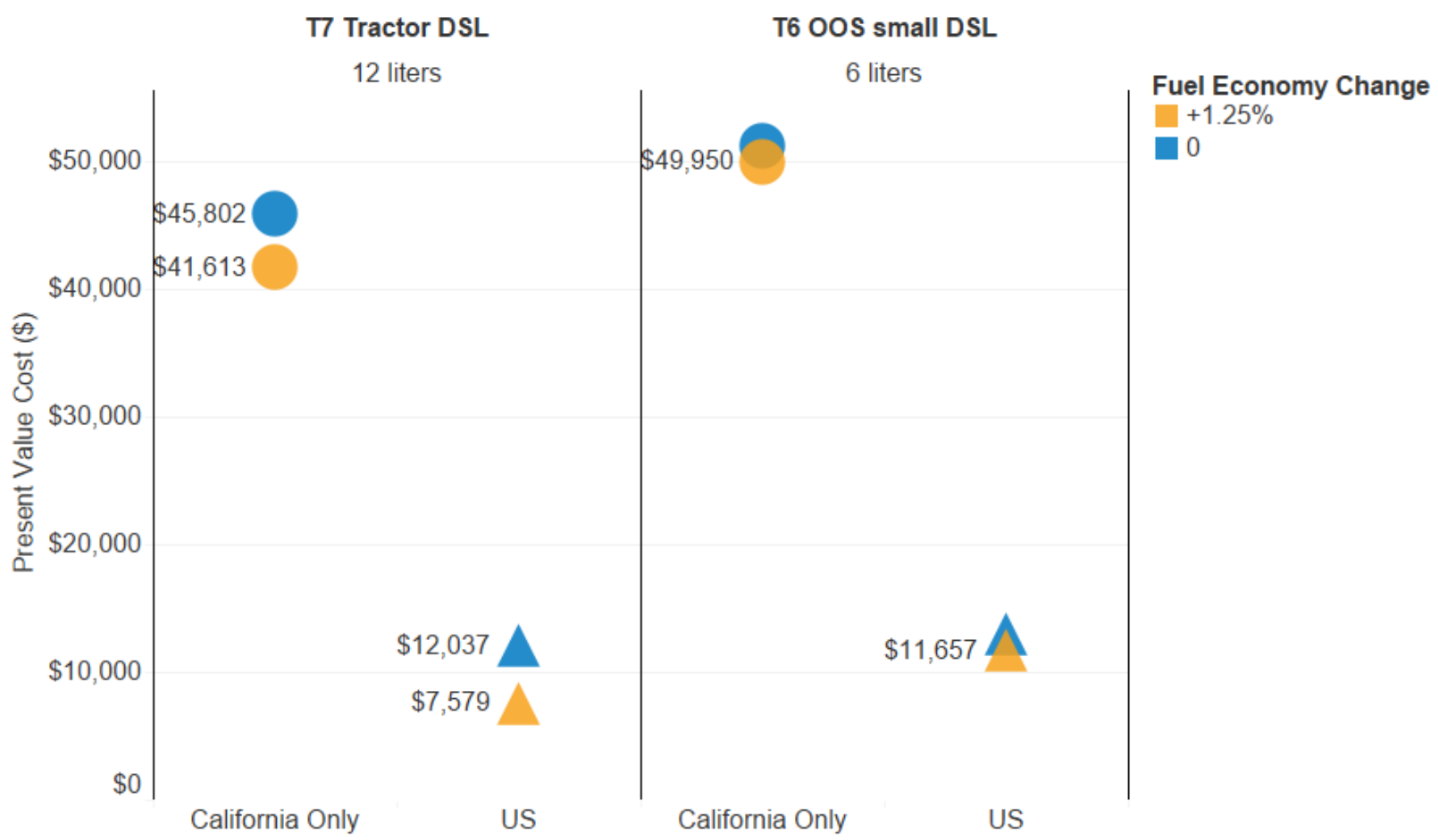

Figure 15. Present value cost for the T7 Tractor and T6 OOS small trucks with diesel engines designed for current full useful life at both California and national manufacturing volumes

Figure 16 and Figure 17 show present value cost for the T7 Tractor and T6 OOS small trucks with diesel engine aftertreatment technologies as a function of the CA Vision model-defined region for current and extended full useful life, respectively. In both cases, regional life-cycle differences are very small — generally less than $\sim \$ 100$. While vehicle miles traveled is dependent on the region the truck operates in, these differences are small across regions. This leads to the conclusion that regional differences in life-cycle costs are not an important factor in the lifecycle cost assessment. 


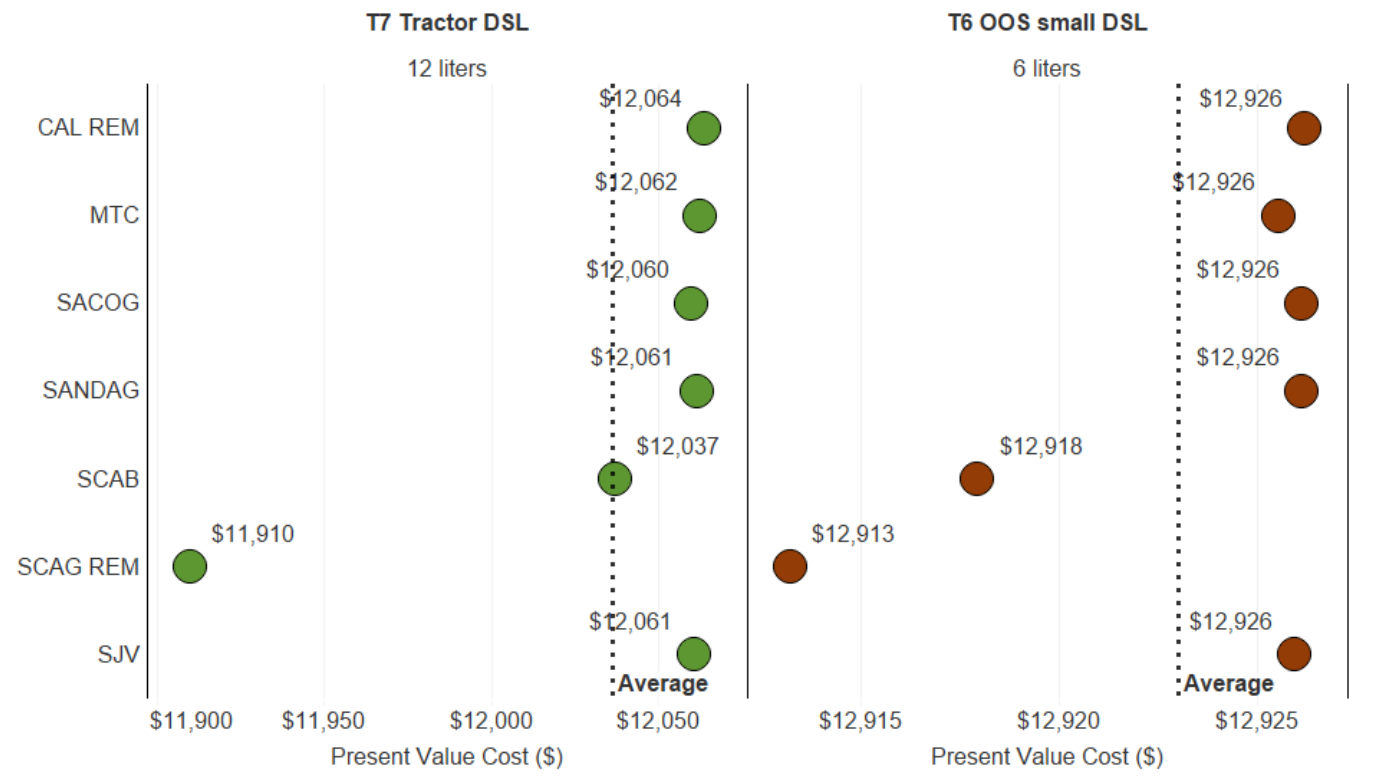

Figure 16. Present value cost for the T7 Tractor and T7 OOS small trucks with diesel engine aftertreatment technologies designed for current FUL as a function of region

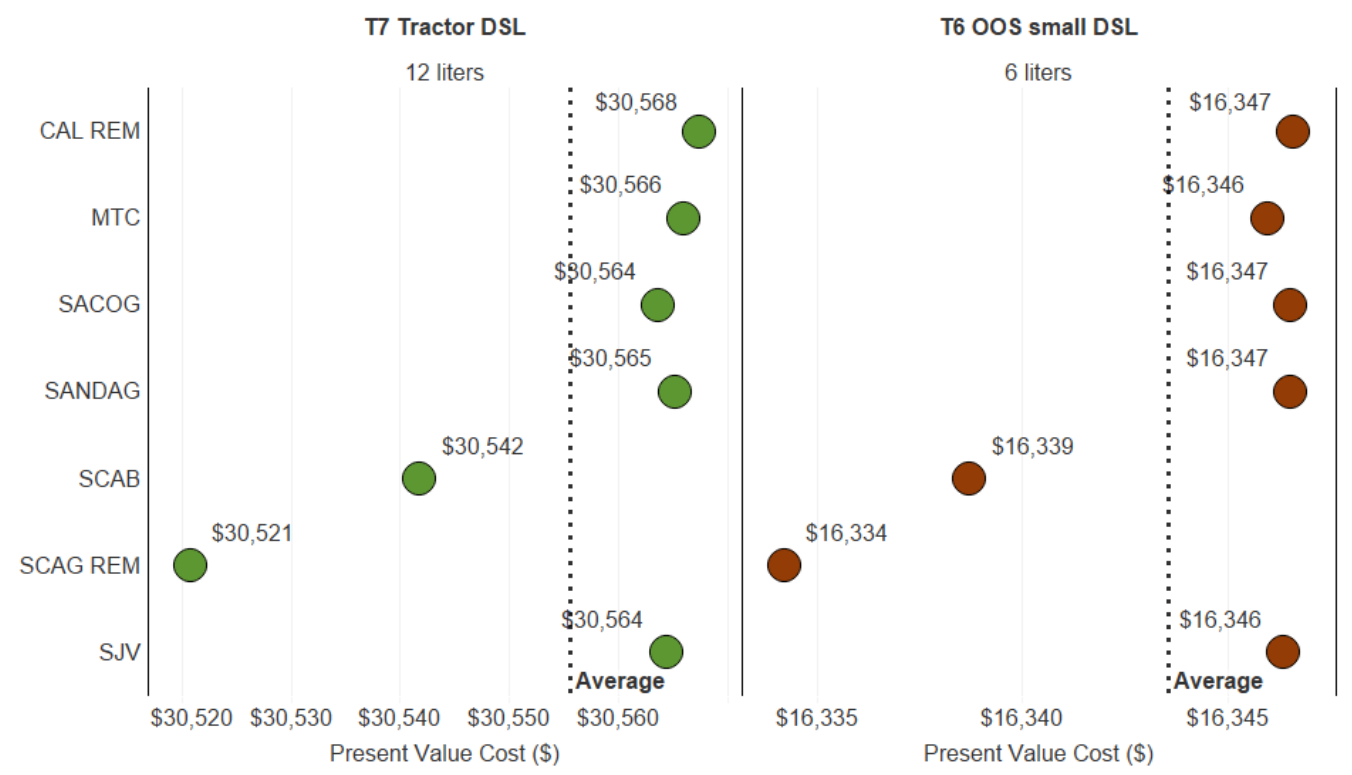

Figure 17. Present value cost for the T7 Tractor and T7 OOS small trucks with diesel engine aftertreatment technologies designed for extended FUL and warranty as a function of region

\subsubsection{Scenario Analysis Results}

This section presents results from a cost analysis of the three different cost scenarios depicted in Table 23. The scenario analysis results are summarized for the three different metrics discussed in Section 2.3.1:

1. Life-cycle costs for each vehicle/displacement/fuel/vocation/region combination 
2. A vehicle sales weighted-average life-cycle cost across all vehicle/displacement/fuel/vocation/region combinations

3. A life-cycle cost across the full California fleet.

\subsubsection{Vehicle-Specific Life-Cycle Costs}

The life-cycle cost was calculated for each EMFAC vehicle, engine displacement, fuel technology, EMFAC vocation, and region within each of the low-, mid-, and high-cost scenarios. This provides vehicle-specific data and can be used to demonstrate the potential life-cycle costs that could be realized for each vehicle owner.

For the low-cost scenario (defined in section 2.3.1), the resulting distribution of vehicle life-cycle costs are shown in Figure 18 for each fuel and engine displacement evaluated in this study. Each EMFAC vehicle is plotted within a density plot that shows the relative proportion of vehicle types that have the associated life-cycle cost. It should be noted that this plot does not account for the projected vehicle sales and how those may differ across vehicle types (e.g., the density shown does not reflect the number of vehicles in California that will have that cost, but rather the number of EMFAC vehicle types that have that cost).

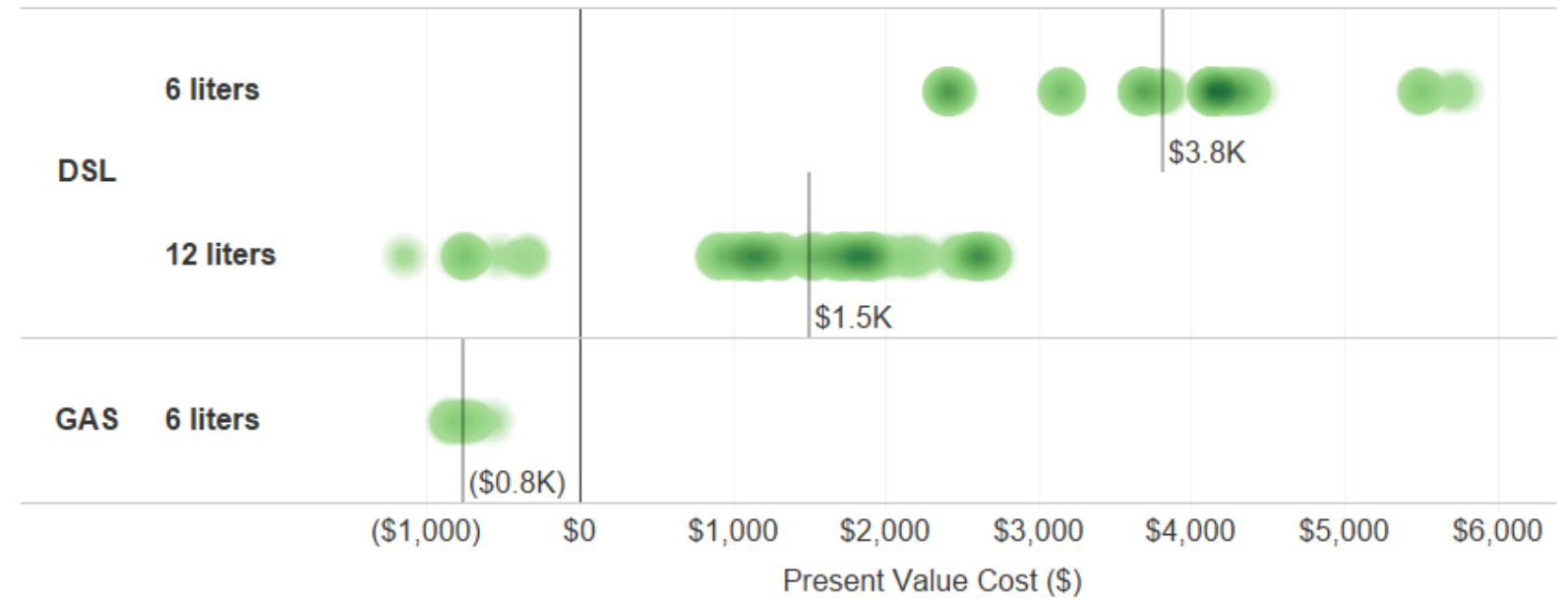

Figure 18. Present value life-cycle cost for all EMFAC vehicles in the low-cost scenario, segmented by fuel type and engine displacement (DSL = diesel, GAS = gasoline)

As seen in Figure 18, some life-cycle costs in the low-cost scenario are negative, indicating the fuel economy benefit outweighs the marginal cost of the aftertreatment package. Additionally, the spread in life-cycle costs is around $\sim \$ 4,000$ for both diesel engine displacements and is primarily due to the different vehicle-miles-traveled profiles across the EMFAC vehicle types. Life-cycle costs for natural gas are not shown, as there was only a single-point estimate of $\$ 3,000$ for the incremental aftertreatment cost rather than low/high bounds, so natural gas was only evaluated for the mid-cost scenario.

Figure 19 shows the present value life-cycle costs for the mid-cost scenario for all three fuel types. As seen in Figure 19, there could be a significant potential spread in life-cycle costs within a single fuel type and engine displacement category. This is primarily due to the different mileage requirements for certain vehicles combined with the aftertreatment maximum useful life assumption. For the diesel engines, the potential spread in life-cycle costs could be $\sim \$ 12,000$ 
depending on which EMFAC vehicle type is evaluated. The spread is significantly lower for gasoline and natural-gas engines because there are very few vehicle types defined in EMFAC that use these fuels.

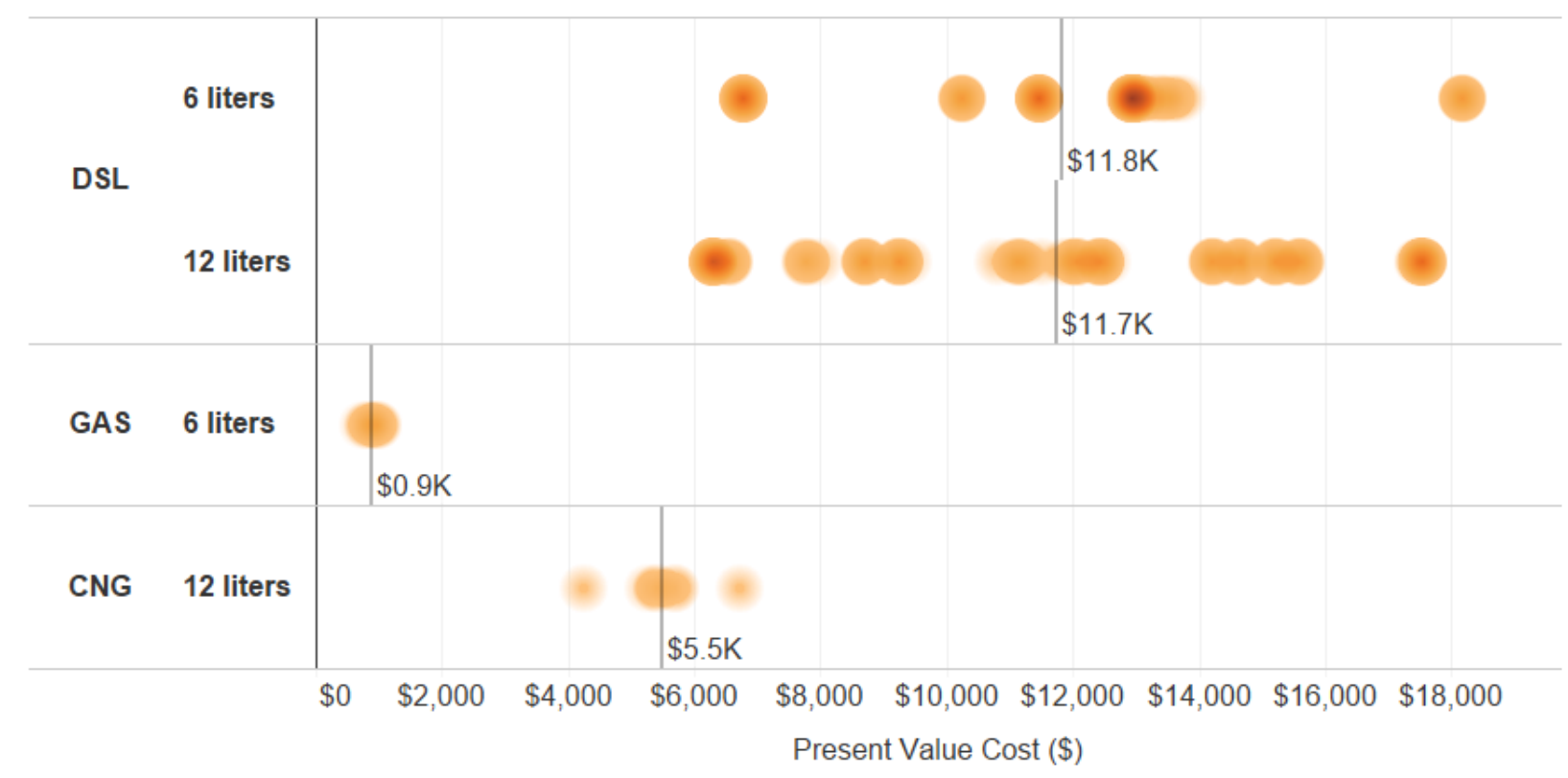

Figure 19. Present value life-cycle cost for all EMFAC vehicles in the mid-cost scenario, segmented by fuel type and engine displacement (DSL = diesel, GAS = gasoline, $C N G=$ compressed natural gas)

The present value life-cycle costs for the high-cost scenario for diesel are shown in Figure 20. Only diesel is shown because this scenario uses the extended useful life cost data, which are not available for gasoline or natural gas. As seen in Figure 20, the life-cycle costs for a vehicle with a 6-L diesel engine in this scenario ranges from $\sim \$ 18,000$ to nearly $\$ 30,000$. The life-cycle cost for a vehicle with a $12-\mathrm{L}$ diesel engine ranges from $\sim \$ 50,000$ to $\$ 88,000$ under this high-cost scenario. As seen previously, these higher costs are due to the high incremental cost of the aftertreatment package with both an extended maximum useful life and warranty combined with the assumption that they are replaced after the vehicle mileage exceeds the maximum useful life. The clear definition of two groups of costs in both the 6-L and 12-L engine displacements seen in Figure 20 shows that if the aftertreatment package does not need to be replaced, the life-cycle cost will be on the lower end of each range. However, if the aftertreatment package is replaced (for vehicles that travel more than the extended useful life), the life-cycle cost increases significantly to the upper end of the range. 


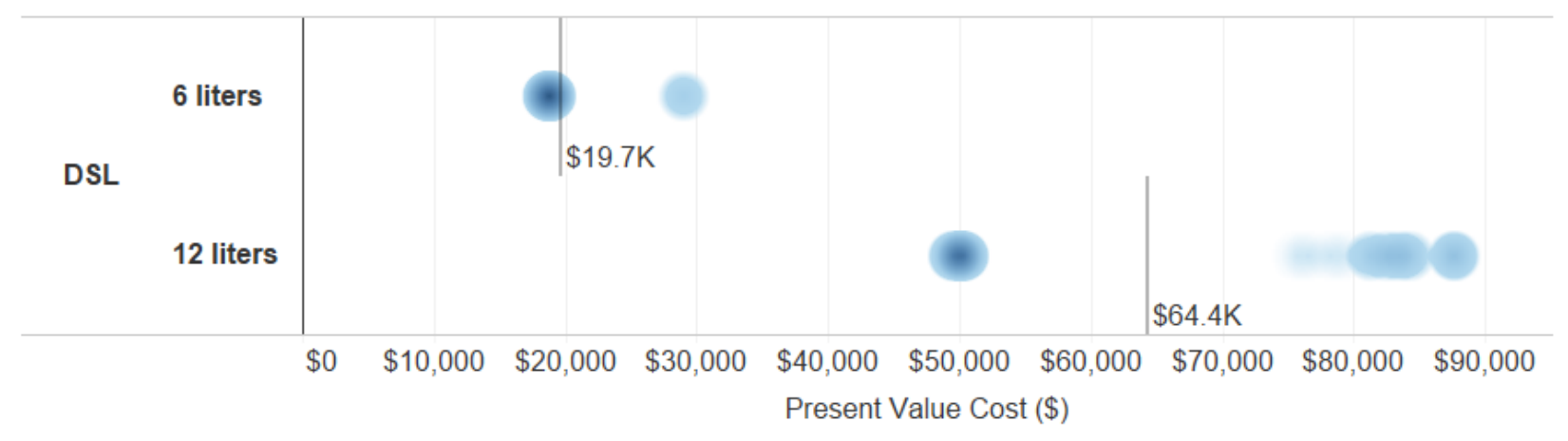

Figure 20. Present value life-cycle cost for all EMFAC vehicles in the high-cost scenario, segmented by fuel type and engine displacement $(\mathrm{DSL}=$ diesel)

\subsubsection{Vehicle Sales Weighted Average Costs}

As seen in Section 2.4.2.1, each EMFAC vehicle has a unique life-cycle cost. To combine these into a single, typical life-cycle cost to evaluate, a vehicle sales weighted average can be completed. Figure 21 shows the vehicle sales weighted-average results for the 6-7-L and 12-13$\mathrm{L}$ engine aftertreatment technologies. The analysis shows a significant spread in potential cost between the three 12-13-L engine cases, ranging from roughly $\$ 1,500$ all the way up to $\$ 71,400 .{ }^{5}$ Most of this spread is associated with the difference between current and extended full useful life as discussed in Section 2.4.2.1. These sensitivities are discussed in the following section.

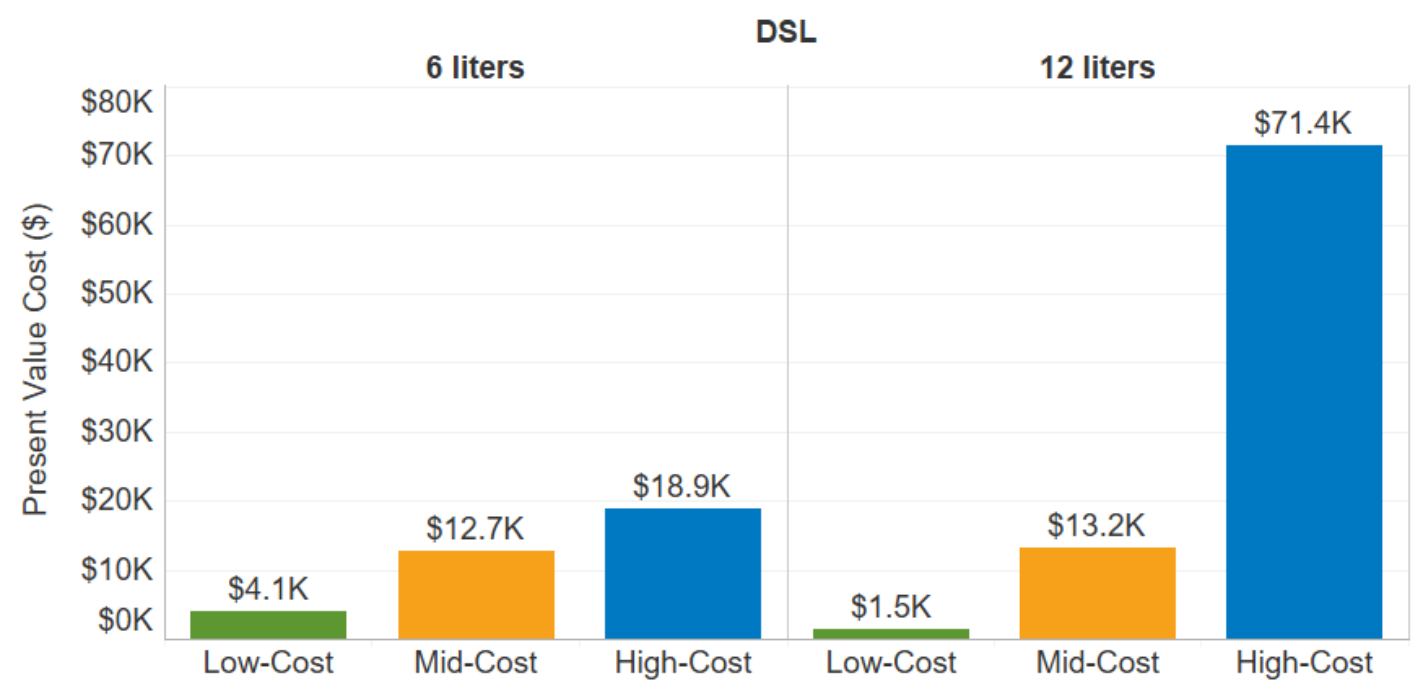

Figure 21. EMFAC vehicle sales-weighted average present value cost for 6-L and 12-L diesel engine technologies under the three cost scenarios described in Table 23

Figure 22 shows the scenario analysis for a 12-L compressed natural-gas engine and a 6-L gasoline engine. The compressed natural-gas costs are based on NREL estimates and do not reflect actual OEM data (only a single-point incremental cost of $\$ 3,000$ for the aftertreatment

\footnotetext{
${ }^{5}$ These vehicle sales weighted averages are different than the average values shown in the figures in Section 2.4.2.1 because those averages are simple averages across EMFAC vehicle types without regard to how many of those vehicle types are actually sold in California.
} 
package). The gasoline engine data are based on a small number of OEM estimates with limited spread in upfront cost. As a result, the differences between cases are small. Interestingly, for the low-cost scenario of the gasoline engine, the fuel economy benefits effectively cancel out the incremental aftertreatment package costs, resulting in a near-zero life-cycle cost.
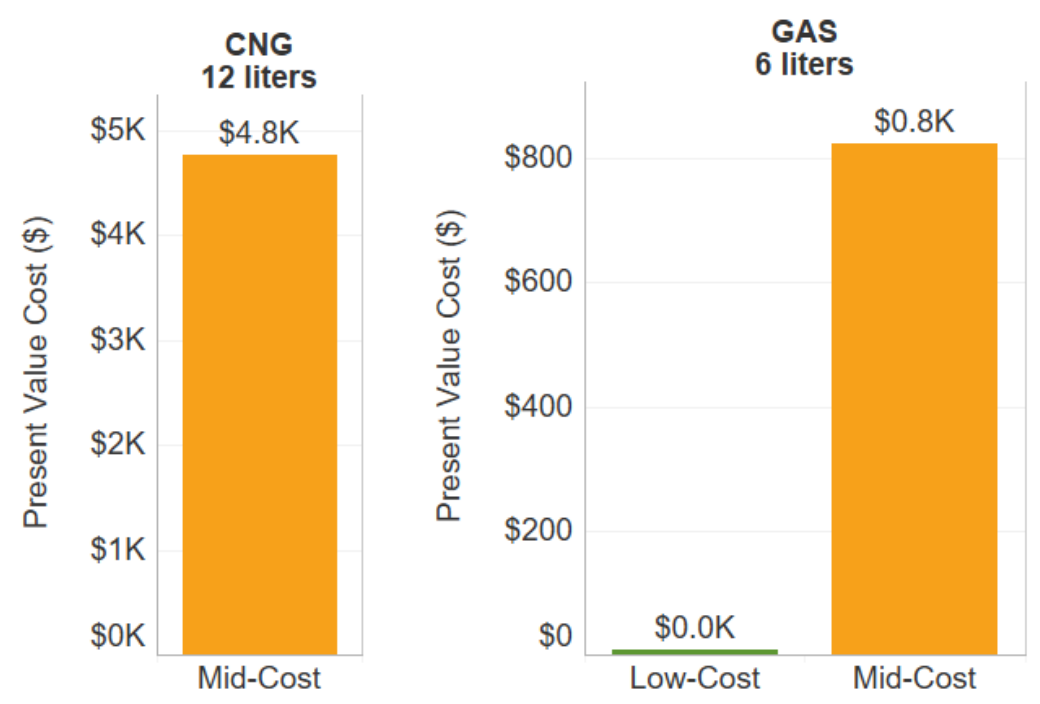

Figure 22. Scenario analysis for a 12-liter compressed natural-gas and 6-liter gasoline engine

\subsubsection{California Fleet Life-Cycle Costs}

The life-cycle cost across the full California fleet was evaluated to better understand what the total cost to all vehicle owners in California would be. As described in Section 2.3.1, this fleet calculation accounts for vehicle attrition over time because not all vehicles in the fleet will last through 2050.

Figure 23 shows the total California fleet costs for MY 2027 for each scenario evaluated in this study. The fleet costs aggregate all fuel types and engine displacements into a single cost metric. As seen in Figure 23, the total fleet life-cycle cost for the MY 2027 vehicles could range from $\$ 92$ million to $\$ 1.2$ billion depending on the scenario. As seen before, the large spread in costs across scenarios is primarily due to the higher incremental costs for the aftertreatment extended useful life and extended warranty, which are used in the high-cost scenario.

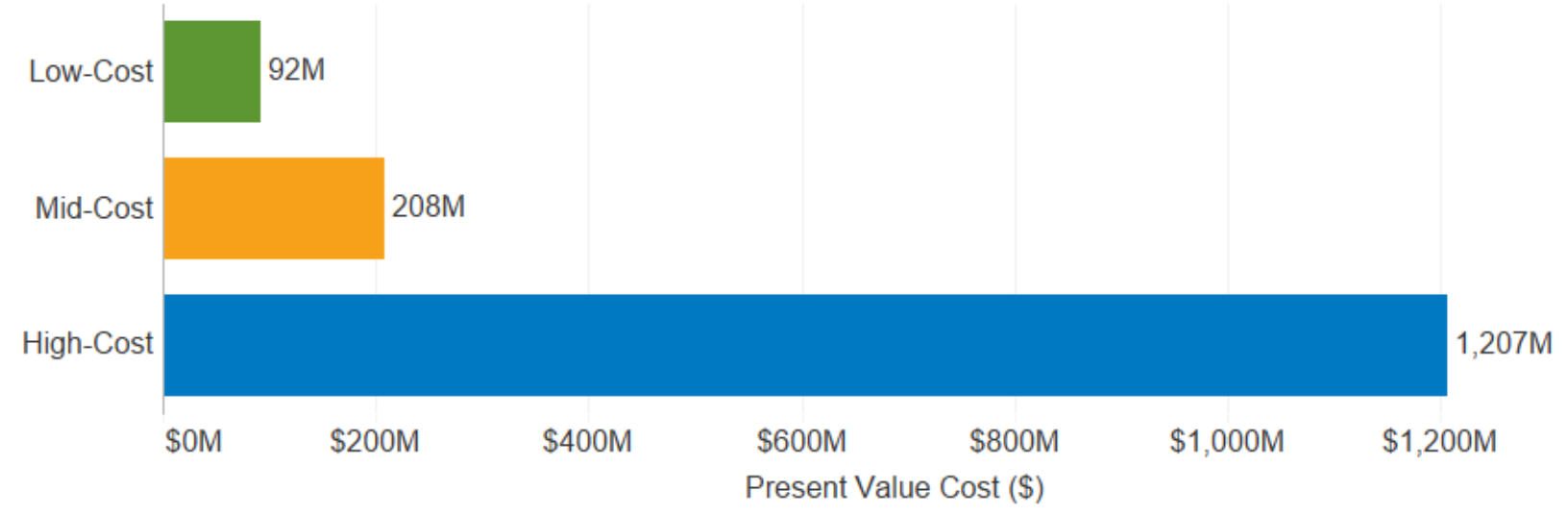

Figure 23. Total California fleet life-cycle cost for the MY 2027 vehicles for each scenario analyzed 


\subsubsection{Sensitivity Analysis Results}

To better understand how each particular parameter assessed in this study impacts the vehicle's incremental life-cycle cost, a sensitivity analysis was completed. The vehicle sales weighted average for the mid-cost scenario (see Section 2.4.2.2 for details) was used as the starting (central) point for the sensitivity analysis.

Figure 24 shows the sensitivity analysis results for the diesel 6-7-L and 12-13-L engines. The sensitivity results are relative to the vehicle sales weighted-average costs of $\$ 12,700$ and $\$ 13,200$ for the 6-7-L and 12-13-L engines, respectively. For the 12-L engine, the most influential parameter is manufacturing volume, but this is based on a very limited feedback in the cost survey (Section 1.3.2) and thus was not used outside of this sensitivity analysis. Extended full useful life is the next most significant parameter, which also includes the cost associated with the extended warranty. Figure 24 shows the impact of the extended useful life along with $25 \%$ increments between the current useful life and extended useful life (linear interpolation of costs from the two data points). Each step helps illustrate how the cost increases as the full useful life increases up to the extended full useful life mileage.

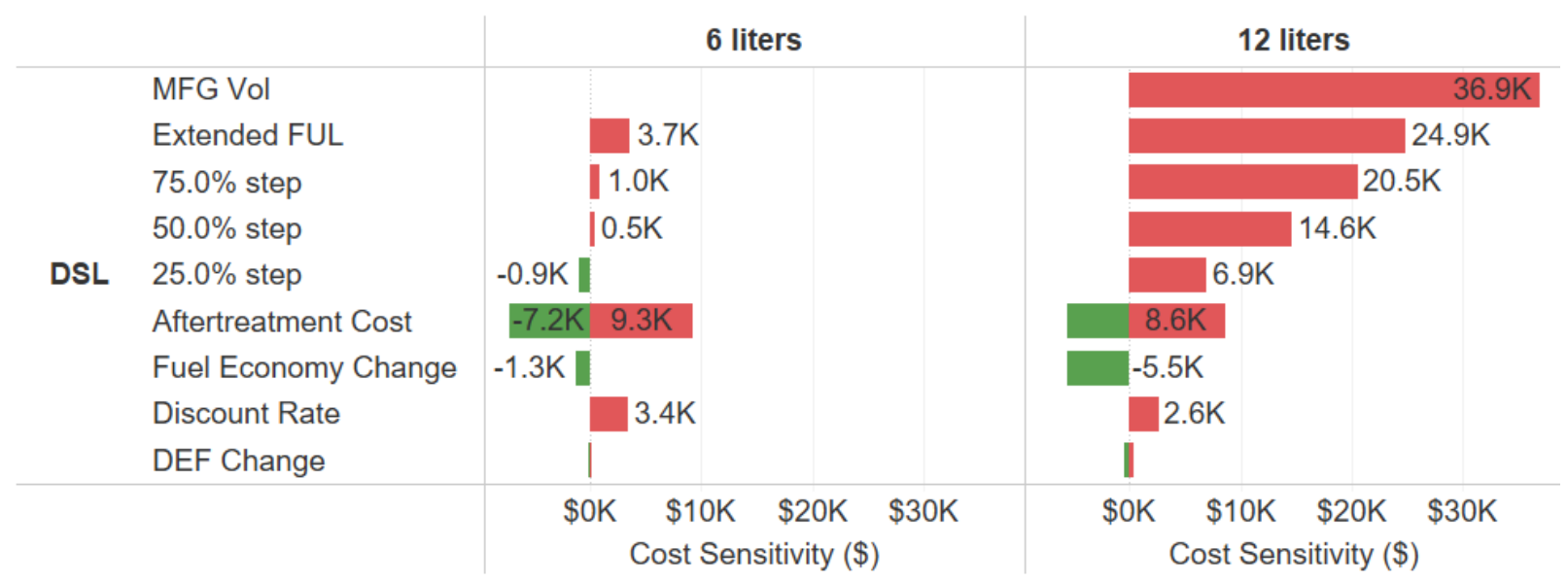

Figure 24. Sensitivity diagram for the diesel $6-7-L$ and $12-13-L$ engines relative to the mid-cost scenario

The influence of the incremental aftertreatment technology cost (Task 1 data) is relatively small compared to the aforementioned factors and has the potential to be nearly offset by fuel economy improvements. Discount rate and DEF consumption have minimal influences on the life-cycle cost. For the 6-7-L diesel engine, the aftertreatment cost (incremental cost data from Task 1) was the most influential sensitivity parameter for which data were available. Manufacturing volume may be more significant, as seen in the 12-13-L engine case, but no data were available for California-only manufacturing volume costs for the 6-7 L.

Because no cost data were available for the effect of manufacturing volume or extended useful life, the sensitivity plots for gasoline and natural gas engines have fewer parameters. Figure 25 shows the sensitivity analysis results for gasoline engines. As seen in Figure 25, the gasoline engine life-cycle cost is impacted most by the fuel economy change and incremental aftertreatment cost parameters. This indicates that if the fuel economy benefit is realized, it will likely fully offset the incremental aftertreatment costs. 


\begin{tabular}{|c|c|c|c|c|c|c|}
\hline GAS & \multirow{3}{*}{$\begin{array}{l}\text { Fuel Economy Change } \\
\text { Aftertreatment Cost }\end{array}$} & \multicolumn{5}{|c|}{6 liters } \\
\hline \multirow{3}{*}{ GAS } & & \multicolumn{5}{|l|}{$-0.7 \mathrm{~K}$} \\
\hline & & & & & $0.1 \mathrm{~K}$ & \multirow[b]{2}{*}{$0.2 \mathrm{~K}$} \\
\hline & \multirow[t]{2}{*}{ Discount Rate } & & & & & \\
\hline & & $(\$ 600)$ & $(\$ 400)$ & $(\$ 200)$ & $\$ 0$ & $\$ 200$ \\
\hline
\end{tabular}

Figure 25. Sensitivity diagram for the gasoline 6-L engine relative to the mid-cost scenario

Figure 26 shows the sensitivity analysis results for the natural-gas engine. Fuel economy impacts and discount rate are approximately equal in magnitude but opposite in the direction of their influence.

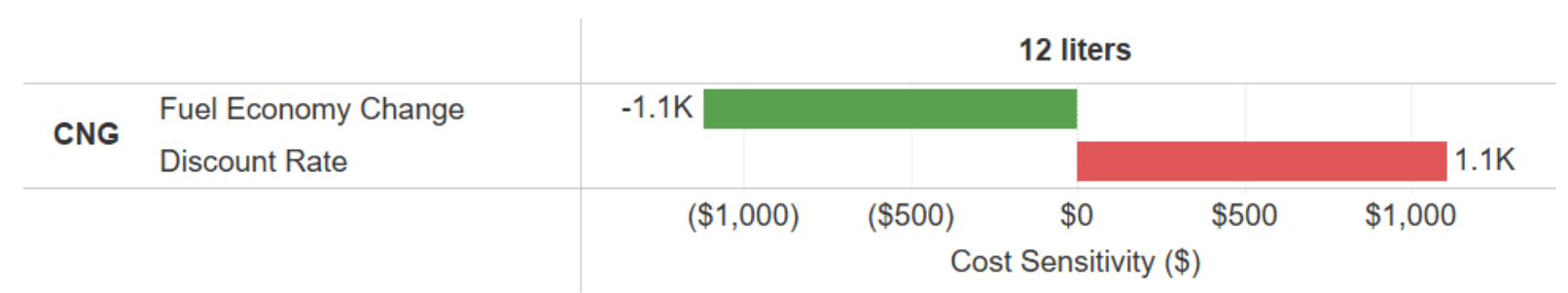

Figure 26. Sensitivity diagram for the natural-gas $12-\mathrm{L}$ engine relative to the mid-cost scenario

\subsection{Life-Cycle Cost Analysis Summary and Conclusions}

The life-cycle cost analysis seeks to incorporate all direct and indirect incremental costs associated with the different engine aftertreatment technologies over the life of the vehicle. Three scenarios were defined and evaluated to estimate the life-cycle cost across vehicles in California under different conditions.

The scenario results suggest that the life-cycle cost incurred to each vehicle owner depends significantly on the vehicle type and scenario evaluated. Within a given scenario, the spread in life-cycle costs incurred ranges from $\$ 4,000$ in the low-cost scenario up to nearly $\$ 40,000$ in the high-cost scenario. Drilling down to the specific EMFAC vehicle definitions (e.g., T7 Tractor), the incremental replacement costs and potential cost savings associated with improved engine fuel economy are two dominant parameters. Because each vehicle has a different mileage profile over its lifetime, the replacement costs and fuel economy savings can vary substantially between vehicles. For example, extending the aftertreatment package's full useful life from current mileages to proposed mileages has the potential to significantly reduce, if not eliminate, the need for aftertreatment technology replacements through 2050 for some vehicles, but not others. Additionally, this extension results in little, if any, reduction in present value cost for the 6-7-L diesel engines and increases present value cost substantially for the 12-13-L diesel engines.

The scenario results also showed that the total California fleet life-cycle costs for the MY 2027 vehicles could be between $\$ 92$ million and $\$ 1.2$ billion depending on the scenario realized. Again, the largest factor differentiating scenarios was whether the current or extended full useful life costs were used. 
Next, the vehicle sales weighted-average costs provide an approximate, representative pervehicle life-cycle cost for each scenario. For the mid-cost scenario, the life-cycle cost could be $\$ 12,700$ and $\$ 13,200$ for the diesel 6-7-L and 12-13-L engines, respectively. For the mid-cost scenario, the natural gas life-cycle cost is estimated to be $\$ 4,800$ while the gasoline engine lifecycle cost is $\$ 800$.

Lastly, the life-cycle cost results suggest that regional impacts across California are minimal, while manufacturing volume could have a significant impact on present value cost. Very little data were available for California-only manufacturing volumes, but the data available suggest the costs could be $4-5$ times more than if a national manufacturing volume was realized. 


\section{Conclusions}

The incremental cost analysis was constructed to bracket a range of potential incremental costs associated with achieving $0.02 \mathrm{~g} / \mathrm{bhp}-\mathrm{hr} \mathrm{NO}_{\mathrm{x}}$ emissions over certification cycles, including a new proposed LLC. Diesel engines were the primary consideration, as they comprise the majority of HD engines. Incremental cost bracketing included three diesel engine and aftertreatment technology packages, two diesel engine displacements, MY 2023 versus 2027 introduction, U.S. versus California-only implementation, and current FUL versus extended FUL and warranty. Direct and indirect incremental costs were broken down to as discrete a level as possible while maintaining data confidentiality. The calculation of incremental costs was limited by the small number of respondents. Engine OEM participation was crucial, as only they could provide estimates for indirect costs, which represented a significant portion of the total cost.

The average incremental cost for the 6-7-L diesel engines for MY 2023 with current FUL ranged from $\$ 3,685$ to $\$ 5,344$, but the absolute low and high bounds were between $\sim \$ 2,000$ and over $\$ 9,000$. Extending FUL and warranty moved the average incremental costs to a range of $\$ 15,370$ to $\$ 16,245$, with tighter low and high bounds (constrained in part by the limited number of responses). The average incremental cost for the 12-13-L diesel engines for MY 2023 with current FUL ranged from $\$ 5,340$ to $\$ 6,063$, but the absolute low and high bounds were between $\sim \$ 3,000$ and over $\$ 10,000$. Extending FUL and warranty moved the average incremental costs to a range of $\$ 28,868$ to $\$ 47,042$, with much wider low and high bounds (driven in part by the limited number of responses). The natural gas 12-L engine application was unable to be studied in detail, but OEM feedback anticipated that the incremental cost for natural-gas engines and aftertreatment technology is within $10 \%$ of the low-cost diesel technology package for equivalent displacement, specifically due to possibly requiring a moving average window method to assess emission compliance. The gasoline engine 6-L application was also unable to be studied in detail, but comparatively low incremental costs were estimated.

Incremental costs are largely driven by indirect costs associated with engineering research and development costs, plus warranty. Those indirect costs, in turn, are driven by production volumes and amortization.

The life-cycle cost analysis incorporates all direct and indirect incremental costs associated with the different engine aftertreatment technologies over the life of the vehicle. The life-cycle costs depend on the vehicle type (mileage), region, fuel, engine displacement, maximum useful life, fuel economy change, diesel exhaust fluid consumption change, and discount rate. The primary drivers of life-cycle cost were the incremental aftertreatment replacement costs and fuel economy benefits.

For the three scenarios evaluated (low-cost, mid-cost, high-cost), the life-cycle costs were evaluated for each EMFAC vehicle type, aggregated to a representative average, and also calculated across the vehicle fleet for the model year 2027 vehicles. The analysis showed that EMFAC vehicles can have significantly different life-cycle costs, and that spread depends on the scenario evaluated: approximately a $\$ 4,000$ spread across vehicle types in the low-cost scenario, while the high-cost scenario had nearly a $\$ 40,000$ difference. This large spread was found to be due to the number of aftertreatment package replacements needed throughout the vehicle lifetime. The aggregated, representative average life-cycle costs for the mid-cost scenario were 
estimated to be $\$ 12,700$ for the 6-7-L diesel engine, $\$ 13,200$ for the 12-13-L diesel engine, $\$ 4,800$ for the 12-L natural-gas engine, and $\$ 800$ for the 6-L gasoline engine. The total life-cycle cost to California vehicle owners for the model year 2027 vehicles was estimated to range between $\$ 92$ million and $\$ 1.2$ billion depending on the scenario (low-cost or high-cost) realized.

The sensitivity analysis indicated that the manufacturing volume may be the most important parameter impacting the life-cycle cost; however, limited data were received from the external stakeholders surveyed. The next most important parameter was the assumption of extended useful life and extended warranty, as the increase in aftertreatment lifetime may not exceed the vehicle's travel requirement, which results in larger replacement costs over the vehicle's life. The aftertreatment cost bound (low/high error bars on the incremental cost data), fuel economy improvement, and discount rate were found to have a moderate impact on the life-cycle cost. Lastly, the region and DEF consumption change were found to have minimal influence on the life-cycle cost. 


\section{References}

Bush, B.; Muratori, M.; Hunter, C.; Zuboy, J.; Melaina, M. 2019. Scenario Evaluation and Regionalization Analysis (SERA) Model: Demand Side and Refueling Infrastructure Buildout. NREL/TP-5400-70090. https://www.nrel.gov/docs/fy19osti/70090.pdf.

California Air Resources Board (CARB). 2017. On-Road Heavy-Duty Low-NOx Technology Cost Study 16MSC005. May 24, 2017. https://caleprocure.ca.gov/event/3900/0000005722.

CARB. 2018a. Appendix C - Economic Impact Analysis/Assessment. May 8, 2018. https://ww3.arb.ca.gov/regact/2018/hdwarranty18/appc.pdf.

CARB. 2018b. EMFAC2017 Volume III - Technical Documentation, V1.0.2. July 20, 2018. https://ww3.arb.ca.gov/msei/downloads/emfac2017-volume-iii-technicaldocumentation.pdf.

CARB. 2019. Heavy-Duty Low NOx Program Workgroup Meeting No. 2. May 7, 2019.

Ou, L.; Cai, H.; Seong, H.J.; Longman, D.E.; Dunn, J.B.; Storey, J.M.E.; Toops, T.J.; Pihl, J.A.; Biddy, M.; Thornton, M. 2019. "Co-optimization of Heavy-Duty Fuels and Engines: Cost Benefit Analysis and Implications." Environmental Science \& Technology 53: 1290412913. http://dx.doi.org/10.1021/acs.est.9b03690.

Posada, F.; Chambliss, S.; Blumberg, K. 2016. Costs of Emission Reduction Technologies for Heavy-Duty Diesel Vehicles. The International Council on Clean Transportation, February 2016. https://theicct.org/sites/default/files/publications/ICCT costs-emissionreduction-tech-HDV_20160229.pdf.

Posada Sanchez, F.; Bandivadekar, A.; German, J. 2012. Estimated Cost of Emission Reduction Technologies for Light-Duty Vehicles. The International Council on Clean Transportation, March 2012. https://theicct.org/sites/default/files/publications/ ICCT LDV costsreport 2012.pdf.

Sharp, C.A.; Webb, C.C.; Neely, G.D.; Smith, I. 2017. Evaluating Technologies and Methods to Lower Nitrogen Oxide Emissions from Heavy-Duty Vehicles. San Antonio, TX:

Southwest Research Institute. April 2017.

Sharp, C.W.; Webb, C.C.; Neely, G.; Carter, M.; Yoon, S.; Henry, C. 2017. "Achieving Ultra Low $\mathrm{NO}_{\mathrm{x}}$ Emissions Levels with a 2017 Heavy-Duty On-Highway TC Diesel Engine and an Advanced Technology Emissions System - Thermal Management Strategies." SAE Int. J. Engines 10(4), 1697-1712. https://doi.org/10.4271/2017-01-0954.

Sharp, C.W.; Webb, C.C.; Neely, G.; Sarlashkar, J.V.; Rengarajan, S.B.; Yoon, S.; Henry, C.; Zavala, B. 2017. "Achieving Ultra Low NOx Emissions Levels with a 2017 Heavy-Duty On-Highway TC Diesel Engine and an Advanced Technology Emissions System - NOX Management Strategies." SAE Int. J. Engines 10(4): 1736-1748. https://doi.org/10.4271/2017-01-0958.

Sharp, C.W.; Webb, C.C.; Yoon, S.; Carter, M.; Henry, C. 2017. "Achieving Ultra Low NOX Emissions Levels with a 2017 Heavy-Duty On-Highway TC Diesel Engine - Comparison of Advanced Technology Approaches." SAE Int. J. Engines 10(4): 1722-1735. https://doi.org/10.4271/2017-01-0956. 


\section{Appendix A. Selected Results for Specific EMFAC Vehicles of Interest to CARB}

In addition to the life-cycle costs presented in this report, the California Air Resources Board (CARB) indicated a specific interest in the following EMission FACtor (EMFAC) vehicles (CARB 2018b):

Table A1. EMFAC Vehicles of Interest to CARB

\begin{tabular}{ll}
\hline \multicolumn{1}{c}{ EMFAC Vehicle } & \multicolumn{1}{c}{ EMFAC Description (GVWR = Gross Vehicle Weight Rating) } \\
\hline T7 Tractor & Heavy Heavy-Duty Diesel Tractor Truck \\
T7 Single & Heavy Heavy-Duty Diesel Single Unit Truck \\
T7 POLA & Heavy Heavy-Duty Diesel Drayage Truck near South Coast \\
T6 OOS Heavy & Medium Heavy-Duty Diesel Out-of-State (OOS) Truck with GVWR > 26,000 lb \\
T6 OOS Small & Medium Heavy-Duty Diesel Out-of-State Truck with GVWR $\leq 26,000 \mathrm{lb}$ \\
\hline
\end{tabular}

Per the CA Vision 2.1 model, the vehicle-miles-traveled profiles for these vehicles with a model year (MY) of 2027 in the South Coast Air Basin (SCAB) region are shown in Figure A1.

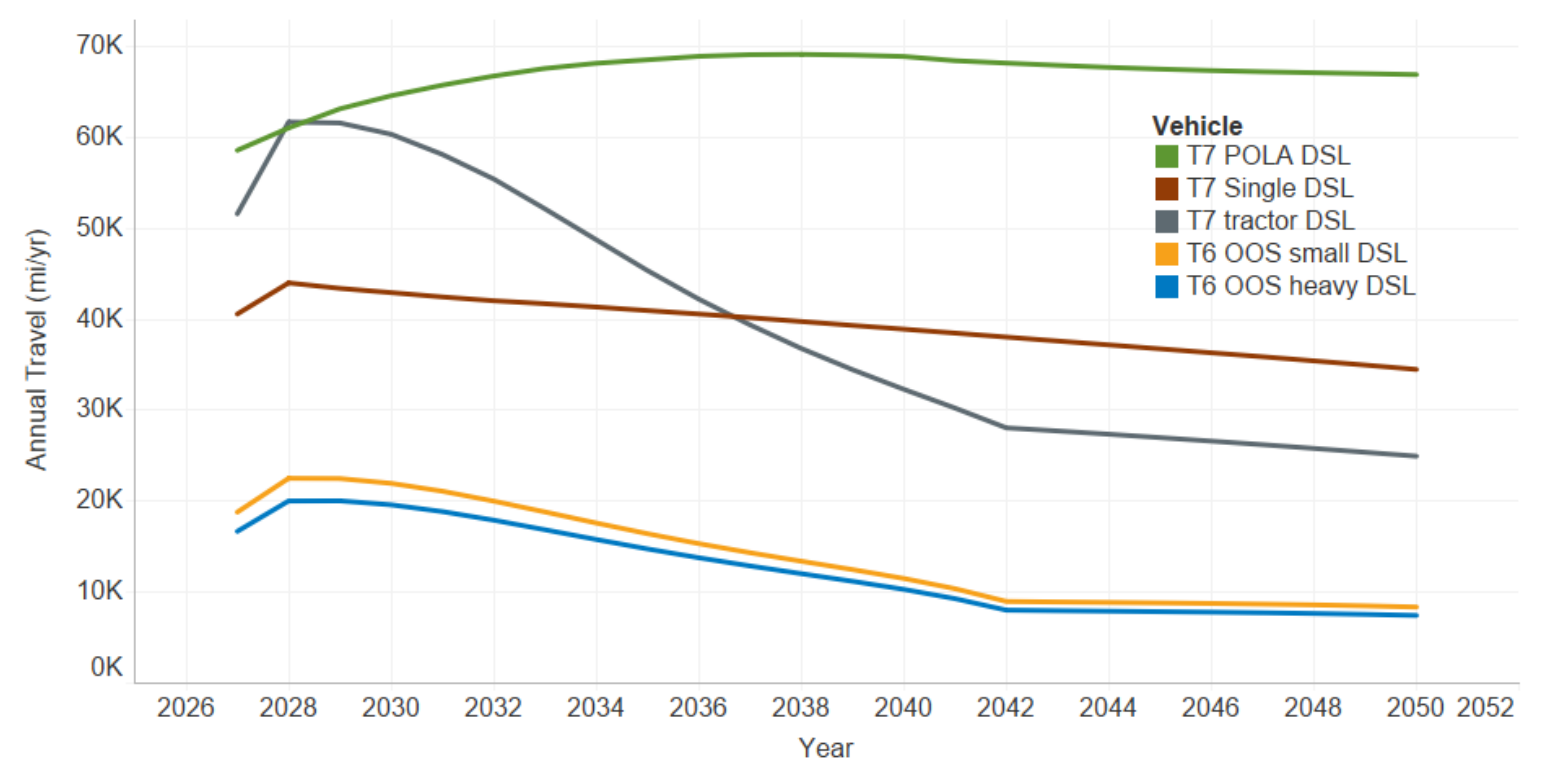

Figure A1. Selected EMFAC vehicle miles traveled for MY 2027 in the SCAB region

For these vehicles, the life-cycle costs for each scenario evaluated (low-cost, mid-cost, and highcost) are shown in the following figures. Figure A2 shows the life-cycle costs for the low-cost scenario, Figure A3 shows the results for the mid-cost scenario, and Figure A4 shows the results for the high-cost scenario. These results are aggregated for each vehicle, which accounts for the costs incurred from the aftertreatment package as well as any potential fuel economy benefit associated with the scenario. 
Of note, the individual vehicle life-cycle cost results are very close to the representative lifecycle costs estimated using the vehicle sales weighted average shown in Figure 21 in Section 2.4.2.2.

\begin{tabular}{|c|c|c|c|c|c|c|c|c|c|c|c|}
\hline T6 oos heavy DSL & 6 liters & & & & & & & & & \multicolumn{2}{|l|}{$\$ 3,774$} \\
\hline T6 oos small DSL & 6 liters & & & & & & & & & & $\$ 4,231$ \\
\hline T7 POLA DSL & 12 liters & & & $\$ 1$, & & & & & & & \\
\hline T7 Single DSL & 12 liters & & & & & $\$ 2$ & 057 & & & & \\
\hline \multirow[t]{2}{*}{ T7 Tractor DSL } & 12 liters & & & & & & $\$ 2,195$ & & & & \\
\hline & & $\$ 0$ & $\$ 500$ & $\$ 1,000$ & $\$ 1,500$ & $\$ 2,000$ & $\$ 2,500$ & $\$ 3,000$ & $\$ 3,500$ & $\$ 4,000$ & $\$ 4,500$ \\
\hline
\end{tabular}

Figure A2. Present value life-cycle cost for selected EMFAC vehicles (MY 2027 in the SCAB region) for the low-cost scenario

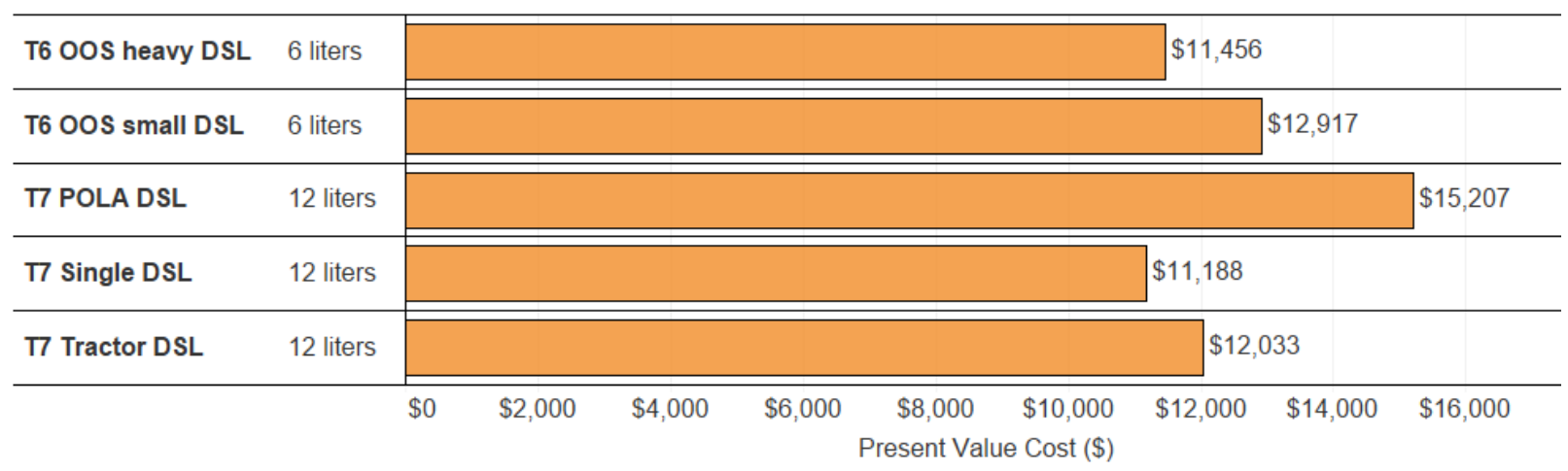

Figure A3. Present value life-cycle cost for selected EMFAC vehicles (MY 2027 in the SCAB region) for the mid-cost scenario

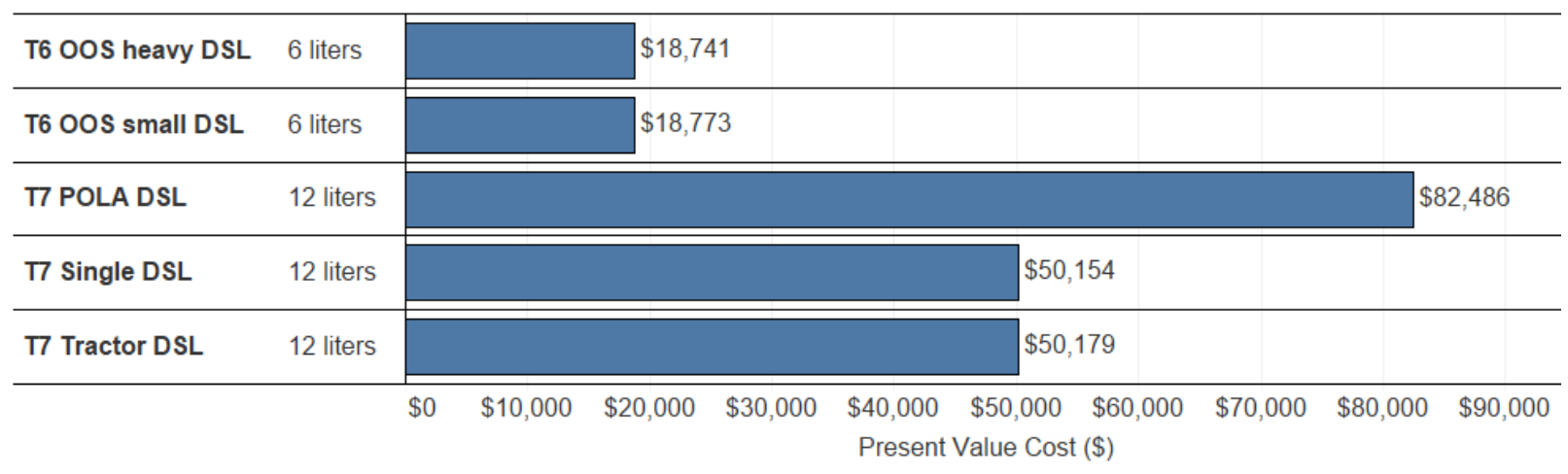

Figure A4. Present value life-cycle cost for selected EMFAC vehicles (MY 2027 in the SCAB region) for the high-cost scenario 


\section{Appendix B. EMFAC Vehicle Disaggregation}

The EMFAC vehicles needed to be broken down into the appropriate fuel and engine displacement categories. The IHS Markit (formerly Polk) Department of Motor Vehicles registration database was used to disaggregate the EMFAC vehicles. The same disaggregation was used for each CA Vision region and the first few results are summarized in Table B1, while the full table is provided in a separate file.

Table B1. EMFAC Vehicle Disaggregation Results

\begin{tabular}{|c|c|c|c|}
\hline EMFAC 2011 Vehicle & $\begin{array}{l}\text { Displacement } \\
\text { (L) }\end{array}$ & GVWR Class & Fraction (veh/veh) \\
\hline $\mathrm{MH}$ & 12 & 7 & 0.6008 \\
\hline $\mathrm{MH}$ & 15 & 7 & 0.3992 \\
\hline $\mathrm{T} 6 \mathrm{Ag}$ & 6 & 4 & 0.3302 \\
\hline $\mathrm{T} 6 \mathrm{Ag}$ & 9 & 4 & 0.0063 \\
\hline $\mathrm{T} 6 \mathrm{Ag}$ & 6 & 5 & 0.1554 \\
\hline T6 Ag & 9 & 5 & 0.0095 \\
\hline $\mathrm{T} 6 \mathrm{Ag}$ & 6 & 6 & 0.1936 \\
\hline $\mathrm{T} 6 \mathrm{Ag}$ & 9 & 6 & 0.0995 \\
\hline $\mathrm{T} 6 \mathrm{Ag}$ & 6 & 7 & 0.0975 \\
\hline $\mathrm{T} 6 \mathrm{Ag}$ & 9 & 7 & 0.1081 \\
\hline T6 CAIRP heavy & 6 & 7 & 0.4743 \\
\hline T6 CAIRP heavy & 9 & 7 & 0.5257 \\
\hline T6 CAIRP small & 6 & 4 & 0.4156 \\
\hline T6 CAIRP small & 9 & 4 & 0.0079 \\
\hline T6 CAIRP small & 6 & 5 & 0.1956 \\
\hline T6 CAIRP small & 9 & 5 & 0.0119 \\
\hline T6 CAIRP small & 6 & 6 & 0.2437 \\
\hline T6 CAIRP small & 9 & 6 & 0.1253 \\
\hline T6 instate construction heavy & 6 & 7 & 0.4743 \\
\hline T6 instate construction heavy & 9 & 7 & 0.5257 \\
\hline T6 instate construction small & 6 & 4 & 0.4156 \\
\hline T6 instate construction small & 9 & 4 & 0.0079 \\
\hline T6 instate construction small & 6 & 5 & 0.1956 \\
\hline
\end{tabular}




\begin{tabular}{lccc}
\hline EMFAC 2011 Vehicle & $\begin{array}{c}\text { Displacement } \\
\text { (L) }\end{array}$ & GVWR Class & Fraction (veh/veh) \\
\hline T6 instate construction small & 9 & 5 & 0.0119 \\
\hline T6 instate construction small & 6 & 6 & 0.2437 \\
\hline T6 instate construction small & 9 & 6 & 0.1253 \\
\hline T6 instate heavy & 6 & 7 & 0.4743 \\
\hline T6 instate heavy & 9 & 7 & 0.5257 \\
\hline T6 instate small & 6 & 4 & 0.4156 \\
\hline T6 instate small & 9 & 4 & 0.0079 \\
\hline T6 instate small & 6 & 5 & 0.1956 \\
\hline T6 instate small & 9 & 5 & 0.0119 \\
\hline T6 instate small & 6 & 6 & 0.2437 \\
\hline T6 instate small & 9 & 6 & 0.1253 \\
\hline
\end{tabular}

